\title{
Laboratório remoto para ensino a distância de sistemas de controle distribuído
}

Dissertação apresentada à Escola de Engenharia de São Carlos da Universidade de São Paulo, como parte dos requisitos para a obtenção do Título de Mestre em Engenharia Mecânica.

Área de Concentração: Dinâmica das Máquinas e Sistemas

Orientador: Prof. Luis Carlos Passarini

São Carlos

2007 
AUTORIZO A REPRODUÇÃO E DIVULGAÇÃO TOTAL OU PARCIAL DESTE TRABALHO, POR QUALQUER MEIO CONVENCIONAL OU ELETRÔNICO, PARA FINS DE ESTUDO E PESQUISA, DESDE QUE CITADA A FONTE.

Ficha catalográfica preparada pela Seção de Tratamento da Informação do Serviço de Biblioteca - EESC/USP

Mossin, Eduardo André

M9131 Laboratório remoto para ensino a distância de sistemas de controle distribuídos / Eduardo André Mossin ; orientador Luis Carlos Passarini. - São Carlos, 2006.

Dissertação (Mestrado) - Programa de Pós-Graduação e Área de Concentração em Engenharia Mecânica -- Escola de Engenharia de São Carlos da Universidade de São Paulo.

1. Ensino a distância. 2. Simulação. 3. Foundation Fieldbus. 4. Web. 5. Sistemas de controle distribuídos. I. Título. 


\section{AGRADECIMENTOS}

Agradeço primeiramente ao mestre e amigo Dr. Luis Carlos Passarini, pela orientação, dedicação e amizade. Não fosse seu convite e orientação, este trabalho não se realizaria;

Tenho grande gratidão ao Dr. Dennis Brandão, que tanto ajudou nesta pesquisa auxiliando em todos os momentos;

Ao Jaime que sempre que necessário me encaminhava direto ao lugar certo;

À Universidade de São Paulo, por colocar à disposição sua estrutura;

Aos engenheiros e amigos da SMAR, pela cooperação sempre muito útil, principalmente ao Cassius Resende Duarte que muito me ajudou a entender as teorias de controle;

À Lívia, pelo companheirismo que mostrou e por tudo que me ajudou;

Quero registrar também a grande ajuda dada pelo Saulo Amui;

Ao Rodrigo Palucci que sempre deu forças para eu continuar a batalha, principalmente nas horas de desgaste;

Sinceramente, aos meus pais e a minha irmã, por tudo, e a Deus, pela vida, por esta oportunidade e por estes irmãos; 



\section{RESUMO}

\section{MOSSIN, E. A. (2007). Laboratório remoto para ensino a distância de sistemas de controle distribuídos. Tese (Mestrado) - Escola de Engenharia de São Carlos, Universidade de São Paulo, São Carlos, 2007.}

Frente a abrangente presença da internet no ambiente acadêmico e residencial, a literatura relata, na última década, um número crescente de experiências de ensino a distância na área de automação e controle industrial, nas quais desde procedimentos teóricos até aulas práticas podem ser realizados através de acesso remoto. Neste contexto, este trabalho apresenta o estado da arte sobre as experiências acadêmicas no emprego de laboratórios on-line relacionados à teoria de controle e introduz uma nova proposta de arquitetura de acesso remoto, que será aplicada ao ensino de sistemas de controle distribuídos via rede de campo no protocolo FOUNDATION Fieldbus em ambiente simulado.

Palavras-chave: ensino a distância, simulação, FOUNDATION Fieldbus, Web, sistemas de controle distribuídos. 



\begin{abstract}
MOSSIN, E.A. (2007). Web Laboratory to Networked Control Systems Distance

Learning. M. Sc Dissertation - Escola de Engenharia de São Carlos, Universidade de São Paulo, São Carlos, 2007.
\end{abstract}

Due to the increasing presence of the Internet in the academic and residential environment, the literature shows an increasing number of experiences of distance learning in the automation and industrial control area in the last decade, in which theoretical procedures as well as practical lessons can be carried out through remote access. In this context, this dissertation presents a brief survey on the academic experiences in the application of on-line laboratories and introduces a new proposal of remote access architecture that will be applied on a distance learning experience in the networked control systems area based on the FOUNDATION Fieldbus protocol using a simulated environment.

Keywords: distance learning, simulation, FOUNDATION Fieldbus, Web, distributed control systems. 



\section{LISTA DE FIGURAS}

Figura 1 - Sistema Fieldbus e seus componentes ........................................................... 19

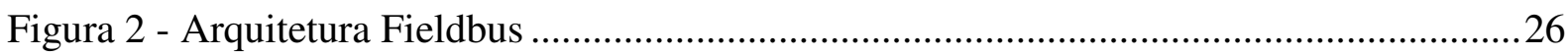

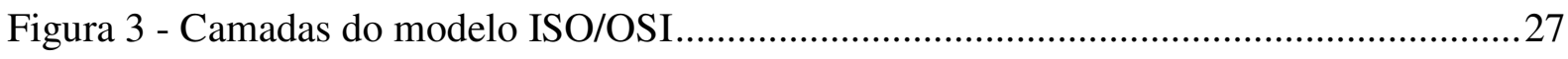

Figura 4 - Modelo de três camadas de redes de sistemas fieldbus .........................................28

Figura 5 - Controle por FOUNDATION Fieldbus da temperatura de um processo usando um transmissor de temperatura e um atuador de válvula. ...................................................... 31

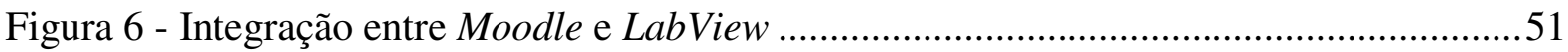

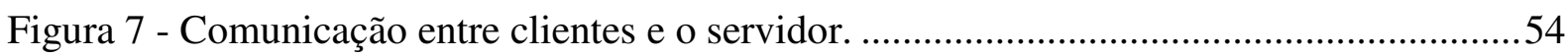

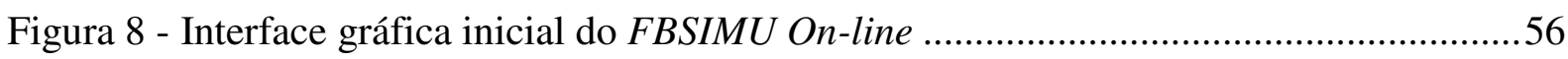

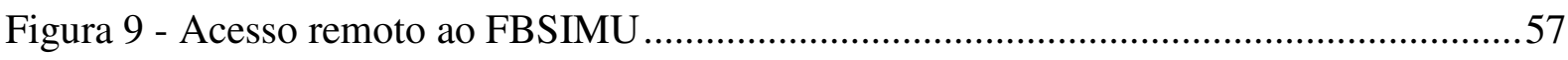

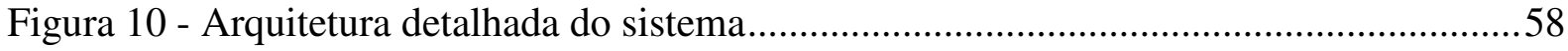

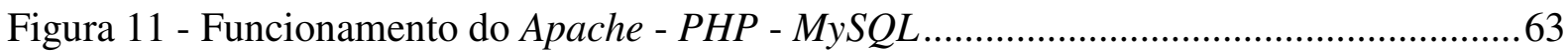

Figura 12 - Número de servidores Apache ativos.................................................................65

Figura 13 - Exemplo do arquivo fbsimu.ini com cinco entradas .............................................69

Figura 14 - Exemplo da "vi1" relacionada ao usuário "rodrigo" ............................................69

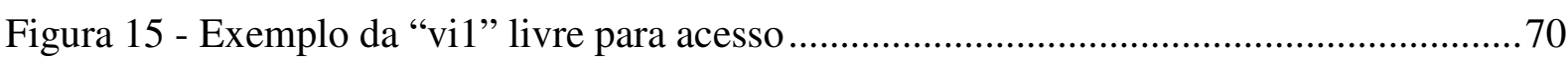

Figura 16 - Diagrama de blocos do LabView para controle de uso do FBSIMU .....................75

Figura 17 - Diagrama de blocos do LabView para controle de tempo ocioso do FBSIMU ..... 76

Figura 18 - Aba (tab) de configuração relacionadas a IP do Moodle e Apache ........................77

Figura 19 - Aba (tab) de configuração relacionada aos tempos usados no sistema ..................78

Figura 20 - Aba $(t a b)$ para criação das VIs do FBSIMU ........................................................... 79

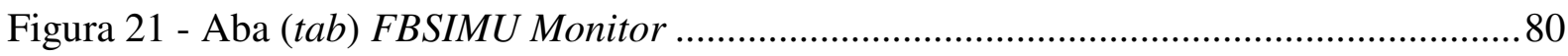

Figura 22 - Aba (tab) de registro de informações de execução do FBSIMU Manager .............81

Figura 23 - Diagrama de Classes do FBSIMU Manager .........................................................82

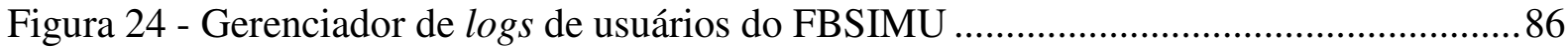

Figura 25 - Gerenciador de arquivos de blocos dos usuários do FBSIMU .............................86

Figura 26 - VI onde o usuário carrega o arquivo com a configuração......................................88

Figura 27 - Interface gráfica da VI da planta utilizada para a execução das simulações ........93

Figura 28 - Planta simulada usada para a execução do teste piloto.........................................94

Figura 29 - Arquivo fbsimu.ini com todas as VIs reservadas ...............................................96 
Figura 30 - Gráfico do LabView com status dos acessos de cinco máquinas remotas ............ 97

Figura 31 - Arquivo fbsimu.ini com todas as VIs liberadas ................................................. 99 


\section{LISTA DE TABELAS}

Tabela 1 - Vantagens e desvantagens do ensino a distância...............................................23

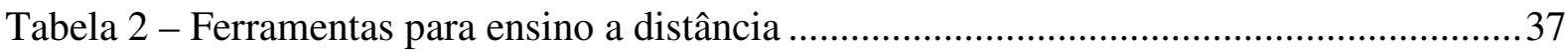

Tabela 3 - Descrição dos métodos PHP do FBSIMU On-line ................................................72

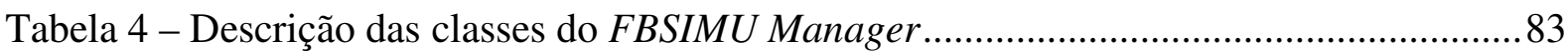





\section{LISTA DE SIGLAS}

AI

$\mathrm{AO}$

ARX

CAN

CISAER

CGI

CMC

CMS

CPU

CS

DCS

DD

DI

DO

FB

FBAP

FBSIMU

FF

FIP

GPL

GNU

I/O

IP

ISA

ISO/OSI

ISP

LAN

LMS

LP
Analog Input

Analog Output

Auto-Regressive eXogenous Model (Modelo linear, auto-regressivo e com entrada externa)

Bias

Control Area Network

Courses on the Internet: Survey, Analysis, Evaluation, Recommendation

Common Gateway Interface

Computer-Mediated Communication

Course Management System

Central Processing Unit

Control Selector

Distributed Control System

Device Description

Discrete Input

Discrete Output

Function Block

Function Block Application Process

Fieldbus Foundation Function Block Simulator

Fieldbus Foundation

Flux Information Processus

General Public License

GNU's Not UNIX

Input / Output

Internet Protocol

International Society for Measurement and Control

International Standards Organization / Open System Interconnection

Interoperable Systems Project

Local Area Network

Learning Management System

Learning Plataform

Java 2 Platform, Enterprise Edition 
ML Manual Loader

MLE Managed Learning Environment

NUS National University of Singapore

OPC OLE for Process Control

OS LMS Open Source Learning Management Systems

PC Personal Computer

PD Controlador de Ação Proporcional-Derivativa

PHP Hipertext Preprocessor

PID Controlador de Ação Proporcional-Integral-Derivativa

RA Ratio

SQL Structured Query Language

TCP Transfer Control Protocol

VI Virtual Instrument

VLE Virtual Learning Environment

VRML Virtual Reality Modelling Language 


\section{SUMÁRIO}

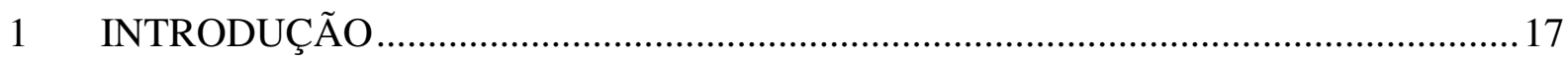

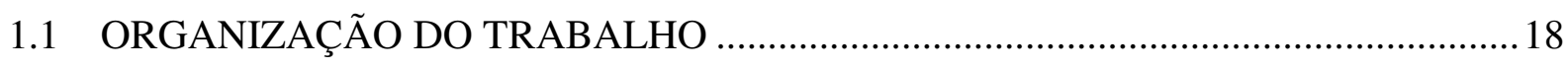

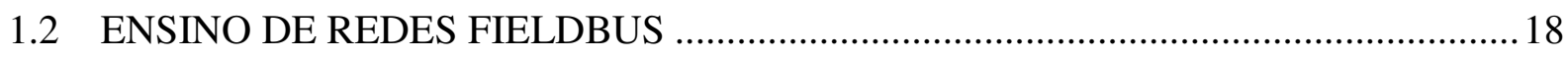

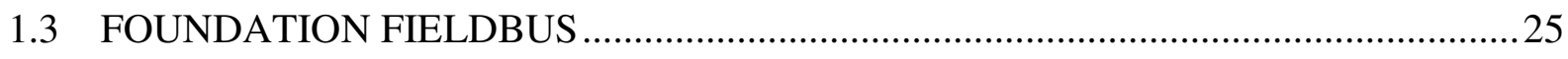

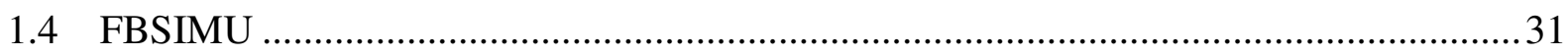

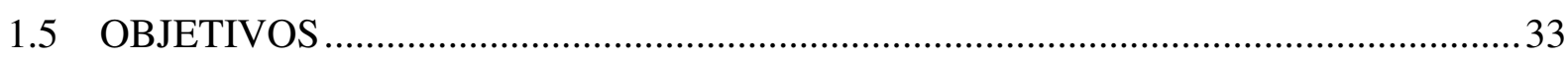

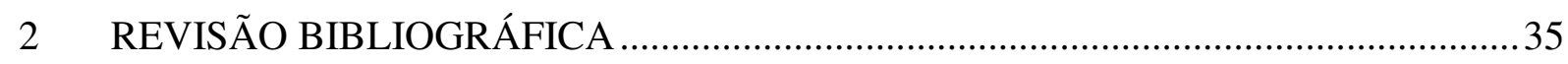

2.1 ACESSO REMOTO A INSTRUMENTOS REAIS ................................................. 41

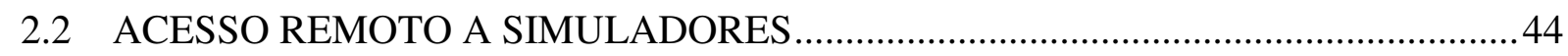

2.3 LABORATÓRIOS REMOTOS PARA ENSINO DE REDES DE CAMPO .................45

3 PLATAFORMA DE DESENVOLVIMENTO E SIMULAÇÃO (FBSIMU ON-LINE) 49

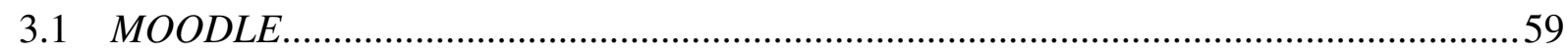

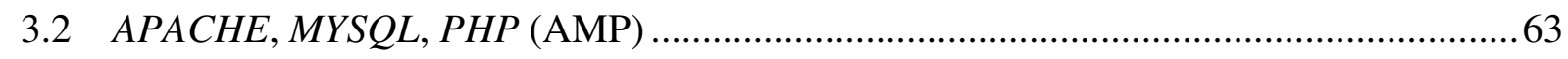

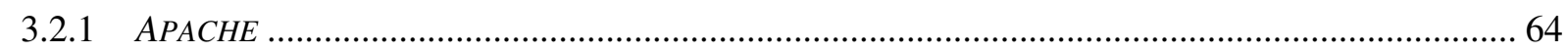

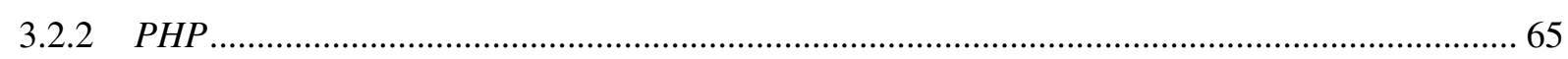

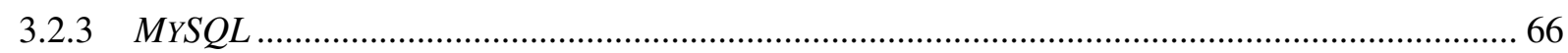

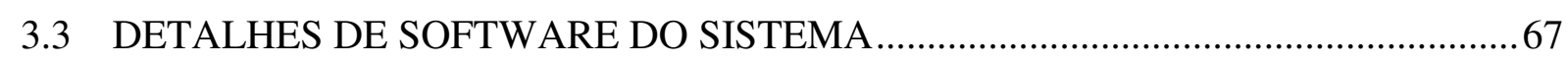

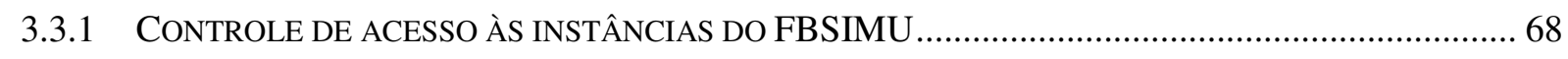

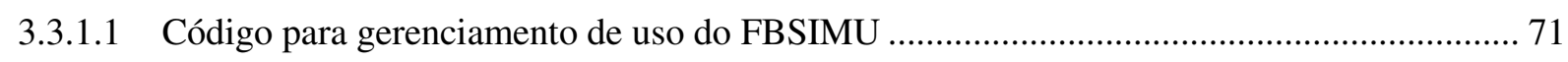

3.3.2 FERRAMENTA DE CONFIGURAÇÃO DO SERVIDOR …............................................................ 76

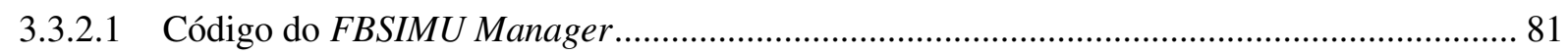

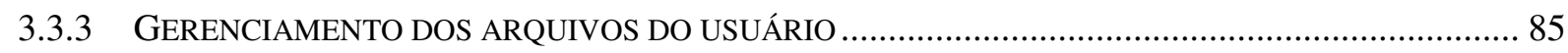

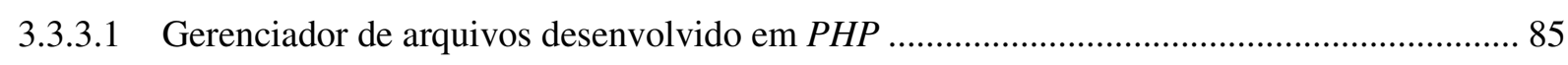

3.3.3.2 Lista dos arquivos de configuração de blocos (FBSIMU) .................................................. 87 


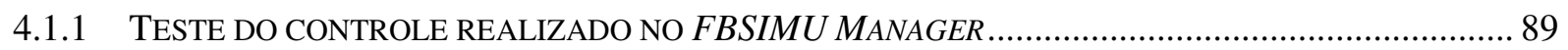

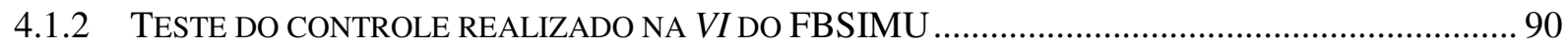

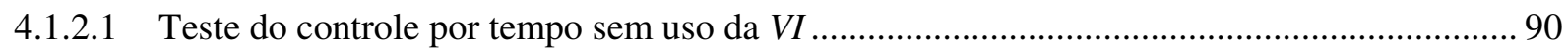

4.1.2.2 Teste do controle relacionado à liberação da $V I$.................................................................. 90

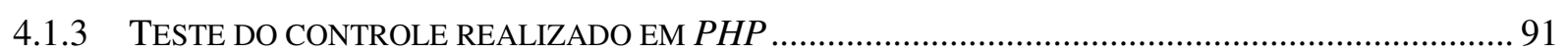

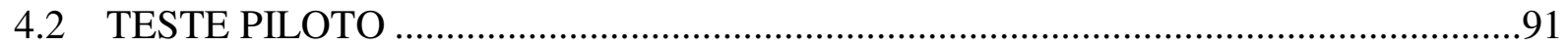

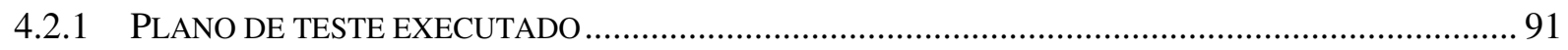

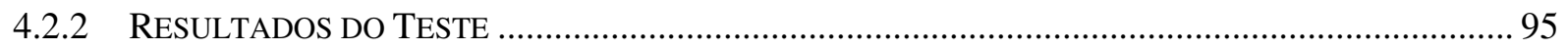

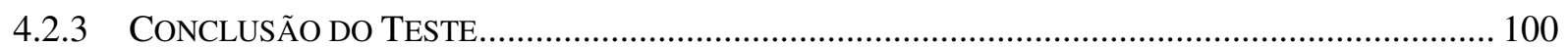

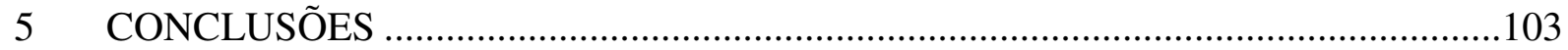

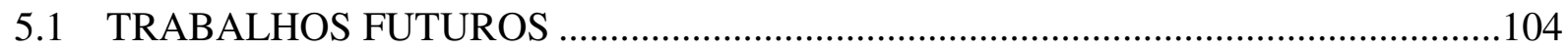

ANEXO A - DESCRIÇÃO DETALHADA DO FBSIMU ....................................................115

APÊNDICE A - PROCEDIMENTOS DE INSTALAÇÃO …...........................................141

APÊNDICE B - FERRAMENTAS PARA CRIAÇÃO DE CURSOS A DISTÂNCIA........149

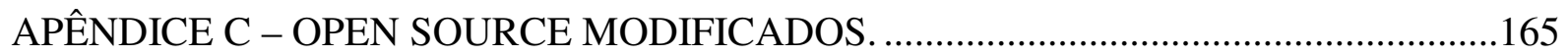




\section{Capítulo}

\section{Introdução}

O aumento da demanda por sistemas de automação e controle de processos baseados em redes de chão de fábrica (fieldbuses) e o significativo número de protocolos digitais de comunicação voltados para esta finalidade (Hart, Profibus, Profinet, Foundation Fieldbus, CAN e DeviceNet), estimulam a comunidade científica ao estudo e desenvolvimento de sistemas de controle via rede, ou Networked Control Systems (TIPSUWAN et. al, 2003).

Algumas ferramentas computacionais de pesquisa e desenvolvimento, elaboradas com o objetivo de expandir os recursos de desenvolvimento e de testes em redes de chão de fábrica reais, fizeram-se necessárias devido aos custos e às restrições de uso dos sistemas fieldbus reais. Neste contexto, inserem-se as ferramentas didáticas de simulação. Através desta classe de ferramentas, pesquisadores e estudantes podem simular processos de comunicação em redes e abranger diferentes aspectos de funcionamento dos mesmos.

Com a abrangente presença da Internet no ambiente acadêmico e doméstico, acessos remotos podem ser explorados, ampliando a flexibilidade de recursos didáticos aos usuários. Razões para o crescimento do uso de acesso remoto nesta área englobam, além dos aspectos de comodidade ao usuário, o fato de que a metodologia de ensino acadêmico, especificamente na área de controle e automação, passa por um processo de adaptação a novas tecnologias de informação. Paralelamente às vantagens no desempenho das tarefas do estudante, o acesso remoto e o conceito de educação a distância (e-learning) possibilitam às entidades de ensino uma maximização do aproveitamento de recursos didáticos, como materiais de laboratório, salas de aula, professores, entre outros. 


\subsection{Organização do trabalho}

Neste capítulo de introdução, o item 1.2 mostra conceitos sobre redes fieldbus e introduz informações relacionadas ao ensino a distância. No item 1.3, uma breve explicação do protocolo FOUNDATION Fieldbus é feita. No item 1.4, alguns detalhes importantes relativos à ferramenta FBSIMU são descritos e, por fim, o item 1.5 mostra os objetivos deste trabalho.

No capítulo 2, é feita uma revisão bibliográfica das pesquisas recentes que estão relacionadas com o trabalho proposto. No capítulo 3, faz-se uma descrição da forma que o trabalho foi desenvolvido, da ferramenta utilizada para a construção do portal FBSIMU, das necessidades de modificação do FBSIMU para a possibilidade de acesso remoto e por fim, uma descrição da arquitetura geral do sistema.

Os testes, resultados e discussões relativas aos mesmos são descritos no Capítulo 4. Por fim, no Capítulo 5, são apresentadas as conclusões e sugestões de novos trabalhos.

\subsection{Ensino de redes fieldbus}

Os primeiros sistemas de controle eram analógicos e construídos com dispositivos simples que executavam funções básicas em uma arquitetura com um número mínimo de CPUs (Unidade Central de Processamento). Na década de 70, sistemas ligados em rede foram introduzidos na indústria de automação. Mais tarde, surgiram os sistemas de controle distribuídos (DCS) e os PLCs (Controlador Lógico Programável), utilizados para conectar os controladores e os consoles de operação. Apesar dessa evolução, a comunicação digital entre dispositivos menores, como os transmissores de chão de fábrica, não foi vista antes da década de 80. Foi somente na década de 90 que o uso de redes de chão de fábrica para a comunicação digital de dispositivos de controle ganhou aceitação no mercado (BERGE, 2002). 
Para gerenciar a comunicação entre esses dispositivos, mais conhecidos como field devices ou instrumentos de campo, foram criados os protocolos fieldbus. Um fieldbus é um protocolo usado em sistemas de controle distribuídos e que possui uma arquitetura na qual cada instrumento de campo tem sua própria inteligência e se comunica através de um barramento de dados. A Fieldbus Foundation (FIELDBUS FOUNDATION, 1999a) define um sistema fieldbus ou rede de campo como:

[...] um sistema distribuído composto por dispositivos de campo e equipamentos de controle e de monitoramento integrados em um ambiente físico de uma planta ou uma fábrica. Os dispositivos do fieldbus trabalham em conjunto para realizar I/O (input/output) e controle em operações e processos automáticos. (FIELDBUS FOUNDATION, 1999a).

Nessas redes, os dispositivos de campo e equipamentos de controle, como, por exemplo, transmissores inteligentes, atuadores, controladores lógicos programáveis e estações de supervisão e de configuração, conectam-se segundo um protocolo especialmente definido para a classe do processo controlado. A figura 1 mostra um exemplo da disposição de componentes de uma rede fieldbus.

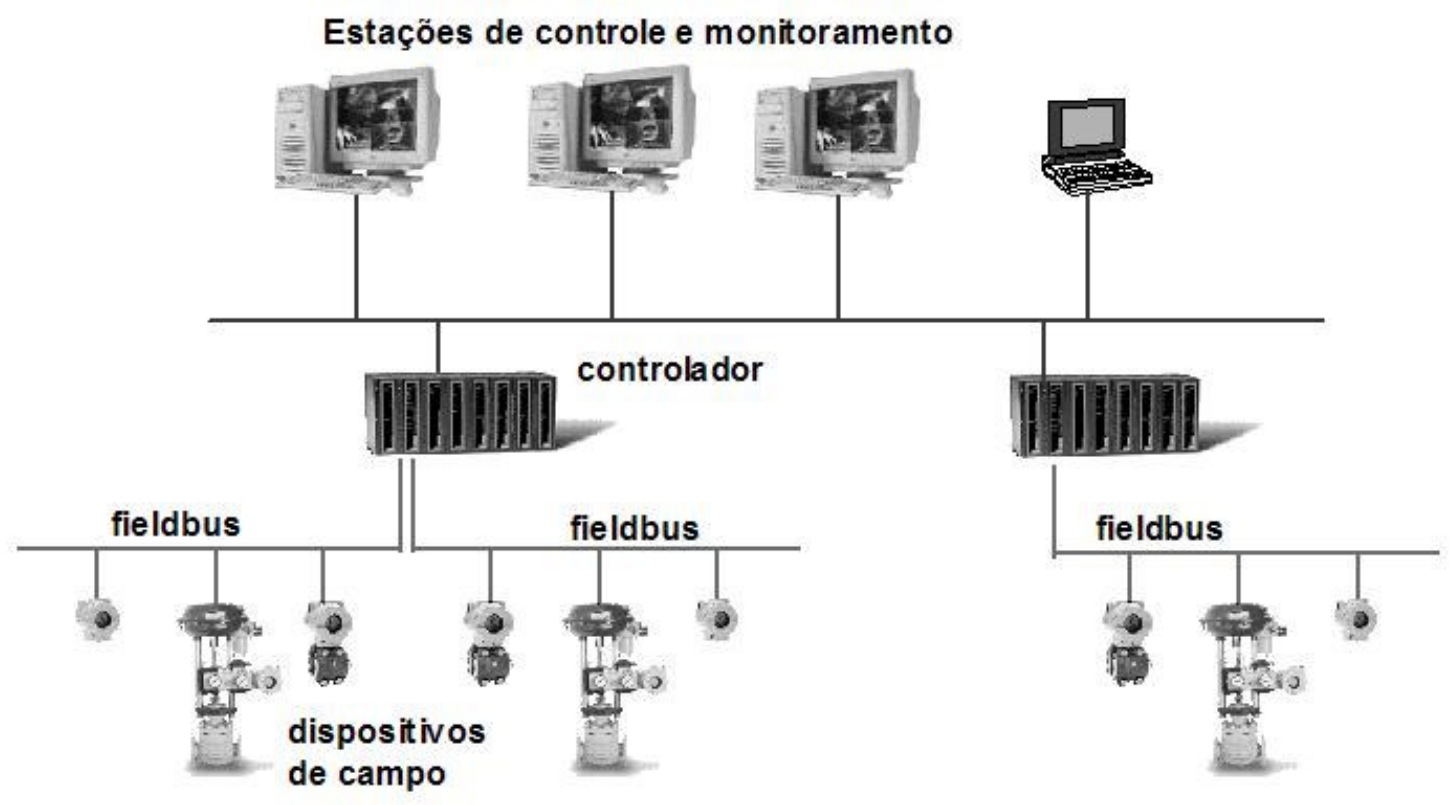

Figura 1 - Sistema Fieldbus e seus componentes

FONTE: BRANDÃO (2005) 
$\mathrm{Na}$ figura, têm-se as estações de controle e monitoramento ligadas a um device (controlador) que, além de executar funções de controle, executa o papel de comunicação entre estas estações e os dispositivos de campo.

No mercado, existem vários protocolos fieldbus, como, por exemplo, CAN (Control Area Network), Interbus, DeviceNet, Hart, Modbus, AS-I (AS-Interface), Profibus e FOUNDATION Fieldbus. Este trabalho refere-se ao FOUNDATION Fieldbus (veja item 1.3 na página 25).

Desde o início da criação desses protocolos, foram necessárias pesquisas sobre os diferentes aspectos e funcionalidades para propor melhorias tecnológicas e otimizações nos meios e formas de comunicação, nos instrumentos de campo (transmissores e atuadores) e nas malhas de controle de processos industriais. Várias ferramentas foram criadas com o objetivo de facilitar essas pesquisas. Como exemplo da dificuldade enfrentada na realização dessas pesquisas, pode-se citar as complicações existentes para estudantes e pesquisadores no acesso a uma planta industrial real. Mesmo eliminando a necessidade de uma planta real, elaborar e montar uma pequena planta voltada somente para pequenos experimentos também é difícil considerando-se o preço dos componentes necessários para a montagem. Foi por isso que ferramentas didáticas de simulação começaram a ser criadas. Através dessas ferramentas, pesquisadores e alunos podem simular a comunicação das redes fieldbus e entender o funcionamento das mesmas.

BRANDÃO (2005) desenvolveu o FBSIMU, Fieldbus Foundation Function Block Simulator, uma plataforma de desenvolvimento e simulação de redes FOUNDATION Fieldbus com foco na camada de aplicação de blocos funcionais (veja o item 1.4 na página 31).

$\mathrm{Na}$ maioria das vezes, as ferramentas e até mesmo plantas didáticas obrigam o aluno ou pesquisador a ir até um laboratório para realizar seus testes e tarefas. Com o grande crescimento da internet, acessos remotos poderiam ser disponibilizados oferecendo uma 
grande flexibilidade desses recursos aos alunos. O mercado cada dia mais exige uma formação mais ampla e impõe uma constante atualização de informações entre os estudantes, e o método de ensino convencional muitas vezes não consegue atender a essa demanda. Por isso, um grande crescimento do uso da internet para o ensino tem acontecido. CASTRO et al. (2001) destacaram a necessidade do estudo contínuo, mesmo depois do período de escolaridade. $\mathrm{O}$ adulto tem várias outras obrigações e o ensino a distância torna-se muito útil para o aprendizado. Além disso, os autores afirmam que manter instituições de ensino exige um grande investimento, e cursos a distância auxiliam na redução destes custos. DEMING (2001) disse que o aprendizado a distância oferece, além das vantagens já citadas, a oportunidade para as pessoas que não tem possibilidade de ir até uma escola.

Estas vantagens do ensino a distância poderiam ser estendidas a acessos remotos a laboratórios e ferramentas. Foi daí que nasceu a idéia principal deste trabalho, que é o desenvolvimento do acesso remoto ao FBSIMU, permitindo ao usuário a utilização dessa ferramenta a partir de qualquer computador que possua acesso a internet (veja item 1.5 na página 33).

Algumas pesquisas relacionadas ao ensino a distância mostraram que, em alguns casos, com este tipo de educação, os alunos aprendem mais do que com o ensino convencional. Uma explicação para este fenômeno é que estudantes que se propõem a este tipo de aprendizado possuem uma responsabilidade maior e por isso são mais interessados nas informações do curso (IRVINE et al., 1999).

Além das considerações citadas acima, alguns pesquisadores destacaram características importantes do ensino a distância. Segundo JONES (1996) e LAWHEAD et al. (1997), o que categoriza o ensino a distância é a separação física entre o professor e o aluno em pelo menos uma das partes de um dado estudo. BUTLER (2003) disse que um curso a distância pode ser caracterizado por alunos que não precisam freqüentar aulas em um horário 
pré-agendado, pelo uso de métodos para distribuir o material usado em aulas e por alunos que executam seus estudos e aprendizado por si só.

Uma modalidade de ensino a distância (distance learning), é a educação on-line (online education). Para este modelo, a literatura também utiliza outros termos: educação virtual (virtual education), educação baseada na internet (Internet-based education), educação baseada na Web (Web-based education), via computer-mediated communication $(C M C)$, elearning, entre outros (PAULSEN, 2003).

KEEGAN (1988) definiu educação online como sendo caracterizada por:

- Separação física dos professores e estudantes, que distingue este modelo de educação da educação face-a-face.

- Influência de uma organização educacional que distingue este modelo de educação do estudo por si só (autodidata).

- Uso de uma rede de computadores para apresentar ou distribuir algum tipo de conteúdo educacional.

- Fornecimento de uma comunicação bidirecional através de uma rede de computadores de forma que estudantes possam se beneficiar de uma comunicação entre os próprios companheiros de classe, professores ou grupo de trabalho.

Todas estas características da educação on-line têm despertado interesse em várias áreas, e por isso as pesquisas e a criação de novos cursos desse tipo têm crescido nas últimas décadas. MORCOS et al. (2001) afirmam que a instituição de ensino que não trabalhar para se manter atualizada em relação ao rápido crescimento da influência da globalização e de novas tecnologias não irá sobreviver. Cursos on-line fazem parte desta evolução do ensino e, portanto, devem ser considerados durante a elaboração do material didático. 
COSTAS (2006) afirma que, até o fim da década passada, o ensino a distância era visto como educação de segunda classe no Brasil. Existiam apenas cursos técnicos de nível médio ou supletivo. Duas mudanças melhoraram este conceito. A primeira foi em 2001, quando o Ministério da Educação regulamentou o ensino de pós-graduação a distância. A outra mudança está relacionada com a metodologia, que usa os vários meios de comunicação para tornar o ensino mais dinâmico e menos solitário. Em 2006, o número de estudantes brasileiros matriculados em programas de pós-graduação semipresenciais (o aluno só vai à instituição de ensino para fazer prova ou aulas práticas) ultrapassou 60.000. Além disso, já existem centenas de cursos de graduação a distância, mas raros já diplomaram a primeira turma. A tabela 1 mostra vantagens e desvantagens desse modelo de ensino.

Tabela 1 - Vantagens e desvantagens do ensino a distância

Fonte: (COSTAS, 2006)

\begin{tabular}{|c|c|}
\hline Vantagens & Desvantagens \\
\hline $\begin{array}{l}\text { Flexibilidade - o conteúdo das aulas pode } \\
\text { ser acessado em qualquer horário. }\end{array}$ & $\begin{array}{l}\text { Solidão - os contatos com colegas } \\
\text { restringem-se aos debates na internet e é } \\
\text { mais difícil fazer amizades. }\end{array}$ \\
\hline $\begin{array}{l}\text { Fim da barreira geográfica - pode-se } \\
\text { estudar nas melhores universidades, } \\
\text { mesmo morando em regiões distantes. }\end{array}$ & $\begin{array}{l}\text { Excesso de independência - é preciso ter } \\
\text { disciplina; não há o estímulo nem a } \\
\text { supervisão constante do professor. }\end{array}$ \\
\hline $\begin{array}{c}\text { É mais barato - gasta-se menos com } \\
\text { mensalidade e transporte. }\end{array}$ & $\begin{array}{c}\text { Falta uma biblioteca - o catálogo de livros } \\
\text { digitalizados na internet é pequeno } \\
\text { comparado com o das bibliotecas das } \\
\text { faculdades. }\end{array}$ \\
\hline
\end{tabular}

Uma pesquisa mostrou que em 2005 a procura pela educação a distância cresceu $62 \%$, atingindo 1,2 milhões de alunos. O número de instituições credenciadas que oferecem educação a distância no Brasil cresceu 30\% (ABED, 2006). 
Acompanhando o crescimento do ensino a distância, a criação de ferramentas voltadas à simplificação da criação de cursos baseados neste modelo de ensino começou a despertar interesse tanto no meio acadêmico quanto no meio comercial.

Foi graças ao avanço tecnológico proporcionado por pesquisas relacionadas a este tipo de ferramenta que surgiu a idéia da criação dos chamados CMS (Sistema de Gerenciamento de Curso - Course Management System), que são sistemas desenvolvidos com o intuito de simplificar o trabalho dos professores no gerenciamento dos cursos a distância. Com este tipo de sistema, os administradores de cursos a distância podem facilmente criar novas páginas para a internet contendo novos cursos, sendo que estes poderão ser criados de forma simples e sem a necessidade de grandes conhecimentos na área de desenvolvimento para a Web.

Assim como existem diferentes termos para referenciar a educação on-line, outros termos são usados para definir estes tipos de sistemas: Sistema de Suporte ao Ensino (Learning Support System - LSS), Ambiente Virtual de Ensino (Virtual Learning Environment - VLE), Sistema de Gerenciamento de Ensino (Learning Management System LMS) e Ambiente de Ensino Gerenciado (Managed Learning Environment - MLE).

Alguns autores elaboraram definições para este tipo de sistema. ADKINS (2005) apresentou a seguinte definição para um LMS:

[...] Software que automatiza a administração de eventos de treinamento. $\mathrm{O}$ LMS registra usuários, acompanha cursos em um catálogo e armazena dados de alunos em registros; este também fornece relatórios voltados à manutenção. Um LMS é tipicamente desenvolvido para o gerenciamento de cursos ser feito por diversos editores e fornecedores. Os LMS geralmente não fornecem suporte para a criação de apresentações ou conteúdo de cursos; em vez disso, focam na manutenção de cursos criados por uma variedade de outras fontes.

HALL (2001) apresentou uma definição alternativa ao mesmo LMS:

[...] Software que automatiza a administração de eventos de treinamento. Todos os Learning Management Systems gerenciam log-in de usuários registrados, gerenciam catálogos de cursos, registram dados de estudantes e fornecem relatórios usados para gerenciar o sistema. Algum tempo atrás, dizia-se haver uma distinção entre um Sistema de Gerenciamento de 
Configuração (Learning Management System) e um Sistema de Gerenciamento de Ensino Integrado (Integrated Learning Management System) mais poderoso. O termo Learning Management System é agora usado para descrever uma grande variedade de aplicações que guiam o treinamento de estudantes e pode ou não incluir funções como: suporte para preparação de cursos (apresentações, tecnologias para criação de páginas interativas), gerenciamento de aulas, gerenciamento de competência, gerenciamento de conhecimento, certificados de conclusão, personalização, suporte para alunos feito pelos instrutores, salas de bate papo (Chat), quadros de discussão.

Estes sistemas geralmente são executados em computadores servidores usando uma ou mais bases de dados e uma linguagem de programação que pode ser Java/J2EE ou mesmo alguma linguagem de script (PHP - Hipertext Preprocessor, por exemplo).

Além disso, estes sistemas são divididos em vários componentes que incluem modelos (templates) para estilos de sites, fóruns, sistema de bate-papo (chat), questionários e exercícios (múltipla escolha, verdadeiro/falso, etc.). Alguns serviços, como o controle de acesso, ferramentas de comunicação, material para ensino a distância e ferramentas para administração do site, também são fornecidos.

Considerando a grande quantidade e variedade de ferramentas CMS existentes no mercado, uma lista fornecendo as características daquelas mais conhecidas é apresentada no APÊNDICE B. Apesar da proposta deste trabalho não ser a criação de um curso a distância, mas sim um acesso a uma ferramenta de simulação através da internet, um CMS foi utilizado devido às várias características úteis apresentadas por estes sistemas. O CMS escolhido foi o Moodle (detalhes no item 3.1 na página 59).

\subsection{FOUNDATION Fieldbus}

A origem do FOUNDATION Fieldbus foi em 1992, quando o grupo ISP (Interoperable Systems Project) demonstrou interesse na criação de um padrão uniforme de fieldbus. Paralelamente, os desenvolvedores e usuários do FIP (Flux Information Processus), criaram uma organização internacional chamada WorldFIP. Em 1994, o ISP e a WorldFIP juntaram- 
se para formar a Fieldbus Foundation com o objetivo de criar um padrão internacional de fieldbus único. A Fieldbus Foundation é uma organização independente, sem fins lucrativos, constituída por usuários e desenvolvedores de dispositivos de campo e sistemas de automação (FIELDBUS FOUNDATION ONLINE, 2005). Deve-se destacar que o termo FOUNDATION Fieldbus não referencia o mesmo que o termo Fieldbus Foundation. O termo FOUNDATION Fieldbus dá nome ao protocolo especificado pela organização Fieldbus Foundation.

O FOUNDATION Fieldbus é um protocolo totalmente digital, serial, bidirecional, distribuído, que interconecta equipamentos de campo como sensores, atuadores e controladores. De forma superficial, pode-se classificar este protocolo como uma LAN (Local Area Network) para instrumentos usados em automação de processos e automação industrial, com a habilidade de distribuir a aplicação de controle pela rede.

A figura 2 ilustra a estrutura de uma rede FOUNDATION Fieldbus simples, onde, uma estação de supervisão/manutenção/diagnóstico se comunica com os dispositivos de uma rede FOUNDATION Fieldbus através do dispositivo de ligação (controlador lógico).

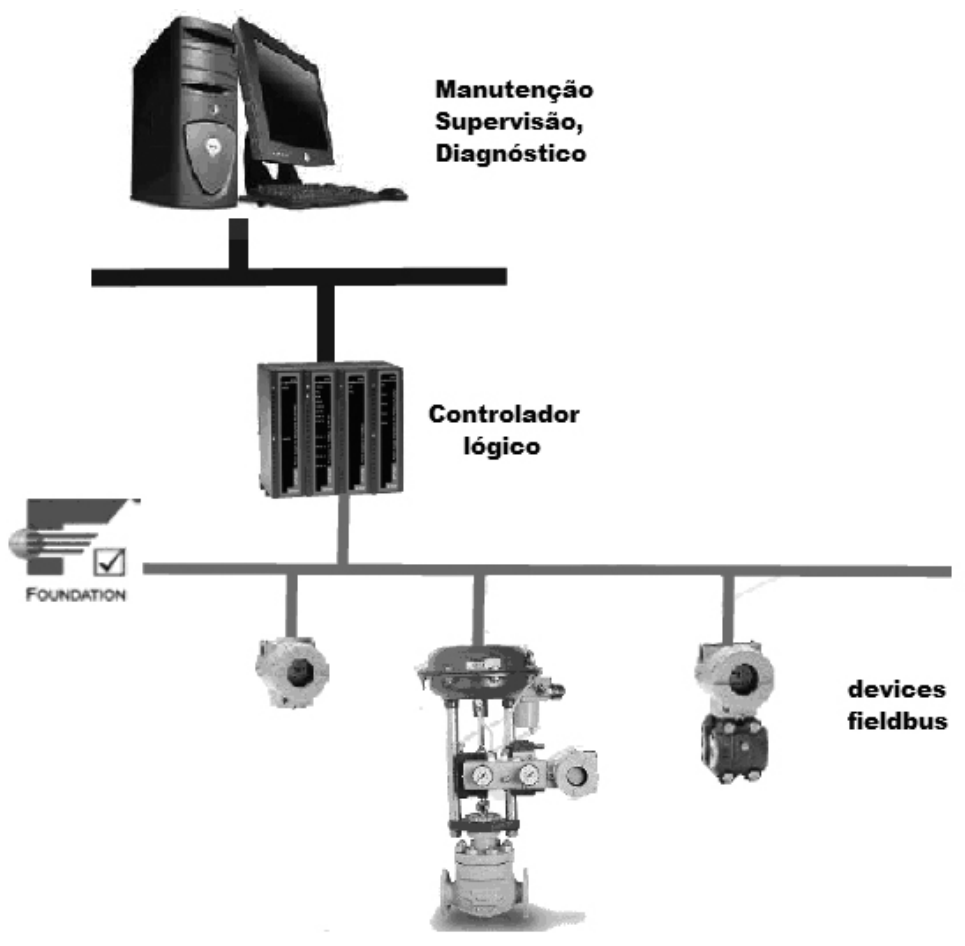

Figura 2 - Arquitetura Fieldbus 
Este protocolo, assim como os outros protocolos fieldbus e algumas redes de computadores, baseia-se no modelo de referência ISO/OSI (International Standards Organization/Open System Interconnection) de sete camadas (INTERNATIONAL ORGANIZATION FOR STANDARDIZATION, 1994).

O modelo é constituído por um conjunto de camadas independentes hierarquicamente sobrepostas, no qual cada camada, responsável por uma classe de tarefas, se comunica com as camadas adjacentes para realizar as tarefas. O modelo ISO/OSI não é por si só um protocolo de rede, ele apenas propõe uma arquitetura que visa reduzir a complexidade do sistema total, segundo o princípio de particularizar a análise do todo pela análise das partes. As sete camadas se comunicam de maneira transparente e horizontal, camada a camada, entre duas máquinas, ainda que localmente a comunicação se faça de maneira vertical. A figura 3 mostra as sete camadas do modelo.

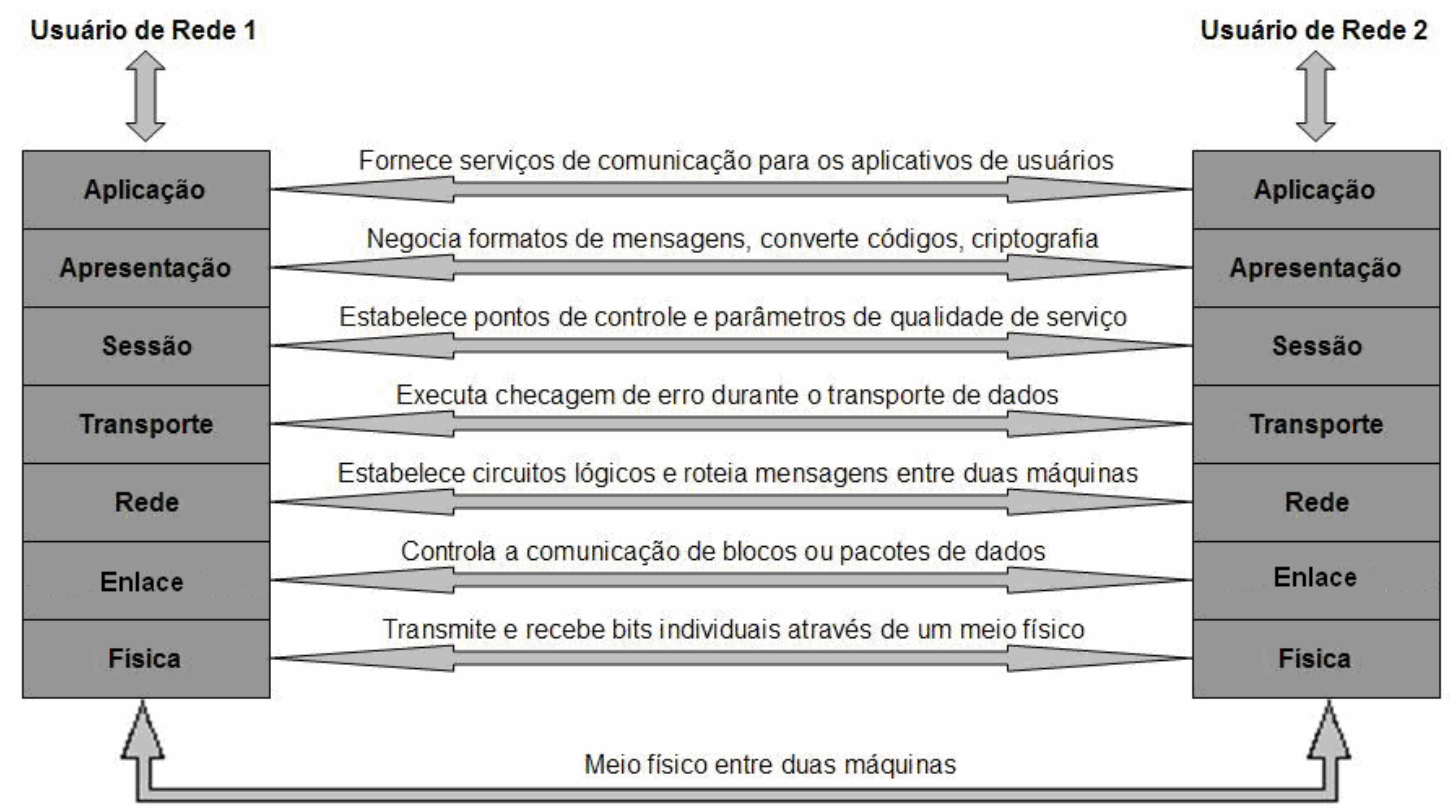

Figura 3 - Camadas do modelo ISO/OSI

A maioria dos protocolos fieldbus, por se restringirem a aplicações locais, não utiliza as camadas de rede, transporte, seção e apresentação do modelo ISO/OSI. Toda a estrutura de 
rede em um fieldbus se concentra nas camadas física, de enlace e de aplicação, conforme representado na figura 4. Com isso, obtem-se uma diminuição da quantidade de processamento de dados e a sobrecarga desnecessária de dados relacionada a informações de cada camada é eliminada.

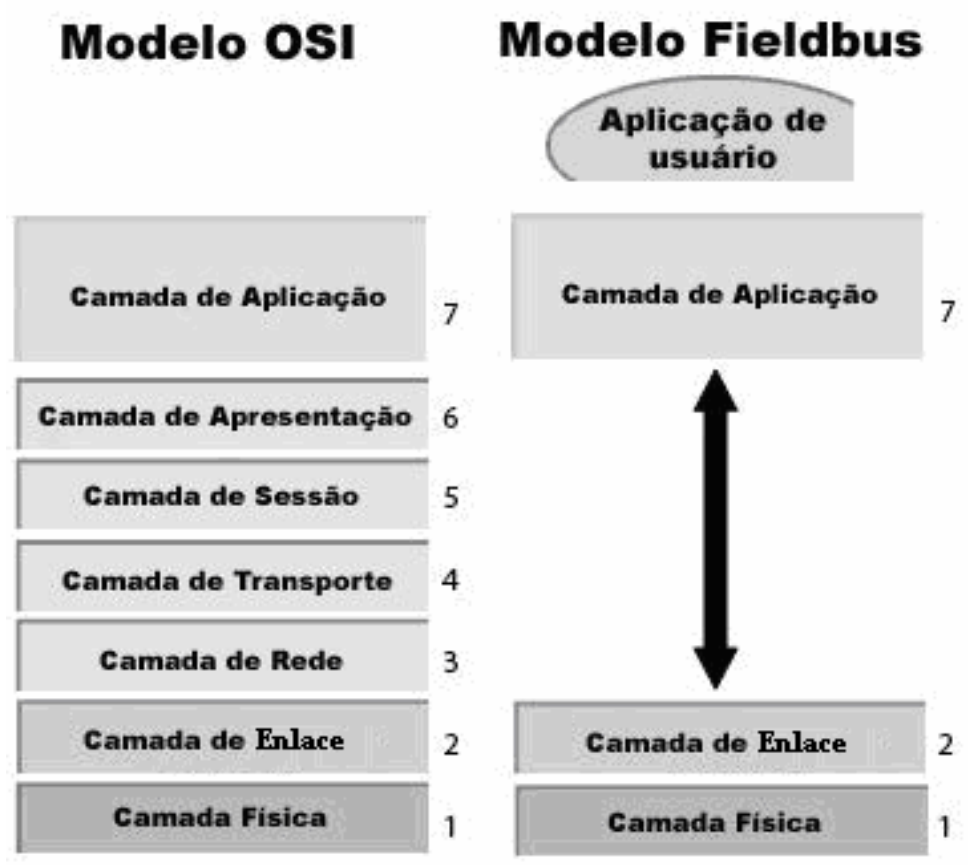

Figura 4 - Modelo de três camadas de redes de sistemas fieldbus

Além das três camadas implementadas pelo protocolo, o FoUNDATION Fieldbus definiu uma camada adicional chamada Aplicação de Usuário (User Application) que não é definida no modelo ISO/OSI.

O simulador utilizado neste trabalho, o FBSIMU, foca apenas a camada de aplicação de usuário do FOUNDATION Fieldbus e, sendo assim, explicações mais detalhadas sobre o funcionamento do protocolo serão centradas apenas em tal camada (maiores detalhes sobre o funcionamento das camadas deste protocolo, inclusive a camada de usuário, podem ser encontrados nas especificações desenvolvidas pela Fieldbus Foundation).

A Camada de Aplicação de Usuário define o Function Block Application Process (FBAP) que é composto de blocos de recurso (Resource Blocks), blocos de função (Function 
Blocks), blocos transdutores (Transducer Blocks) e da tecnologia de Device Description (DD) (FIELDBUS FOUNDATION, 1999b).

A DD é usada para descrever parâmetros de blocos padrões e para fornecer um formato padrão para que os configuradores, ou algum outro tipo de aplicativo, possam trabalhar com qualquer tipo de bloco de device padronizado.

Os blocos são basicamente funções automáticas de controle, distribuídos pelos dispositivos de uma rede FOUNDATION Fieldbus. A seguir segue uma breve explicação de cada um dos três tipos de blocos deste protocolo:

- Transducer blocks: este tipo de bloco sabe detalhes de E/S (entrada/saída) de devices e como agir para ler um sensor ou fazer mudanças no atuador. Ele fornece aos function blocks o valor lido no sensor e pode também atuar na calibração e linearização de um device. Os blocos transducer foram definidos para retirar dos function blocks a função de ler um sensor, por exemplo. Isso faz com que a leitura do sensor possa ser feita sem sobrecarregar os function blocks. A especificação do FOUNDATION Fieldbus define três tipos de transducer blocks. O Input Transducer Block é responsável pela leitura dos sensores ou outros tipos de entradas. O outro bloco é o Output Transducer Block, que manda valores para os atuadores ou para outros tipos de saídas. Por fim, existe o Display Transducer Block, responsável por informar à interface de exibição do device (display) alguns parâmetros internos.

- Function blocks: o function block descreve as funções de um device e define como este poderá ser acessado. Cada bloco tem uma determinada tarefa e cada device é equipado com pelo menos um function block. A especificação do FOUNDATION Fieldbus definiu alguns function blocks padrão que podem ser usados para realizar algumas funções básicas. Estes blocos são: analog input 
(AI), analog output (AO), bias (B), control selector (CS), discrete input (DI), discrete output (DO), manual loader (ML), ratio (RA), proportional/derivative (PD) e proportional/integral/derivative (PID).

- Resource blocks: este tipo de bloco descreve características de um dado device como o nome, fabricante, número de série, versões de hardware e firmware, etc.

Apesar da breve explicação sobre os três tipos de blocos do FOUNDATION Fieldbus, apenas os blocos funcionais (function blocks) são disponibilizados para simulação no FBSIMU. No item 1.4, página 31, maiores detalhes sobre o uso dessa ferramenta são apresentados.

Para exemplificar o funcionamento prático dos conceitos transmitidos acima, tem-se o exemplo da figura 5, que mostra a estrutura de uma estratégia de controle que faz uso dos blocos Proportional/Integral/Derivative (PID), Analog Input (AI) e Analog Output (AO) para o controle de temperatura de um determinado processo. 


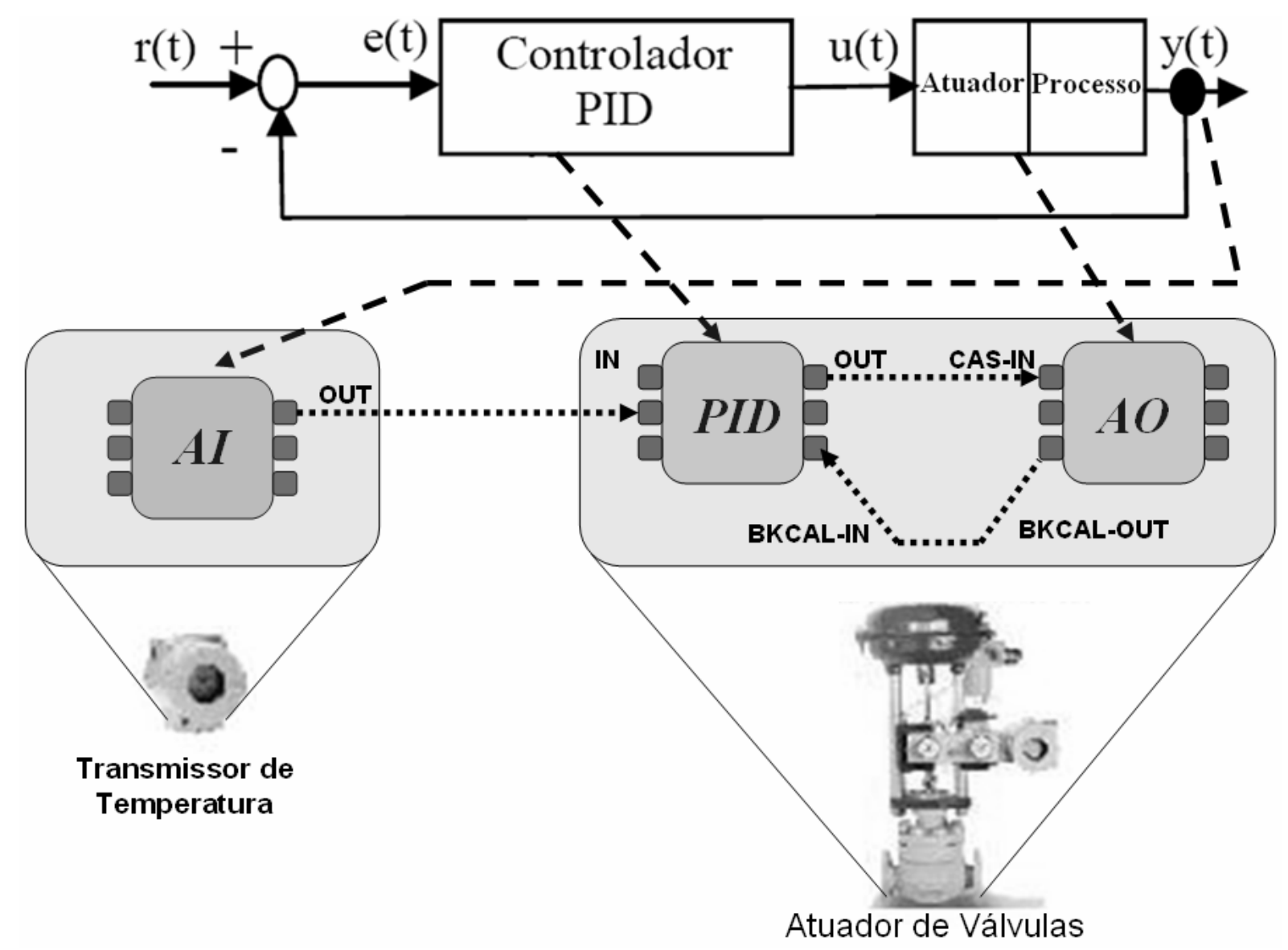

Figura 5 - Controle por FOUNDATION Fieldbus da temperatura de um processo usando um transmissor de temperatura e um atuador de válvula.

Neste exemplo, o transmissor de temperatura vai ler a temperatura e, através do bloco AI, enviará esta informação para o bloco PID. O PID irá comparar o valor lido com o "set point" (ponto de ajuste) e aplicar seu algoritmo a fim de encontrar a ação de controle necessária, passando para o bloco AO uma informação indicando alguma correção a ser feita. O AO, localizado junto ao atuador da planta, irá passar esta informação para o atuador que irá agir sobre a planta conforme for necessário.

\subsection{FBSIMU}

O FBSIMU, Fieldbus Foundation Function Block Simulator, é uma plataforma de desenvolvimento e simulação de redes fieldbus com foco na camada de aplicação de blocos 
funcionais de estrutura modular e escalonável, composto somente por software. Cada módulo ou unidade de software do FBSIMU simula um elemento ou estrutura de um sistema FOUNDATION Fieldbus real (BRANDÃO, 2005).

As funções do FBSIMU são:

- Proporcionar ferramentas e estruturas para o projeto e implementação de blocos funcionais personalizados ou blocos funcionais padrão no ambiente de simulação;

- Executar blocos funcionais de forma contínua ou única, com a possibilidade de monitorar e modificar parâmetros de configuração e de entrada;

- Configurar e executar malhas de controle de blocos funcionais segundo uma tabela configurável de escalonamento de blocos funcionais e de mensagens;

- Utilizar modelos de simulação de sistemas dinâmicos, conjugados às malhas de blocos funcionais, de modo a estabelecer um sistema de controle de malha fechada sincronizado com a planta simulada;

- Realizar a aquisição de dados de barramento de fieldbuses reais e analisá-los de modo a estimar parâmetros e variáveis de comunicação.

O FBSIMU foi concebido e programado baseando-se nas especificações da Fieldbus Foundation, e foi desenvolvido no ambiente LabVIEW através da linguagem de programação gráfica $\mathrm{G}$, nativa deste ambiente.

O FBSIMU foi desenvolvido através da construção de módulos ou bibliotecas de software e posterior integração destes, com o objetivo de construir os módulos principais e secundários. As funções das bibliotecas foram especialmente desenvolvidas para a construção do simulador e simulam as tarefas típicas de uma rede de campo FOUNDATION Fieldbus.

Para maior entendimento da construção e uso do software, referencie o Anexo A. 


\subsection{Objetivos}

O primeiro objetivo deste trabalho é fazer uma análise dos tipos de cursos e laboratórios remotos relacionados às áreas de controle e automação existentes atualmente, tanto nos meios acadêmicos como no mercado em geral. Com esta análise, é possível saber as tendências e necessidades para esta área. Esta análise está detalhada na revisão bibliográfica deste trabalho.

O segundo e principal objetivo deste trabalho é projetar e implementar um portal de acesso remoto à ferramenta de simulação descrita no item 1.4 (FBSIMU), com aplicação em ensino e treinamento de sistemas FOUNDATION Fieldbus. Além do acesso remoto ao FBSIMU, este portal deverá possuir controle de usuários e extensibilidade para a inserção de novos laboratórios e até mesmo cursos remotos. 



\section{Revisão Bibliográfica}

Na história do ensino a distância, o uso da internet é apenas o capítulo mais recente. Segundo DANIELS (1997), este tipo de ensino surgiu no século XIX, mas somente nas últimas décadas assumiu o status que o coloca no cume das atenções pedagógicas de um número cada vez maior de países. No século XIX, os poucos cursos que seguiam o modelo de ensino a distância usavam como meio de comunicação a correspondência. Nas décadas de 60 e 70, o uso do rádio e do videocassete foi um grande salto para o crescimento deste tipo de curso. Continuando a evolução, a televisão, o videotexto, o computador e mais recentemente a tecnologia de multimídia, que combina textos, sons e imagens, habilitam a criação de cursos cada vez mais avançados impulsionando a criação de ferramentas especializadas neste tipo de ensino.

De forma geral, um curso a distância pode ser classificado atualmente em duas categorias, síncrona e assíncrona. $\mathrm{O}$ aprendizado síncrono foca a comunicação em tempo real. Nestes sistemas, o aluno, além de visualizar uma aula remotamente, pode interagir através de perguntas em tempo real. Já os sistemas assíncronos não exigem que instrutores e alunos estejam conectados ao mesmo tempo.

GAL-EZER et al. (1997) afirmaram que antes de decidir oferecer o ensino a distância, algumas considerações devem ser feitas: por quem, para quem e como o curso será desenvolvido; qual é o suporte profissional necessário e disponível para o desenvolvimento desse curso; qual a estrutura que será disponibilizada para os alunos que usarão este curso; como será feita a avaliação dos alunos; que tipo de equipamento e software os estudantes deverão possuir para poder usufruir do curso; quais serão os benefícios da integração da 
tecnologia no curso em questão, e assim por diante. Também não se pode esquecer de considerações relacionadas ao custo/benefício dos cursos desenvolvidos nestes moldes. Estas preocupações relacionadas ao ensino a distância são também relevantes quanto a criação de um laboratório remoto como o FBSIMU On-line e, por isso, as questões levantadas acima foram levadas em consideração no capítulo 3, onde maiores detalhes serão apresentados. POINDEXTER et al. (2000) mostraram que para integrar tecnologia em um curso tradicional, deve-se saber quem serão os usuários do curso, o porquê de usar a internet, quais características irão ajudar a atingir os objetivos propostos. Além disso, deve-se fornecer treinamentos aos estudantes para permitir integração dos mesmos com novas características.

Mesmo depois de pensar nestas questões, ainda é necessário atentar-se a cuidados que devem ser tomados em relação ao formato do sistema de ensino a distância para evitar complicações e problemas futuros. Segundo SHIH et al. (2003), o ensino a distância, apesar de suas grandes vantagens, cria novos problemas também. Como um professor vai desenvolver um curso a distância e como mantê-lo? Como manter o registro dos estudantes envolvidos? É possível uma prova on-line? Como avaliar o desempenho de um estudante? É possível fornecer um curso individual para cada aluno? Um curso on-line pode complicar muito a vida de um instrutor que não está acostumado com o uso dos computadores. Além do instrutor, um aluno também precisa saber todos os possíveis recursos oferecidos pelo curso para melhor aproveitá-lo. Se inicialmente os criadores dos cursos por correspondência tinham o trabalho de escrever uma apostila e enviá-la ao estudante, ou editar um vídeo, ou gravar uma aula em áudio, hoje o trabalho dos desenvolvedores dos cursos a distância é criar algo que utilize como meio de comunicação a internet. Apesar da tecnologia ter trazido este tipo de facilidade, ela trouxe uma necessidade de cursos com um conteúdo mais completo, e com isso maior quantidade de trabalho ao desenvolvedor do curso. Em relação à criação de laboratórios remotos, os problemas e dificuldades encontradas são as mesmas e a preocupação com 
relação a extensibilidade e facilidade de manutenção deve ser priorizada a fim de amenizar tal dificuldade. Levando em conta esta complexidade, vários pesquisadores e empresas preocupam-se em desenvolver ferramentas que forneçam objetos prontos para serem usados pelos instrutores para a criação de seus cursos e laboratórios. Isso ajuda a manter o padrão destes portais de aprendizado e, consequentemente, a dificuldade dos alunos de utilizar estas ferramentas diminui. Como exemplo de objetos prontos, pode-se destacar a criação de tutoriais de forma automática através de informações recolhidas do próprio aluno.

EBERHARDT (1998) ressalta a importância de que a arquitetura de um sistema deste tipo deva ser flexível e escalável para poder lidar com futuros tipos de mídia, tecnologias de comunicação e outras futuras tendências.

Foi a partir da necessidade de sistemas com módulos/objetos prontos que facilitam a criação e padronização do estudo a distância e da necessidade de sistemas escaláveis e flexíveis que as primeiras ferramentas voltadas para a criação e administração dos cursos ou laboratórios a distância começaram a surgir. A tabela 2 mostra um conjunto dessas ferramentas. Além disso, a tabela mostra o tipo de licença de cada ferramenta e a plataforma compatível com cada uma. Os detalhes sobre as ferramentas apresentadas nesta tabela estão no APÊNDICE B.

Tabela 2 - Ferramentas para ensino a distância

\section{Ferramentas para ensino a distância}

\begin{tabular}{|c|c|c|}
\hline Nome & Licença & Plataforma \\
\hline LNR & GNU GPL & Linux/Unix \\
\hline ANGEL & $\begin{array}{c}\text { Baseado no número de } \\
\text { estudantes }\end{array}$ & Windows \\
\hline
\end{tabular}




\begin{tabular}{|c|c|c|}
\hline Nome & Licença & Plataforma \\
\hline ATutor & $G N U G P L$ & Linux/Unix/Windows \\
\hline Aulanet & Freeware & Windows NT 4.0 \\
\hline Avilar WebMentor & $\begin{array}{l}\text { Depende de termos de } \\
\text { licença }\end{array}$ & Windows \\
\hline Bazaar & $G N U G P L$ & Linux/Unix/Windows \\
\hline Blackboard & $\begin{array}{l}\text { Depende de termos de } \\
\text { licença }\end{array}$ & Linux/Unix/Windows \\
\hline Bodington & $G N U G P L$ & Linux/Solaris/Windows \\
\hline BSCW & $\begin{array}{l}\text { Livre para instituições de } \\
\text { ensino }\end{array}$ & $\begin{array}{c}\text { Windows/Solaris/SunOS/ } \\
\text { Linux/DECOSF/HP-UX/Irix/ } \\
\text { BSD/OS/AIX }\end{array}$ \\
\hline CentraOne & $\begin{array}{l}\text { Depende de termos de } \\
\text { licença }\end{array}$ & Windows \\
\hline Claroline & $G N U G P L$ & Linux/Unix/Windows \\
\hline ClassWeb & $G N U G P L$ & Windows \\
\hline Colloquia & $\begin{array}{c}\text { Livre para instituições } \\
\text { educacionais sem fins } \\
\text { lucrativos } \\
\end{array}$ & Todas compatíveis com Java \\
\hline COSE & Open Source licensing & Linux/Unix/Windows/Solaris \\
\hline Desire2Learn & $\begin{array}{l}\text { Possui diferentes formas de } \\
\text { cobrança }\end{array}$ & Windows \\
\hline eCollege AU+ & $\begin{array}{l}\text { Depende de termos de } \\
\text { licença }\end{array}$ & Windows \\
\hline Educator & $\begin{array}{l}\text { Depende de termos de } \\
\text { licença }\end{array}$ & Linux/Unix/MAC OS $X$ \\
\hline Eledge & $G N U G P L$ & $U N I X$ \\
\hline
\end{tabular}




\begin{tabular}{|c|c|c|}
\hline Nome & Licença & Plataforma \\
\hline FirstClass & $\begin{array}{l}\text { Depende de termos de } \\
\text { licença }\end{array}$ & $\begin{array}{l}\text { Windows/Macintosh OS X/ } \\
\text { Macintosh OS 9/Linux. }\end{array}$ \\
\hline Fle3 & $G N U G P L$ & UNIX/Windows \\
\hline Ganesha & $G N U G P L$ & $\begin{array}{c}\text { UNIX/Linux/MAC OS X/ } \\
\text { Windows }\end{array}$ \\
\hline Internet Course Assistant & Livre & Não se aplica \\
\hline ILIAS & $G N U G P L$ & Linux/Solaris/Unix \\
\hline IntraLearn SME & $\begin{array}{l}\text { Depende de termos de } \\
\text { licença }\end{array}$ & Windows \\
\hline Janison Toolbox & $\begin{array}{c}\text { Depende de termos e local } \\
\text { onde será usada }\end{array}$ & Windows \\
\hline $\begin{array}{c}\text { Jenzabar Internet Campus } \\
\text { Solution }\end{array}$ & $\begin{array}{l}\text { Depende de termos de } \\
\text { licença }\end{array}$ & Windows \\
\hline KEWL & Livre (Open Source) & Windows \\
\hline KnowEdge eLearning Suite & Freeware & Windows \\
\hline Learnwise & $\begin{array}{l}\text { Baseado no número de } \\
\text { estudantes }\end{array}$ & Windows 2000/2003 \\
\hline LON-CAPA & $G N U G P L$ & Linux \\
\hline $\begin{array}{l}\text { Manhattan Virtual } \\
\text { Classroom }\end{array}$ & $G N U G P L$ & Linux/Unix \\
\hline Moodle & $G N U G P L$ & Linux/Unix/Windows \\
\hline MimerDesk & $G N U G P L$ & Linux/Unix \\
\hline Sakai & $\begin{array}{l}\text { Educational Community } \\
\text { License Version } 1.0\end{array}$ & Linux/Unix/Windows \\
\hline
\end{tabular}




\begin{tabular}{|c|c|c|}
\hline Nome & Licença & Plataforma \\
\hline Teleduc & GNU GPL versão 2 & Linux \\
\hline Teknical Virtual Campus & $\begin{array}{c}\text { Baseado no número de } \\
\text { estudantes }\end{array}$ & Windows 2000/2003 \\
\hline The Learning Manager & $\begin{array}{c}\text { Baseado no número de } \\
\text { estudantes }\end{array}$ \\
\hline Unicon Academus & $\begin{array}{c}\text { Depende de termos de } \\
\text { licença }\end{array}$ & Unix/Windows \\
\hline Virtual-U & $\begin{array}{c}\text { Baseado no número de } \\
\text { servidores }\end{array}$ \\
\hline WebCT & $\begin{array}{c}\text { Baseado no número de } \\
\text { estudantes }\end{array}$ & Linux/Unix/Windows \\
\hline
\end{tabular}

Independente do uso das ferramentas citadas acima existe hoje na literatura uma série de cursos a distância e laboratórios remotos desenvolvidos com foco na área de automação. Dentre estes, é possível destacar duas abordagens distintas. A primeira é baseada em laboratórios com acesso remoto a instrumentos reais (descrito no item 2.1 na página 41). A segunda baseia-se em acesso remoto a simuladores dinâmicos de malhas de controle e, eventualmente, de dispositivos de campo (descrito no item 2.2 na página 44).

Em relação a estas abordagens, pode-se afirmar que a segunda tem a vantagem de permitir ao aluno fazer qualquer tipo de experimento sem restrições de segurança. Já no uso de dispositivos de campo e instrumentos reais tem-se a desvantagem de limitar o estudante a executar poucos tipos de experimentos para preservar sua segurança pessoal, a segurança dos dispositivos e até mesmo do laboratório. Uma vantagem do contato direto a dispositivos reais em relação ao acesso remoto a dispositivos simulados é proporcionar ao estudante uma experiência mais realista com equipamentos industriais. Entretanto, se o simulador for realista o suficiente, esta vantagem desaparece. 
Independente do uso de simuladores ou plantas reais, pode-se destacar também os sistemas remotos voltados para o ensino de protocolos fieldbus como o CAN ou o FOUNDATION Fieldbus (descritos no item 2.3 na página 45).

\subsection{Acesso remoto a instrumentos reais}

Um exemplo deste tipo de abordagem é descrito por SÁNCHEZ et al. (2002) e é constituído de um ambiente para operação a distância de uma planta real de testes através da internet. A planta do projeto é um pêndulo invertido. O sistema foi desenvolvido com a finalidade de não mostrar ao estudante as características físicas da planta, e, por isso, o mesmo pode se adaptar facilmente a outras plantas localizadas neste laboratório. Os softwares utilizados na elaboração e funcionamento do laboratório de controle virtual apresentados são o Matlab com o Simulink (simulação). Uma característica destacada do trabalho é que os professores podem adicionar diferentes experimentos através da simples edição de um arquivo de configuração.

Outro sistema concebido sob a mesma abordagem foi criado por AKTAN et al. (1996) e consiste de um laboratório onde o estudante, de forma remota, pode testar seu próprio código desenvolvido para controlar um braço de um robô com três graus de liberdade. Através da interface gráfica desenvolvida para o projeto, é possível assistir o funcionamento do robô, acessar o diagrama de blocos da planta, enviar comandos por um Xterminal e interromper um experimento utilizando um botão de stop (panic mode).

Em outra experiência, CASINI et al. (2003) disponibilizaram remotamente o acesso aos seguintes processos dinâmicos: um motor DC, um tanque para controle de nível, um sistema de levitação magnética e um simulador de helicóptero com dois graus de liberdade. $\mathrm{O}$ acesso é realizado através de um navegador Web em conjunto com os softwares 
Matlab/Simulink instalados na máquina cliente e permite ao estudante executar seu próprio algoritmo de controle.

Exemplificando ainda experiências didáticas através do acesso a plantas reais, LIOU et al. (1999) desenvolveram um sistema que permite aos estudantes o acesso a instrumentos via Web e permite aos instrutores configurar equipamentos até mesmo durante uma aula. A arquitetura do sistema é composta por um servidor conectado a diversos instrumentos (sensores, atuadores, motores, fontes de energia) e o controle dos equipamentos é realizado através do software LabView. Com o acesso remoto via Web, o instrutor conecta-se ao LabView para modificar diferentes parâmetros nos instrumentos, tendo assim a condição de tomar diferentes rumos em suas aulas. Nesse sistema, os alunos possuem acesso limitado aos parâmetros por motivos de segurança.

A mesma abordagem de acesso remoto é aplicada a um sistema de controle de vazão de fluidos em diversas tubulações (multi-pipe fluid flow). Neste laboratório, os estudantes podem tanto monitorar como controlar a planta. O ambiente foi desenvolvido com o LabView e foi criado com o objetivo de explorar e experimentar conceitos de engenharia e de auxiliar na resolução de problemas, na análise de dados e na análise de erros experimentais. Além disso, uma interface para o Matlab é fornecida para os alunos validarem seus próprios códigos (IMBRIE e RAGHAVAN, 2005).

Um laboratório remoto de sistemas lineares foi proposto por VIEDMA et al. (2005) com base no $I L A B$, ferramenta que fornece uma estrutura para o desenvolvimento de laboratórios remotos. O acesso a este laboratório se dá através de um software cliente baseado em Java. O estudante envia parâmetros para um servidor que se comunica com um analisador de sinais digitais, executa as tarefas necessárias e retorna as respostas requeridas. O cliente pode então visualizar diagramas de Bode, Nyquist e Nichols relacionados ao experimento realizado. 
No departamento de Engenharia Elétrica na Universidade Nacional de Singapura (NUS), o acesso remoto a um laboratório com quatro tipos de malhas de controle (controle manual, PID, controle por algoritmos em espaços de estados e controle com lógica fuzzy) foi implementado por KO et al. (2001). Nesse laboratório também é possível o acesso remoto a uma plataforma para pesquisadores realizarem testes sobre os algoritmos de controle. Para tal projeto, foi utilizado o software LabView e as linguagens Java, HTML, Java Script e VB script. O sistema fornece imagens e sons do laboratório através de uma câmera montada em uma plataforma móvel. O software utilizado para o envio destes dados é o NetMeeting da Microsoft. A planta utilizada no experimento consiste de dois tanques transparentes acoplados, montados sobre um reservatório de água, no qual o nível de líquido de cada tanque pode ser controlado.

Outro experimento que usa o mesmo exemplo de planta de KO et al. (2001) foi desenvolvido por BING et al. (2004). O acesso à planta neste caso se dá através de um cliente com um navegador Web. Os serviços requeridos chegam a um servidor que se comunica com duas plantas, dependendo de qual experimento o aluno está utilizando. Um dos experimentos é o controle de um pêndulo invertido e o outro, o controle do nível em tanques acoplados.

APKARIAN e DAWES (2000) utilizam o acesso remoto em um experimento de controle dinâmico de um helicóptero, no qual o estudante pode modificar remotamente parâmetros de controle e avaliar o desempenho do sistema através de uma página Web. O hardware do sistema é composto por um equipamento que simula os movimentos de um helicóptero real e de um computador equipado com instrumentos para aquisição de valores dos sensores e envio de comandos para os amplificadores que controlam os motores da planta. Os softwares utilizados neste sistema são o Matlab, Simulink, WinCon (ferramentas de execução das funções de controle e acesso remoto) e o Maple. A ferramenta criada foi denominada WebLab, e utilizou-se a tecnologia Java em seu desenvolvimento. 


\subsection{Acesso remoto a simuladores}

A substituição de plantas reais por simulações computacionais em procedimentos didáticos e de pesquisa é prática amplamente consolidada. Todavia a extensão dessa prática para o ensino a distância começou a ser adotada como objeto de pesquisa e de desenvolvimento a partir da última década.

SCHMID e ALI (2000) criaram experimentos que envolvem seções de tutorial, exercícios teóricos, além de experimentos em plantas simuladas, através de um sistema baseado no plug-in do Matlab para acesso remoto, na linguagem para animação de modelos dinâmicos Virtual Reality Modelling Language (VRML), em ferramentas do Matlab/Simulink, no Maple e em Java applets. Embora o sistema seja de acesso remoto, a máquina cliente deve ter o software Matlab instalado.

CLAUSEN et al. (1998) desenvolveram uma ferramenta que simula um laboratório voltado para o ensino do processamento digital de sinais (DSP). O laboratório engloba cinco exercícios que cobrem as teorias de transformada_z, pólos \& zeros, transformada de Fourier, entre outros. A ferramenta apresenta páginas Web que descrevem o exercício proposto e suporta programas em Java que permitem aos estudantes desenvolverem simulações de sistemas.

Um outro sistema, também voltado para processamento digital de sinais, denominado $J-D S P$, foi desenvolvido por SPANIAS et al. (2000). Este sistema, além de experimentos online, suporta a submissão de relatórios e de avaliações.

Mais voltado para o ensino das bases teóricas dos sistemas de controle, QINGCANG et al. (2004) utilizam uma ferramenta baseada na linguagem $C h$ (interpretador $\mathrm{C} / \mathrm{C}++$ ) que cobre várias técnicas para análise de sistemas de controle sob a luz das teorias de controle clássica e moderna. A ferramenta suporta modelos representados por espaço de estado e por 
funções transferência. O estudante, através de um navegador Web, pode escolher os métodos de projeto e análise do controlador, especificar o tipo de sistema de controle e configurar os parâmetros do mesmo. Os dados são enviados a um servidor para a computação numérica e os resultados são enviados de volta ao cliente com o uso do CGI (Common Gateway Interface).

Para a análise do desempenho e estabilidade de sistemas de primeira e segunda ordem, um sistema on-line desenvolvido em Visual Basic foi criado por CHAN et al. (2002). O sistema é dividido em três seções. A primeira apresenta conceitos básicos da teoria de controle. Em outra parte, o estudante pode realizar alguns testes em simulação com respostas na forma de gráfico de lugar das raízes e resposta temporal a excitações (ex. degrau). Além disso, o sistema possui um questionário em que o estudante responde a perguntas e testa seus conhecimentos.

EXEL et al. (2000) exploram experimentos on-line que permitem comparar o desempenho de diferentes controladores, como o PD e o PID, em situações de mudanças de set point e distúrbios. Os autores deste experimento afirmam que simulações são muito relevantes para a assimilação da teoria, mas que elas não podem substituir um experimento real em laboratório. Estas simulações são disponibilizadas remotamente através do WinCon, software que permite a realização de experimentos em tempo real de malhas de controle do Simulink. Para o acesso remoto, a máquina servidora precisará manter o WinCon Server operante e uma máquina cliente se conectará utilizando o cliente WinCon.

\subsection{Laboratórios remotos para ensino de redes de campo}

Além da teoria de controle, alguns sistemas de ensino a distância exploram o ensino de redes de campo. Um laboratório virtual, voltado para redes CAN, foi desenvolvido por BUHLER et al. (2000). Este laboratório, o Virtual Automation Lab, é uma ferramenta interativa de ensino via Web para operação do protocolo. A ferramenta pode ser empregada 
de duas formas: a primeira é através de um laboratório real conectado à internet por meio de uma interface remota, por onde o estudante opera um instrumento real e observa características da rede de campo como atrasos de comunicação, falhas, etc. A segunda forma é através de simulações que permitem a ambientação dos estudantes antes da manipulação de instrumentos reais. A rede de campo utilizada no experimento possui um microcomputador, uma webcam, alguns transmissores inteligentes com o protocolo CANopen e uma placa de interface CAN. As etapas do curso cobrem a motivação, objetivos do grupo, objetivos educacionais, pré-requisitos, visão geral e os exercícios propriamente ditos. Para a realização de um exercício são necessárias a disponibilidade de uso dos instrumentos (só é permitido o acesso de um estudante por vez) e a observação de restrições de segurança.

Uma outra prática experimental, também com acesso remoto, de uma planta industrial piloto instrumentada por sistemas de controle via rede no protocolo FOUNDATION Fieldbus foi desenvolvida por ZEILMANN et al. (2003). O acesso remoto permite a um estudante a realização de experimentos de controle e supervisão da planta piloto. Este sistema é também utilizado como uma plataforma para pesquisas em automação industrial. A planta piloto adotada consiste de três tanques acoplados, bombas de fluxo e cinco válvulas de controle para manipular as vazões de líquidos no sistema. É possível configurar estratégias de controle distintas sobre as variáveis de níveis dos tanques, vazões e temperaturas. A arquitetura do sistema segue o modelo cliente/servidor. O cliente é um applet que se comunica com o Web Server empregando socket. No servidor, existe um sistema supervisório com interface OPC (OLE for Process Control) que recebe informações da rede fieldbus. Este supervisório é responsável por criar uma página Web com todos os dados de processo necessários e disponibilizá-los para o estudante remoto. O sistema possui também uma webcam para acompanhamento visual da dinâmica da planta. Como funções auxiliares aos procedimentos didáticos, o sistema possui controle de acesso e validação de usuários, agendamento de 
experimentos, monitoramento da duração das seções práticas e inicialização e parametrização dos experimentos. Devido ao uso de uma planta piloto, os experimentos não podem ser realizados por mais de um estudante ao mesmo tempo. 



\section{Plataforma de Desenvolvimento e Simulação (FBSIMU On-}

\section{Line)}

Como já dito anteriormente, o acesso remoto ao FBSIMU é o principal foco deste trabalho. Neste capítulo, uma descrição detalhada de como este acesso foi desenvolvido é mostrada. O portal de acesso remoto ao FBSIMU foi chamado de FBSIMU On-line.

Antes de iniciar qualquer tipo de implementação deste tipo de portal voltado para a educação a distância, algumas considerações são tomadas com referência à experiência de alguns autores, como, por exemplo, GAL-EZER et al. (1997), que afirmaram que é necessário saber como, para quem, por quem, de que maneira o acesso remoto será desenvolvido, etc.

Seguindo este pensamento, foi definido que o acesso remoto será disponibilizado inicialmente apenas para os alunos e professores da Escola de Engenharia de São Carlos (USP) que desejarem fazer simulações ou mesmo entender o funcionamento do protocolo FOUNDATION Fieldbus. Os usuários precisarão apenas de um navegador Web e de uma senha para ter o acesso à ferramenta. Em relação às considerações sugeridas por Gal-ezer et al. (1997), faltaria definir a maneira como o acesso remoto será desenvolvido e isto será feito no decorrer deste capítulo.

Como já foi ilustrado nos capítulos anteriores, implementar um portal voltado para educação a distância não é um objetivo incomum e, por isso, ferramentas e sistemas voltados para este tipo de atividade evoluíram muito, fazendo com que o uso dos CMSs transforme-se em um caminho inevitável a ser tomado na implementação deste tipo de portal. Com base nos estudos feitos em relação aos CMSs disponíveis no mercado (APÊNDICE B) e seguindo a 
orientação do CCE da USP (UNIVERSIDADE DE SÃO PAULO. Centro de Computação Eletrônica, 2006), o CMS escolhido para este trabalho foi o Moodle. O Moodle é um software livre distribuído sob os termos de licença GNU General Public License (GPL) e, além de oferecer um uso simples, possui compatibilidade com vários sistemas, é eficiente, não exige grande poder de processamento e, por fim, não exige navegadores de internet complexos nas máquinas clientes (os detalhes são apresentados no item 3.1, página 59).

Além da parte de gerenciamento do portal, é necessário colocar a ferramenta FBSIMU disponível para acesso remoto. Esta disponibilização será feita pelo próprio LabView (software proprietário da National Instruments) e será detalhada no decorrer deste texto.

Considerando que o sistema é composto pelo Moodle (responsável pelo gerenciamento do portal) e pelo LabView (responsável por executar o FBSIMU), a necessidade da integração entre estes dois componentes se torna evidente. Assim, o grande desafio desta implementação é integrar estas duas partes, levando-se em conta que estas serão executadas na mesma máquina servidora.

A figura 6 mostra uma visão superficial do sistema. Os números indicados nas setas $(1,2$ e 3) mostram a ordem de funcionamento de cada componente durante o acesso de um determinado usuário. Figuras mais detalhadas serão apresentadas conforme maiores detalhes do sistema forem sendo explicados neste capítulo. 


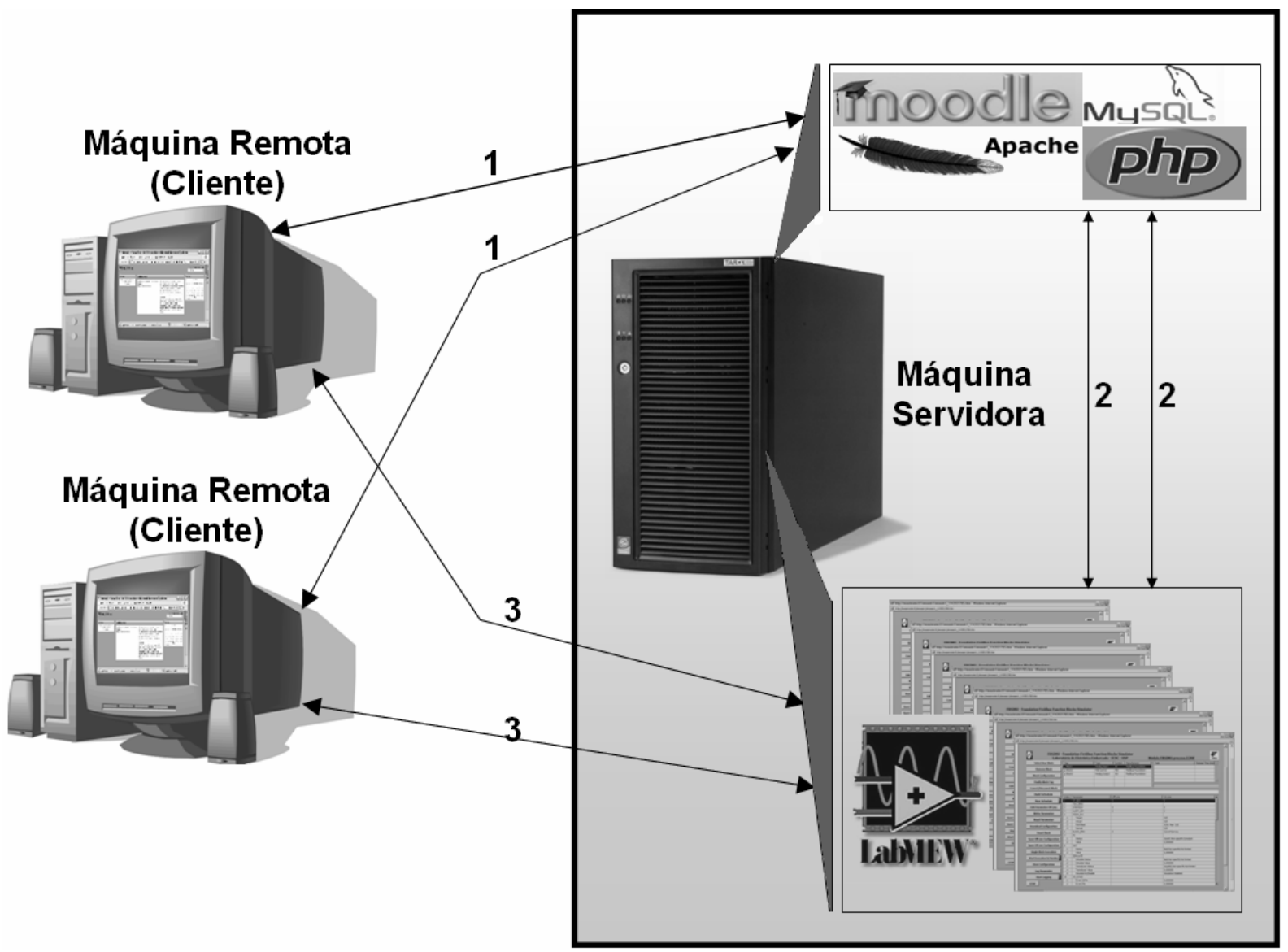

Figura 6 - Integração entre Moodle e LabView

Como podemos notar através da figura 6, o sistema possuirá uma máquina servidora (server) com acesso HTTP liberado para vários clientes (máquinas remotas). Na máquina servidora, dois softwares servidores Web estarão configurados: um deles, o Apache, fornecerá o acesso para o portal principal de entrada no sistema (Moodle usa o Apache como servidor Web) e o outro, o servidor Web do LabView, fornecerá o acesso para a ferramenta FBSIMU.

Também observando a figura, têm-se as máquinas clientes que farão o acesso remoto. Para isso, basta que estas máquinas possuam instalados um navegador Web e o LabView RunTime Engine (software desenvolvido para a execução de aplicativos do LabView através de um navegador Web, fornecido pela National Instruments).

Um sistema de um laboratório remoto usando o Moodle e o LabView também foi desenvolvido por PASCHOAL (2006). Apesar da ferramenta disponibilizada para acesso 
remoto não possuir nenhuma semelhança com o FBSIMU, a arquitetura geral do sistema é muito parecida. A grande diferença é que o laboratório remoto criado por PASCHOAL (2006) não oferece acesso remoto a vários usuários de forma paralela. Nesse sistema, foi implementado um módulo de agendamento para permitir que apenas um aluno acesse a ferramenta em um determinado momento. Além disso, o sistema desenvolvido por PASCHOAL (2006) possui uma máquina para executar o servidor Web do Moodle (Apache) e uma máquina para executar o servidor Web do LabView. No FBSIMU On-Line, os dois servidores Web são instalados na mesma máquina e vários alunos podem acessar o FBSIMU ao mesmo tempo sem que um interfira no trabalho do outro.

Nota-se através desta visão macro da arquitetura deste sistema que a grande complexidade do mesmo encontra-se na máquina servidora.

Focando a explicação no módulo responsável pelo acesso ao FBSIMU, tem-se que o LabView possui um pacote responsável por fornecer o acesso remoto às suas VIs (Virtual Instruments), o que facilita a implementação da ferramenta on-line. Uma VI é um conjunto de instruções ou software que executam processos no LabView. O FBSIMU, por exemplo, é um conjunto destas instruções que estão armazenadas em arquivos desse tipo. Quando uma instância do FBSIMU é executada pelo LabView, a VI principal desse projeto é carregada e fornece a interface gráfica ao usuário, e através desta interface, tal usuário cria seus blocos e executa seus testes (maiores detalhes são mostrados no ANEXO A).

Partindo-se do fato que o FBSIMU é um conjunto de VIs do LabView, entende-se que para disponibilizar o acesso remoto ao mesmo é necessário permitir ao usuário trabalhar com esta VI a partir de um navegador Web. Este suporte é feito por meio da criação de um servidor Web por parte do LabView instalado na máquina servidora. Neste servidor, é necessário fazer a configuração de um diretório onde todos os arquivos HTML gerados pelo LabView serão armazenados (mais detalhes estão no APÊNDICE A). Basicamente, para criar uma estrutura 
para um futuro acesso, o administrador do LabView precisa abrir a VI que será disponibilizada, escolher a opção de acesso remoto, requerer a geração do arquivo $H T M L$ referente a esta VI e inicializar a conexão. Apesar de parecer que o acesso está pronto e que nenhum trabalho extra seria gerado, diversas modificações precisaram ser feitas no FBSIMU devido a verificações necessárias para o funcionamento correto do acesso remoto (maiores detalhes são apresentados no item 3.3.1 na página 68). A fim de otimizar este processo de configuração, foi criado o FBSIMU Manager. Esta otimização é apenas uma das funções desta ferramenta e maiores detalhes do funcionamento da mesma estão detalhados no item

\subsection{2 na página 76 .}

Para um usuário acessar uma determinada VI a partir de um navegador Web instalado em uma máquina cliente, esta VI deverá estar ativa na máquina servidora, isto é, o LabView deverá estar executando esta VI nesta segunda máquina. Apenas um único usuário poderá acessar tal VI em um determinado momento. O LabView oferece suporte para controlar a concorrência deste recurso, ou seja, o LabView garante que apenas um usuário utilizará uma dada VI em um determinado momento. Este suporte funciona de forma simples. Quando um cliente se conectar a uma VI (no caso deste trabalho, a VI do FBSIMU), o mesmo deverá enviar um comando para reservar esta VI (Request Control Of VI) e, desta forma, a VI ficará reservada somente a este usuário. A liberação acontece também através de um comando (Release Control of VI) ou de forma automática, quando o usuário fecha o navegador Web.

Mesmo com este suporte do LabView ao acesso remoto, o sistema apresentaria limitações em alguns pontos. Por exemplo, se o FBSIMU é uma VI que poderá ser executada somente por um usuário de cada vez e esta VI, juntamente com o LabView, deverá estar em operação na máquina servidora, como será o acesso de vários alunos ao mesmo tempo? A solução encontrada para este problema foi a utilização de várias instâncias de FBSIMU (o LabView ficaria executando várias VIs do FBSIMU, cada uma com sua região de memória, sem 
interferir uma na outra) operando ao mesmo tempo em um determinado servidor. Assim, para cada novo usuário que requerer o serviço, uma nova instância do FBSIMU será disponibilizada, fazendo com que cada usuário possa executar seu experimento sem interferir em experimentos executados por outros alunos.

A figura 7 mostra o modelo de instâncias e máquinas clientes acessando cada uma destas VIs.

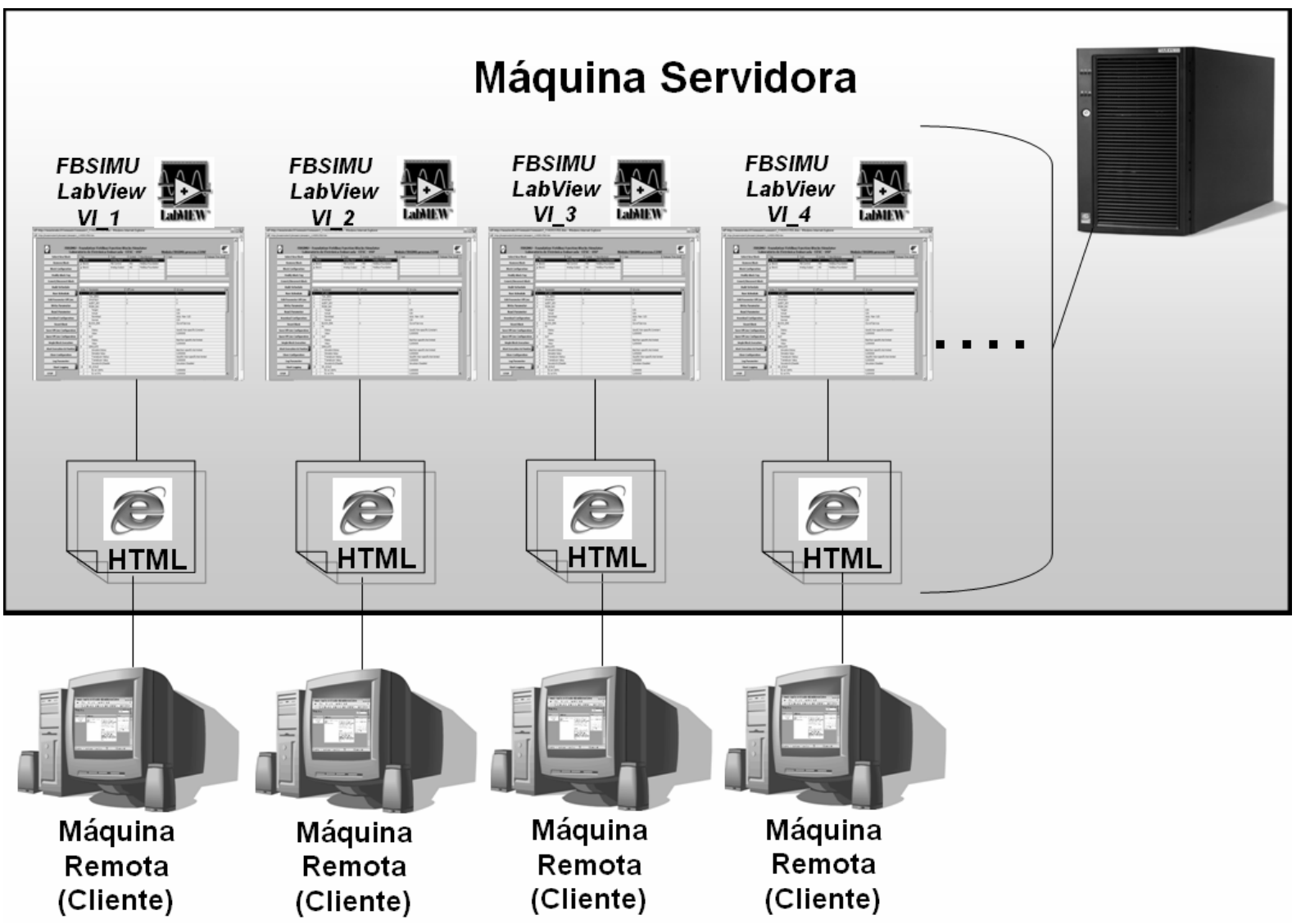

Figura 7 - Comunicação entre clientes e o servidor.

Nota-se que cada máquina cliente possui acesso para uma diferente instância do FBSIMU. Para controlar o uso dessas instâncias, alguns algoritmos foram desenvolvidos. Detalhes desses algoritmos que controlam quais usuários estão usando uma determinada instância ou mesmo qual instância ainda está livre para uso em um determinado momento estão descritos no item 3.3.1 na página 68. Assim, conclui-se que não basta apenas liberar o 
acesso através do LabView e permitir que qualquer usuário faça uso do sistema, é preciso implementar uma estrutura mais completa para este gerenciamento. Apesar do LabView fornecer um controle de acesso a partir do endereço IP (Internet Protocol) das máquinas clientes, este tipo de restrição não é suficiente para este trabalho, que requer um controle de acesso mais completo (cadastro de usuários, nível de permissão, login, senha, etc.).

É neste momento que a necessidade de um CMS começa a aparecer, pois um controle de acesso e de conteúdo precisa ser implementado para garantir o uso correto do portal. Assim, o uso do CMS se torna ideal, pois um sistema deste tipo, além de disponibilizar ferramentas para controle de acesso, tem estrutura para criação de fóruns, criação de novos cursos (extensibilidade para novos projetos), etc.

Uma observação relacionada ao controle de acesso é o tipo de acesso que cada usuário vai possuir. Segundo TSANG (1999), em um sistema de ensino, é importante a existência de três tipos de usuários. Estes são: o administrador, os instrutores e os estudantes.

- O administrador do sistema será responsável por gerenciar e manter todos os aspectos do sistema, como, por exemplo, os direitos de acesso dos alunos, a criação de novos fóruns de discussão, a adição de novos materiais de estudo, etc.

- Os instrutores serão capazes de modificar o formato de alguma parte do curso, criar novos materiais no formato de páginas $H T M L$, apresentações, multimídia, etc. Estes poderão também dar assistência para seus alunos através da criação de novos fóruns ou mesmo disponibilizando o e-mail para o contato dos alunos. Na maioria dos casos, os instrutores serão os próprios professores.

- Os estudantes serão capazes de navegar pelo site, fazer pedidos de novos fóruns, enviar mensagens nos fóruns, utilizar o FBSIMU para fazer experiências, etc.

Como já foi dito anteriormente, o CMS usado no desenvolvimento deste trabalho foi o Moodle e para o funcionamento deste na máquina servidora, alguns softwares (Apache, 
MySQL, PHP) devem estar em operação na mesma. No item 3.2, página 63, detalhes destes softwares e da estrutura dos mesmos são apresentados. Da mesma forma que a criação das instâncias do FBSIMU foi otimizada através de uma função adicionada ao FBSIMU Manager (item 3.3.2 página 76), uma função responsável por configurar todos estes softwares instalados no servidor foi criada e adicionada nessa mesma ferramenta (FBSIMU Manager).

Ainda em relação à parte do trabalho relacionada ao CMS, tem-se a interface inicial do FBSIMU On-line. É esta interface que o aluno ou professor irá visualizar quando acessar o portal (figura 8).

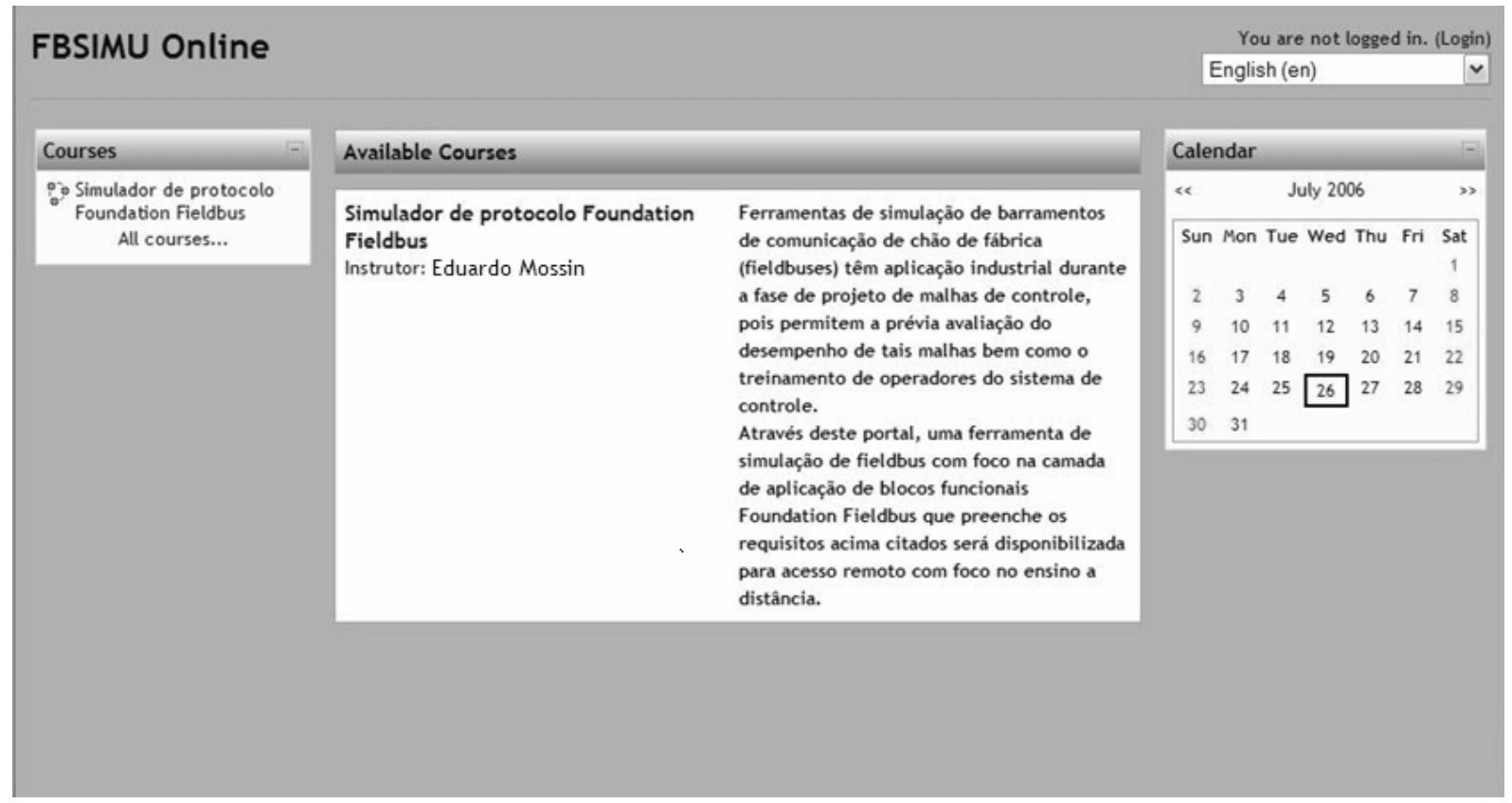

Figura 8 - Interface gráfica inicial do FBSIMU On-line

Feito o acesso, o usuário visualizará os fóruns disponíveis para discussão de dúvidas, salas de bate papo (chats), gerenciamento de arquivos e, por fim, o item principal, que será composto por uma lista de cursos. Para este trabalho, apenas o FBSIMU On-line estará disponível e possuirá: acessos para o usuário gerenciar os arquivos de $\log$ (arquivo que armazena registros das operações de processamento em software) gerados em um experimento; acessos para gerenciar configurações de blocos criadas e salvas (maiores 
detalhes são apresentados no item 3.3.3 na página 85); acesso ao painel remoto do FBSIMU. No momento em que o usuário acessar a ferramenta, uma nova janela do navegador Web será aberta e a interface gráfica do FBSIMU irá aparecer para o controle do usuário. A figura 9 ilustra esta interface.

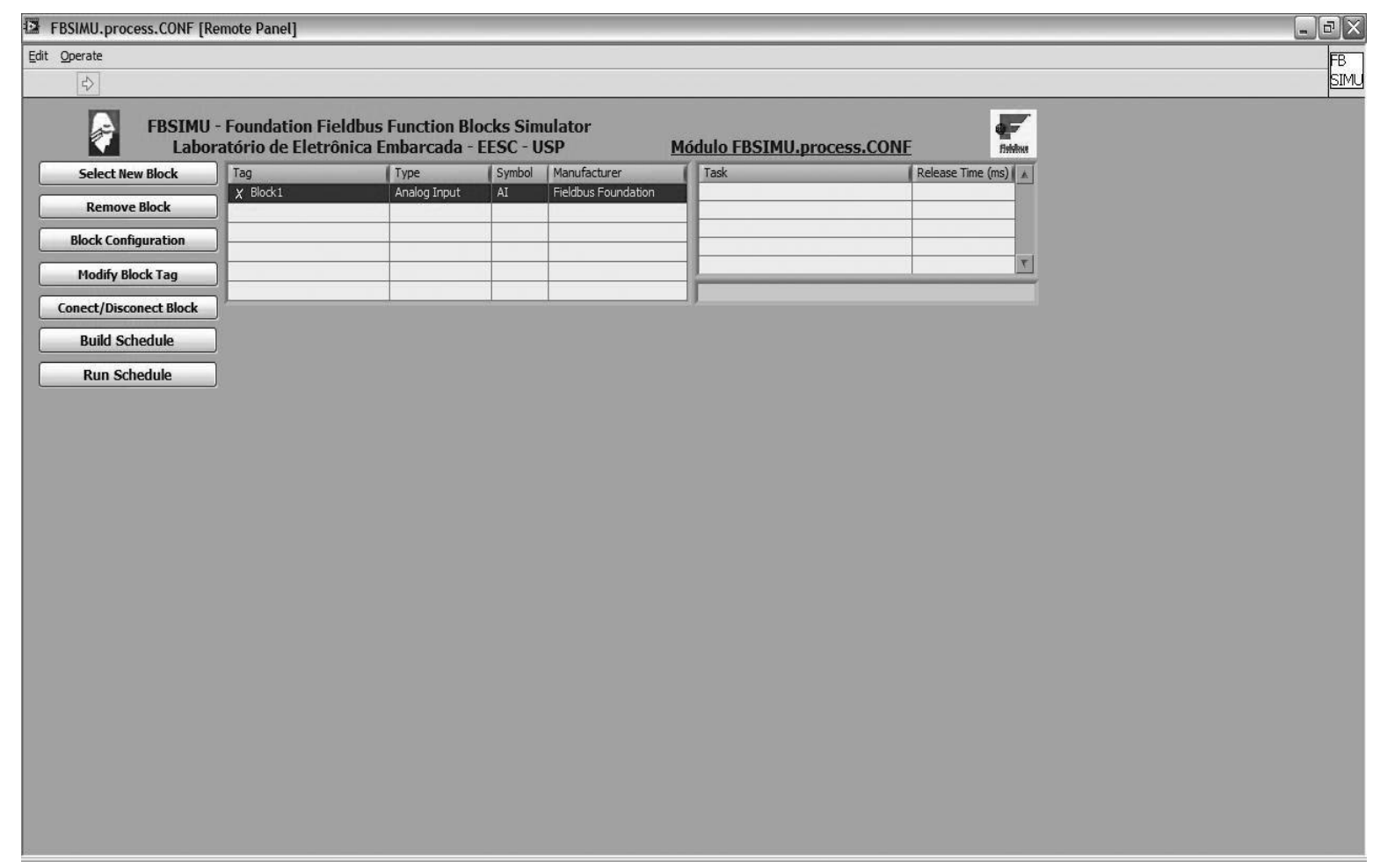

Figura 9 - Acesso remoto ao FBSIMU

Definidas as formas de operação individual do Moodle e do LabView, torna-se necessário esclarecer a forma que a integração entre estas duas partes irá funcionar. Para uma visão melhor desta integração entre tais partes, a figura 10 mostra de forma detalhada a arquitetura deste sistema. 


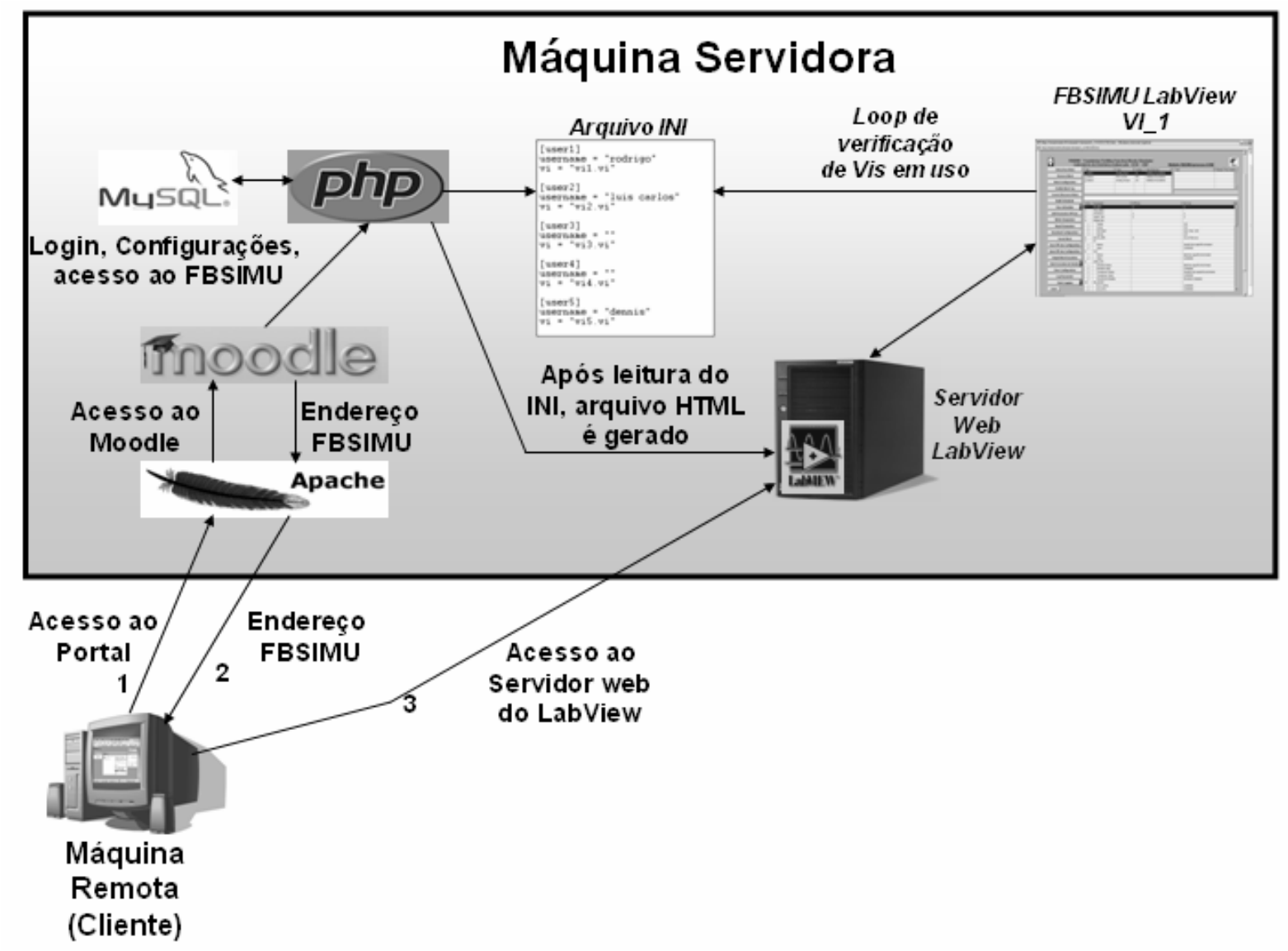

Figura 10 - Arquitetura detalhada do sistema

Seguindo esta arquitetura, têm-se os passos percorridos pelo sistema desde o registro de um usuário até a sua saída. Os números 1, 2 e 3 ilustram a ordem de funcionamento da comunicação entre a máquina cliente e a servidora. A seguir tem-se os passos que uma operação deste tipo realiza:

i) Moodle valida o usuário que acaba de entrar no sistema. Neste momento, o usuário possuirá permissão para acessar o FBSIMU.

ii) Usuário acessa o FBSIMU. Ao acessar tal ferramenta, é executado automaticamente um código em PHP que controlará quais usuários estão operando e quais instâncias do FBSIMU (VIs) estão em uso. Assim, uma VI livre será disponibilizada para tal usuário. O arquivo de configuração do tipo INI mostrado na figura é responsável por armazenar as 
informações para possibilitar este controle. (os detalhes do arquivo estão no item 3.3.1 página 68).

iii) Quando a VI disponível é identificada, outro código PHP gera o arquivo HTML que será usado para acessá-la. Este arquivo será armazenado no diretório raiz do servidor Web do LabView. Para cada acesso ao link do FBSIMU, um novo arquivo com nome diferente é gerado.

iv) Gerado tal arquivo, o endereço de acesso ao mesmo é retornado para a máquina cliente e uma nova janela do navegador Web é aberta com o painel remoto da ferramenta FBSIMU disponível para uso, ou seja, é através da página $H T M L$ gerada dinamicamente a partir do código em PHP executado na máquina servidora que o FBSIMU será acessado.

v) O usuário trabalha com a VI disponibilizada e, feito o trabalho, sai do sistema. Neste momento, outro código em PHP é executado e, através de uma nova modificação feita no arquivo de configuração, aquela VI é liberada para outros usuários a utilizarem. Além disso, o arquivo HTML usado para acesso remoto do FBSIMU é apagado, evitando assim que o mesmo usuário faça o acesso a esta VI sem ter feito o log-in no sistema, pois a remoção deste arquivo implica na remoção do link de acesso a VI do FBSIMU.

Mais detalhes sobre o uso do arquivo de configuração tanto pelo LabView quanto pelo código PHP executado conforme o uso do portal FBSIMU encontram-se no item 3.3 página 67.

\subsection{Moodle}

O Moodle (MOODLE, 2006) é um software livre sob os termos de licença $G N U$ General Public License (GPL). Tais termos têm por objetivo garantir a liberdade de compartilhar e modificar estes tipos de softwares. 
O Moodle oferece simplicidade no seu uso, possui uma compatibilidade com os sistemas operacionais Windows, Linux e Unix, é eficiente, não exige grande poder de processamento e, além disso, não exige navegadores de internet complexos.

Outra característica importante é a facilidade de instalação na maioria das plataformas que suportam $P H P$ (os detalhes da instalação estão no APÊNDICE A). O portal criado através do Moodle poderá possuir vários tipos de cursos que poderão permitir acesso a visitantes de forma controlada e, além disso, poderão ser categorizados.

Uma grande ênfase é dada para a questão da segurança. Todos os dados são validados, informações são criptografadas, etc. Existem cinco tipos de usuários. O primeiro é o administrador, que possui todos os privilégios possíveis, desde adicionar um aluno até remover um professor da base de usuários. O administrador será definido durante a instalação e será responsável pelo gerenciamento do site. Ele poderá escolher o tema gráfico utilizado pelo site, além de escolher cores, fontes e layout do portal. Existem também os professores e os professores assistentes: o primeiro tem acesso a uma área onde poderá incluir seus cursos e seus arquivos, e o segundo possuirá os mesmos acessos, mas não possuirá direito de edição dessa área, ou seja, poderão apenas visualizar informações restritas do curso e trabalhar com as mesmas sem modificá-las. Por último, têm-se os estudantes e visitantes que acessarão os cursos disponíveis. Para o portal FBSIMU, apenas os tipos administrador, professor e estudante serão aplicados. Os outros tipos de usuários poderão ser incluídos em caso de futuras necessidades, como, por exemplo, quando novos cursos ou laboratórios forem adicionados ao portal.

O código do Moodle é escrito em PHP de forma clara e, por estar sob as condições de licença GPL, poderá ser facilmente modificado para as necessidades do usuário. 
O Moodle possui vários módulos responsáveis por diferentes características. Como exemplo pode-se citar o módulo de gerenciamento de usuários, gerenciamento de cursos, exercícios, questionários, fórum e salas de bate-papo (chat).

Um dos objetivos do Moodle é reduzir ao máximo o envolvimento do administrador com detalhes de segurança. Os estudantes interessados poderão requisitar a criação de suas próprias contas ou, dependendo da configuração feita, estes usuários poderão criar seus registros por si só. O administrador tem controle sobre a criação dos cursos e pode também delegar aos usuários o atributo de professor. Um professor poderá adicionar ou remover a permissão de um aluno para acessar o curso ministrado. Os alunos poderão colocar informações próprias como e-mail, telefone e até mesmo fotografia. Dependendo da configuração feita, qualquer usuário poderá modificar a linguagem do portal de forma simples.

Outro objetivo do Moodle é facilitar o gerenciamento de cursos. Um professor com permissão total terá controle sobre todas as características do curso ministrado por ele. Além disso, o mesmo poderá criar vários formatos de cursos (semanais, por tópico, etc.). Vários módulos de apoio poderão ser inseridos ao curso, como, por exemplo, os fóruns, quizzes, glossários, bate-papos, seminários, entre outros. Quando uma mudança no curso é feita, uma lista é fornecida aos alunos para que se atualizem com as novas características. Relatórios com detalhes de acesso dos alunos são fornecidos. O professor também poderá fazer backup de seus cursos e restaurá-los em outros portais Moodle. Tarefas podem ser designadas aos alunos com uma data de entrega especificada. Os estudantes poderão enviar duas tarefas para o servidor mesmo depois do prazo de entrega, considerando que o professor verá claramente este atraso. O retorno do professor poderá ser dado ao aluno através de um e-mail e o professor poderá também permitir que os alunos reenviem uma dada tarefa para uma nova correção. 
Enquêtes podem ser criadas para recolher informações para melhoria do curso. Os usuários poderão utilizar-se de fóruns. Para isso, o Moodle oferece vários tipos diferentes de fóruns, como fóruns voltados apenas para professores, fóruns de notícias de cursos, fóruns que são abertos a todos os usuários, etc. Nestes fóruns, o autor da mensagem é identificado pelo nome e, se disponível, por sua foto. Conjuntos de questões (quizzes) podem ser criados para os alunos testarem o próprio rendimento. Os professores poderão definir uma base de dados de questões e utilizá-las em diferentes quizzes. A pontuação destas questões é feita de forma automática.

O Moodle oferece suporte para apresentar informações de várias formas (MS-Word, MS-PowerPoint, Animações, Vídeo, Sons, etc.). Os usuários poderão enviar arquivos (provas, cursos, tabela de notas, etc.) e armazená-los no servidor.

Uma análise de comportamento de um portal desenvolvido com o Moodle poderá ser feita através de relatórios disponibilizados em vários formatos, inclusive na forma de gráficos.

Um dos propósitos do Moodle é ser portável para uma grande variedade de servidores Web e bases de dados. Além disso, o sistema deverá suportar uma grande quantidade de registros, tanto de usuários quanto de cursos. Hoje, o maior portal de ensino a distância que usa o Moodle possui cerca de 45.000 estudantes e 6.500 cursos cadastrados (na Open Polytechnic of New Zealand). Uma outra preocupação do Moodle é manter uma interface padrão para facilitar a usabilidade do sistema. Para isso, o projeto disponibiliza um documento para direcionar o administrador a desenvolver interfaces simples e poderosas.

O funcionamento do Moodle é dependente de um servidor Web (Apache), um banco de dados $(M y S Q L)$ e suporte para a linguagem $P H P$ descritos a seguir. 


\subsection{Apache, MySQL, PHP (AMP)}

Antes de entender o funcionamento de cada uma das ferramentas (Apache, MySQL, $P H P)$, é necessário entender o funcionamento das mesmas trabalhando em conjunto. Resumidamente, a função do Apache é trabalhar como servidor HTTP do sistema (detalhes no item 3.2.1 na página 64). O MySQL será responsável pelo armazenamento de dados (detalhes no item 3.2.3 na página 65) e o $P H P$ (detalhes no item 3.2.2 na página 66) tem a função de mapear as informações vindas do Apache para o MySQL e vice-versa.

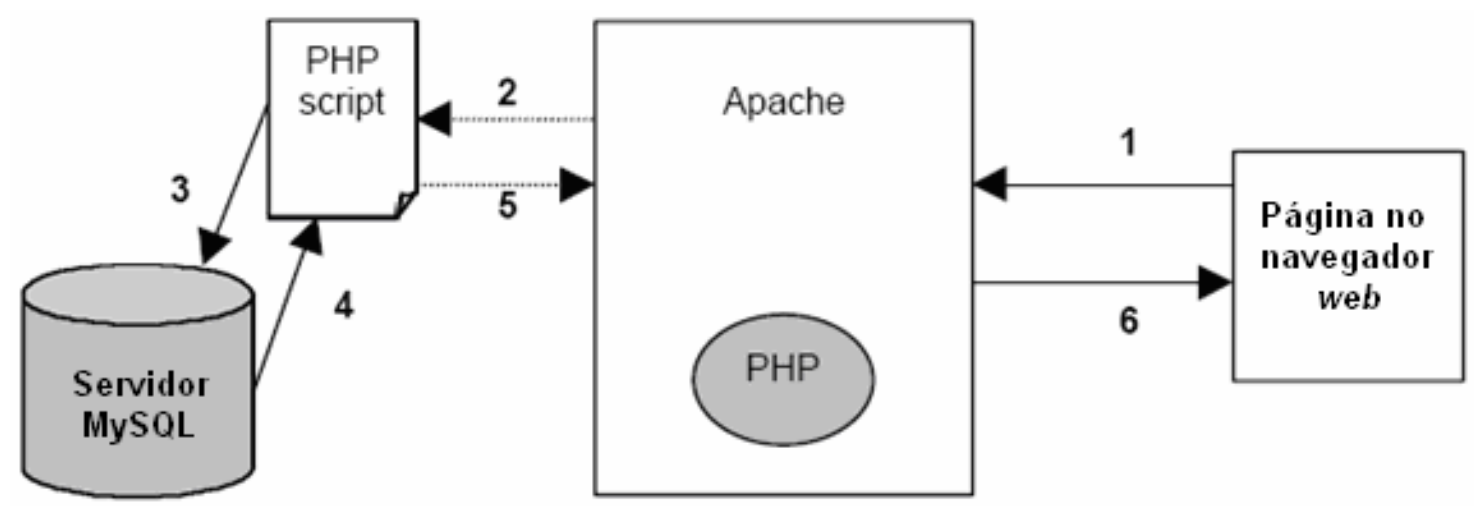

Figura 11 - Funcionamento do Apache - PHP - MySQL

Fonte: Web Database Step-by-Step Guide

Cada número indicado pela figura 11, mostra uma etapa que será detalhada para melhor entendimento:

1) Um usuário clica em um dado link (www.exemplo.com/exemplo.php) a partir de um navegador web (Mozilla Firefox, Internet Explorer, etc.) que manda um pedido para o servidor Web (Apache).

2) O Apache recebe o pedido relacionado ao exemplo.php e sabendo que arquivos $P H P$ devem ser encaminhados para o processador $P H P$, executa esta função.

3) $\mathrm{O}$ arquivo exemplo.php é um script que contém comandos. Um dos comandos é um pedido para a abertura de conexão com o banco de dados e a obtenção de algumas informações. 
4) Os dados são retornados pelo banco de dados e formatados pelo PHP. Esta formatação é feita para adequar os dados para uma posterior formatação em $H T M L$.

5) O HTML então é retornado para o Apache.

6) O Apache envia esta informação de volta ao navegador web como uma resposta do pedido feito anteriormente, e o navegador mostrará estas informações obtidas do banco de dados de forma legível ao usuário.

A instalação e configuração do AMP (Apache, MySQL, PHP) não é trivial. Para abstrair esta complexidade, alguns pacotes foram criados para instalar e pré-configurar estas ferramentas. Neste trabalho, a versão 1.8.0.1 do EasyPHP foi utilizada. Este pacote inclui a versão 4.1.9 do MySQL, o Apache 1.3.33 e o PHP 4.3.33.

\subsubsection{Apache}

O Apache vai agir como o servidor HTTP. Este software é open source e tem como objetivo ser um produto robusto e completo, onde seu código fonte é disponibilizado de forma livre. O gerenciamento do Apache é feito por um grupo de voluntários distribuídos pelo mundo e que, utilizando a internet como meio de comunicação, planejam e desenvolvem este servidor juntamente com sua documentação. O software faz parte da Apache Software Foundation. Seu principal trabalho é fazer a interpretação de um dado arquivo requerido por um navegador web e mostrar os resultados de acordo com o conteúdo deste arquivo. O Apache é um servidor muito poderoso, capaz de resolver qualquer tarefa requerida por um desenvolvedor Web. A versão do Apache usada neste trabalho é o Apache 1.3.33. Esta versão apresenta, entre outras características, um sistema de proteção com password das páginas para uma grande quantidade de usuários, páginas de erro personalizadas, $\log s$ de uso e de erro em vários formatos personalizáveis, etc (APACHE HTTP SERVER PROJECT, 2006). 
De acordo com NETCRAFT (2006), o Apache é, de longe, o servidor mais usado na internet, com um número maior do que a combinação dos servidores Microsoft, Sun e Zeus juntos. Sua praticidade, suas características e seu preço é que garantem ao Apache a posição de servidor de internet mais popular. Ele pode ser usado para hospedar um site na Web para um público geral, ou para uma Intranet de uma grande companhia, entre outras várias opções. O gráfico da figura 12 mostra a grande diferença de uso entre os servidores de internet ativos desde julho de 2000 até janeiro de 2006.

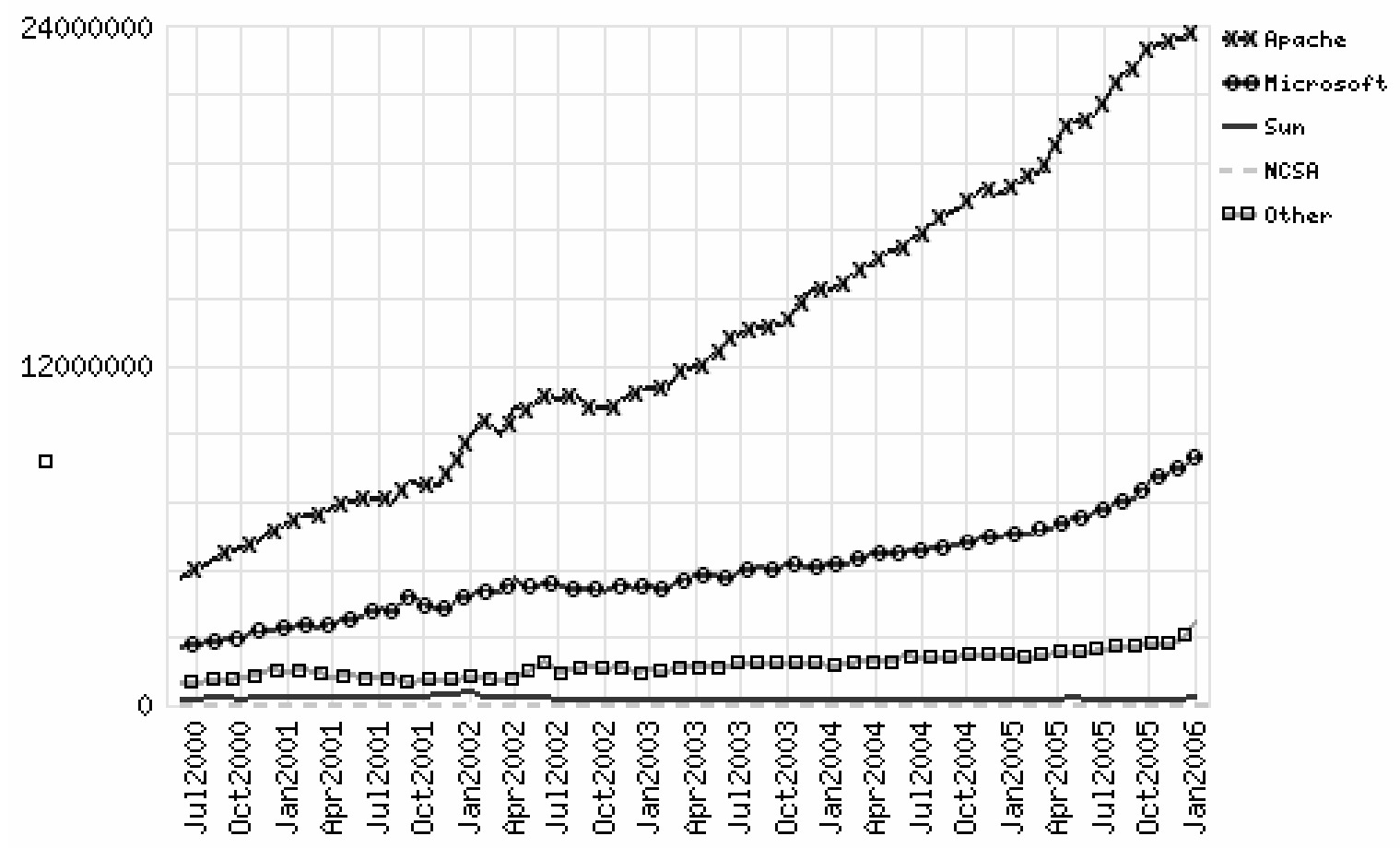

Figura 12 - Número de servidores Apache ativos

FONTE: NETCRAFT (2006)

\subsubsection{PHP}

O PHP é uma linguagem de script que é executada na máquina servidora e que permite uma grande dinâmica para o desenvolvimento de páginas Web. É uma linguagem flexível que não exige muito para seu aprendizado, principalmente para programadores que já possuem conhecimento em linguagens como C, Java ou Perl. 
Existem três principais áreas em que o PHP é usado hoje. A primeira e mais comum é a server-side scripting, onde o PHP é acessado através de um navegador de internet e é executado em um servidor Web conectado a um processador PHP. A segunda maneira é o command line scripting e será usada sem um servidor ou navegador Web. Ela será executada diretamente por um PHP parser. Esta maneira é usada principalmente para executar tarefas agendadas nos sistemas operacionais (Cron para o UNIX e o Task Scheduler para o Windows). Por fim, a última maneira e menos usada é a writing desktop applications, que usa uma extensão do $P H P$ chamada $P H P-G T K$. É usada para a criação de aplicativos que são executados de forma local (PHP GROUP, 2006). A versão de PHP usada neste trabalho é a 4.3.33.

Como justificativa da escolha do uso do $P H P$ neste trabalho, pode-se destacar:

[...] $P H P$ é a linguagem para o desenvolvimento de aplicações Web mais utilizada no mundo. A popularidade do $P H P$ deve-se à sua facilidade para criar aplicações dinâmicas para a Web, com suporte à maioria dos gerenciadores de bancos de dados existentes, além de um conjunto de funções que permitem desde a criação de simples portais até complexas aplicações de comércio eletrônico. (DALL’OGLIO, 2004).

\subsubsection{MySQL}

Um banco de dados é uma coleção de dados ou informações que são organizados de forma estruturada para um bom desempenho na busca, armazenamento, modificação e remoção destes dados. Com a evolução da tecnologia, existem hoje no mercado vários softwares de gerenciamento de banco de dados, como, por exemplo, Microsoft Access, FileMaker, e MySQL.

O MySQL é um sistema de gerenciamento de bancos de dados relacional, que permite armazenar dados em tabelas separadas em vez de colocar todos os dados em um só local. A parte $S Q L$ do nome "MySQL" significa "Structured Query Language - Linguagem Estrutural de Consultas“. $S Q L$ é a linguagem padrão mais comum usada para acessar banco de dados e é 
definida pelo padrão $A N S I / I S O S Q L$. O padrão $S Q L$ vem evoluindo desde 1986 e possui diversas versões. Assim como o PHP e o Apache, o MySQL é um software livre de código aberto. O Servidor $M y S Q L$ foi desenvolvido originalmente para lidar com bancos de dados muito grandes de maneira muito mais rápida que as soluções existentes e tem sido usado em ambientes de produção de alta demanda por diversos anos de maneira bem sucedida. A conectividade, velocidade, e segurança fazem com que o $M y S Q L$ seja altamente adaptável para acessar bancos de dados na internet. O programa de banco de dados $M y S Q L$ é um sistema cliente/servidor que consiste de um servidor $S Q L$ multitarefa que suporta acessos diferentes de diversos programas clientes e ferramentas administrativas. A versão do $M y S Q L$ utilizada neste trabalho é a versão 4.1.9.

Hoje, o MySQL é usado em mais de 8 milhões de instalações, desde grandes corporações até aplicações especializadas embarcadas em todos os continentes do mundo (MYSQL AB, 2006).

Além desses softwares usados na construção do sistema, alguns outros precisaram ser desenvolvidos e, no item 3.3, detalhes da implementação e do funcionamento desses softwares são apresentados.

\subsection{Detalhes de software do sistema}

Nesta seção, alguns detalhes importantes sobre a implementação deste sistema são explicados. O item 3.3.1 mostra detalhes relativos ao controle de uso das instâncias de VIs do FBSIMU. O item 3.3.2, página 76, mostra detalhes relativos à ferramenta FBSIMU Manager, criada para o gerenciamento da estação servidora. O item 3.3.3, página 85 , mostra detalhes do sistema de gerenciamento de arquivos de $\log$ e de configurações que são gerados pelo FBSIMU. 


\subsubsection{Controle de acesso às instâncias do FBSIMU}

Como já explicado nos itens anteriores, o LabView executa módulos de software chamados VIs. Para o acesso remoto, uma VI deve ser publicada para a internet e assim, através de um navegador Web, um cliente é capaz de acessar esta VI remotamente. O LabView controla estes acessos de forma que cada VI é acessada por apenas um usuário de cada vez. Além deste controle, um controle de usuários deve ser feito e para isso o Moodle é usado. Assim, o problema aqui é fazer a integração entre o Moodle e o LabView.

Primeiramente, é importante ficar claro que na máquina servidora, todas as instâncias do FBSIMU estarão sendo executadas ao mesmo tempo. Quando um usuário requisitar um acesso a uma dessas instâncias, o sistema deverá saber quais dessas estão livres para uso e alocá-la para tal usuário. Da mesma forma, quando este usuário sair do sistema, esta instância deverá ser liberada e reiniciada pelo LabView (ver item 3.3.1.1.1-página 71 e 3.3.1.1.2-página 74). Para isso, um arquivo de configuração do tipo INI foi criado, onde informações de instâncias e seus respectivos usuários são armazenadas. Considerando o fato de que dois programas (LabView e Moodle) irão fazer acesso a este arquivo, é necessário atentar-se para eventuais problemas de concorrência. Uma solução para isso seria a adaptação deste arquivo de configuração do tipo INI para um banco de dados. Para isso, seria necessário que este modelo de informações armazenadas no arquivo de configuração fosse mapeado em uma tabela do banco de dados e, em vez do FBSIMU e do código PHP acessarem o arquivo de configuração, os mesmos acessariam estes dados através de uma comunicação direta com o banco de dados que já possui implementado um mecanismo para evitar acesso concorrente a um mesmo registro de informação. Assim, a concorrência entre o Moodle e o LabView seria evitada. Na figura 13, segue um exemplo desse arquivo. Neste exemplo, apenas cinco VIs são disponibilizadas para acesso. $\mathrm{O}$ administrador deste sistema poderá configurar tal arquivo de forma a liberar o número de VIs desejadas. Esta configuração pode ser feita através do 
aplicativo mostrado no item 3.3.2, página 76. O controle de qual usuário está utilizando uma determinada VI é feito a partir do campo "username". Caso este campo esteja vazio (“"), considera-se que a VI relacionada está livre para acesso.

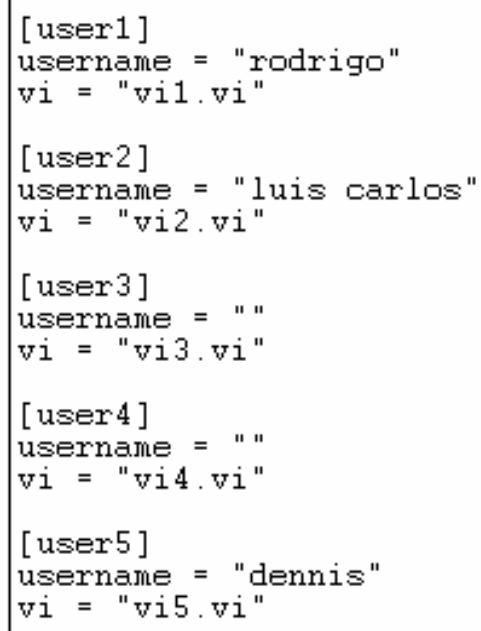

Figura 13 - Exemplo do arquivo fbsimu.ini com cinco entradas

Este arquivo será manipulado tanto pelo LabView quanto por um código desenvolvido em $P H P$, que será executado no momento que um usuário requisitar o acesso remoto ao FBSIMU e no momento que o usuário liberar este recurso (log-out). Detalhando um pouco mais este mecanismo, tem-se que, no momento que o usuário inicia o uso de uma dada $V I$, a respectiva entrada do arquivo de configuração é relacionada a este usuário. Esta relação é feita pelo código desenvolvido em $P H P$ que é executado no momento da requisição da VI pelo usuário. O exemplo da figura 14 mostra a "vi1" sendo relacionada ao usuário "rodrigo".

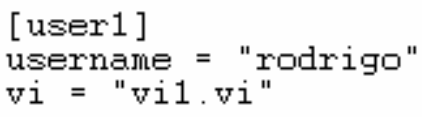

Figura 14 - Exemplo da "vi1" relacionada ao usuário "rodrigo"

Continuando o caso acima, considera-se o momento que este mesmo usuário sai do sistema. Neste momento, um outro código, também escrito em PHP, é executado e tal entrada é liberada. O exemplo da figura 15 mostra a $V I$ em questão já liberada para uso. 


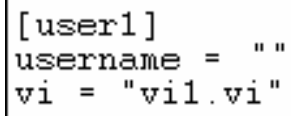

Figura 15 - Exemplo da “vi1” livre para acesso

Paralelamente a isso, no LabView, um código é executado pela VI do FBSIMU, ou melhor, periódicamente, uma verificação é feita para analisar se o usuário que está utilizando tal VI ainda está ativo ou não. Neste caso, enquanto a entrada "username" for diferente de vazio (“"), o acesso a tal VI não será liberado para nenhum outro usuário. No momento que tal $V I$ é liberada, o código em $P H P$ já explicado acima modifica o arquivo de configuração. Quando o LabView detecta esta mudança, todos os valores da respectiva VI são reiniciados e a VI fica pronta para o acesso de um novo usuário.

O procedimento descrito acima funciona perfeitamente considerando-se que um usuário use o sistema de forma correta, ou seja, o usuário acessa o FBSIMU, faz seus experimentos e sai do sistema executando a operação de log-out.

Considerando o uso não adequado do sistema, alguns problemas com o controle de acesso a estas instâncias de VIs do FBSIMU acontecem e com isso uma VI pode não ser liberada. A saída de um usuário de forma inadequada pode variar desde o simples fechamento do navegador Web sem efetuar o log-out até uma queda de conexão entre o cliente e o servidor.

Para comportar estes cenários de exceção, foi criado na VI do FBSIMU um processo que controla o tempo ocioso de uma determinada instância (item 3.3.1.1.2.2, página 75). A idéia deste processo é controlar o uso de uma instância de FBSIMU, isto é, se um usuário estiver com uma instância reservada para si e esta instância não for utilizada por um determinado período (dez minutos será o tempo pré-configurado), tal instância será liberada para acesso de outro usuário (este processo só é executado caso a instância do FBSIMU esteja em modo "Run"). Assim, se o cliente abandonar uma VI ou sair do sistema sem executar um 
log-out, em dez minutos esta VI será liberada para acesso de outro usuário, evitando assim que esta fique reservada por um tempo indeterminado.

Considerando o fato de que uma VI pode estar em modo "Stop" e, portanto, sem executar o controle descrito no último parágrafo, um outro procedimento foi criado. $\mathrm{O}$ FBSIMU Manager executa um processo que, de tempos em tempos, analisa se o tempo máximo de uso de uma determinada VI do FBSIMU já foi atingido (mais detalhes no item 3.3.2, página 76). Este tempo é configurável e caso seja atingido, a VI que estava reservada para um determinado usuário será liberada.

Os softwares criados para a execução dos algoritmos descritos acima são detalhados nos itens seguintes.

\subsubsection{Código para gerenciamento de uso do FBSIMU}

Os algoritmos para o controle de uso das instâncias do FBSIMU foram implementados tanto em PHP quanto na linguagem $G$ do LabView. Os itens 3.3.1.1.1 na página 71 e 3.3.1.1.2 na página 74 mostram detalhes da implementação deste controle.

\subsection{Controle de uso do FBSIMU desenvolvido em PHP}

Além do código PHP fornecido pelo projeto Moodle, algumas implementações foram necessárias para o funcionamento correto do gerenciamento de usuários.

O código PHP criado é voltado para o gerenciamento do uso das VIs do FBSIMU. Tal código é dividido em dois arquivos (fbsimu_labview.php3 e general_fbsimu_functions.php) que são armazenados no diretório fixPages que fica dentro do diretório onde a instalação do Moodle foi feita.

O arquivo fbsimu_labview.php3 será executado quando o acesso a uma determinada $V I$ for requerido por algum usuário. Primeiramente, algumas verificações são feitas (se o usuário fez log-in, se há espaço em disco para tal usuário) e então, os arquivos necessários 
para o acesso ao FBSIMU são criados (arquivo HTML). Feito isso, um script em Java (Javascript) é executado e o usuário é direcionado para o painel remoto do FBSIMU. Para a execução dessas tarefas, tal arquivo utiliza funções que estão armazenadas no arquivo general_fbsimu_functions.php. Tais funções são descritas na tabela 3.

Tabela 3 - Descrição dos métodos PHP do FBSIMU On-line

\begin{tabular}{|c|c|}
\hline Nome do método & Descrição \\
\hline removeCurrentVIByUser & $\begin{array}{l}\text { Esta função é responsável por remover a referência } \\
\text { de um usuário do arquivo fbsimu.ini. O método } \\
\text { será usado no momento em que o usuário executar } \\
\text { o log-out do sistema. }\end{array}$ \\
\hline getFullDirName & $\begin{array}{c}\text { Esta função irá montar o nome do diretório onde as } \\
\text { informações de um determinado usuário serão } \\
\text { salvas. }\end{array}$ \\
\hline write_ini_file & $\begin{array}{c}\text { Esta função irá obter uma lista de informações e } \\
\text { montar o arquivo } f b \text { simu.ini. }\end{array}$ \\
\hline getNextFreeVi & $\begin{array}{l}\text { Esta função é responsável por percorrer o arquivo } \\
\text { fbsimu.ini para encontrar qual VI está livre. }\end{array}$ \\
\hline getCurrentVIByUser & $\begin{array}{c}\text { Esta função é responsável por percorrer o arquivo } \\
\text { fbsimu.ini para encontrar qual } V I \text { está relacionada a } \\
\text { um determinado usuário. }\end{array}$ \\
\hline getFullFileName & $\begin{array}{c}\text { Esta função é responsável pela criação do nome do } \\
\text { arquivo } H T M L \text { que fará referência a uma } \\
\text { determinada } V I .\end{array}$ \\
\hline createDirWithUserName & $\begin{array}{l}\text { Este método irá criar um diretório onde serão } \\
\text { armazenados os arquivo HTML para acessar as } \\
\text { VIs. Para cada usuário, um diretório será criado. }\end{array}$ \\
\hline
\end{tabular}




\begin{tabular}{|c|c|}
\hline Nome do método & Descrição \\
\hline removeHTMLFileFromDirByUser & $\begin{array}{l}\text { Esta função é responsável por remover todos os } \\
\text { arquivos } H T M L \text { gerados para acessar as VIs do } \\
\text { FBSIMU. Estes arquivos são relacionados a um } \\
\text { determinado usuário. }\end{array}$ \\
\hline fulldelete & $\begin{array}{l}\text { Esta função é responsável pela remoção de todos } \\
\text { os arquivos e subdiretórios de um determinado } \\
\text { diretório. }\end{array}$ \\
\hline createNewFile & $\begin{array}{l}\text { Esta função cria um arquivo relacionado a um } \\
\text { determinado usuário. }\end{array}$ \\
\hline createLabViewHTMLTMPFile & $\begin{array}{l}\text { Esta função irá criar o arquivo HTML para acesso } \\
\text { da VI do LabView. }\end{array}$ \\
\hline get_size & $\begin{array}{c}\text { Esta função é usada para ler o tamanho de um dado } \\
\text { diretório. }\end{array}$ \\
\hline clearFBSIMUFilesOnExit & $\begin{array}{c}\text { Esta função irá chamar as funções responsáveis } \\
\text { por remover os arquivos temporários criados pelo } \\
\text { FBSIMU e as funções criadas para controlar o } \\
\text { arquivo fbsimu.ini. }\end{array}$ \\
\hline getTextToLabViewHTMLTMPFile & $\begin{array}{l}\text { Esta função irá montar o conteúdo do arquivo } \\
H T M L \text { usado para acessar uma determinada VI. }\end{array}$ \\
\hline
\end{tabular}

Além desses arquivos criados, foi necessária a modificação de uma parte do código do Moodle. Quando um usuário executa a operação de log-out, é necessário atualizar o arquivo fbsimu.ini. As funções de atualização deste arquivo de configuração estão no arquivo general_fbsimu_functions.php. Como este procedimento deve ser feito no momento do logout do usuário, estas funções devem ser chamadas a partir do código PHP nativo do Moodle. Este código está no arquivo logout.php localizado no diretório login (dentro do diretório de instalação do Moodle). Por este motivo, o arquivo logout.php foi modificado de forma que a 
função clearFBSIMUFilesOnExit seja chamada. No APÊNDICE C, uma figura com a comparação entre o arquivo original do Moodle e o arquivo modificado é apresentada.

\subsection{Gerenciamento do controle de uso implementado na VI do FBSIMU}

Além dos algoritmos que foram implementados usando a linguagem $P H P$, algoritmos gerados usando a linguagem $G$ do LabView foram criados. Os itens 3.3.1.1.2.1 na página 74 e 3.3.1.1.2.2 na página 75 detalham os dois algoritmos implementados dessa forma.

\subsection{Controle para log-out do sistema}

Como já explicado no item 3.3.1, página 68, o sistema controlará o uso das VIs através do arquivo fbsimu.ini. Assim, da mesma forma que este arquivo é manipulado por um código PHP executado a partir das páginas do Moodle, o arquivo de configuração em questão será manipulado pela VI do FBSIMU.

A idéia é criar um ciclo de verificação que será executado em cada instância do FBSIMU ativa na máquina servidora (este algoritmo será executado por todas as instâncias ativas). Assim, de tempos em tempos, o arquivo fbsimu.ini será analisado a fim de verificar se o usuário que está usando uma dada VI ainda está ativo. Caso a VI que estiver fazendo tal verificação possua um usuário relacionado, nenhuma operação será executada. Caso a VI não tenha nenhum usuário relacionado, o algoritmo irá entender que o usuário que estava utilizando tal VI saiu do sistema e com esta conclusão, a VI será reiniciada.

A figura 16 mostra o diagrama de blocos que executará o procedimento descrito acima. 


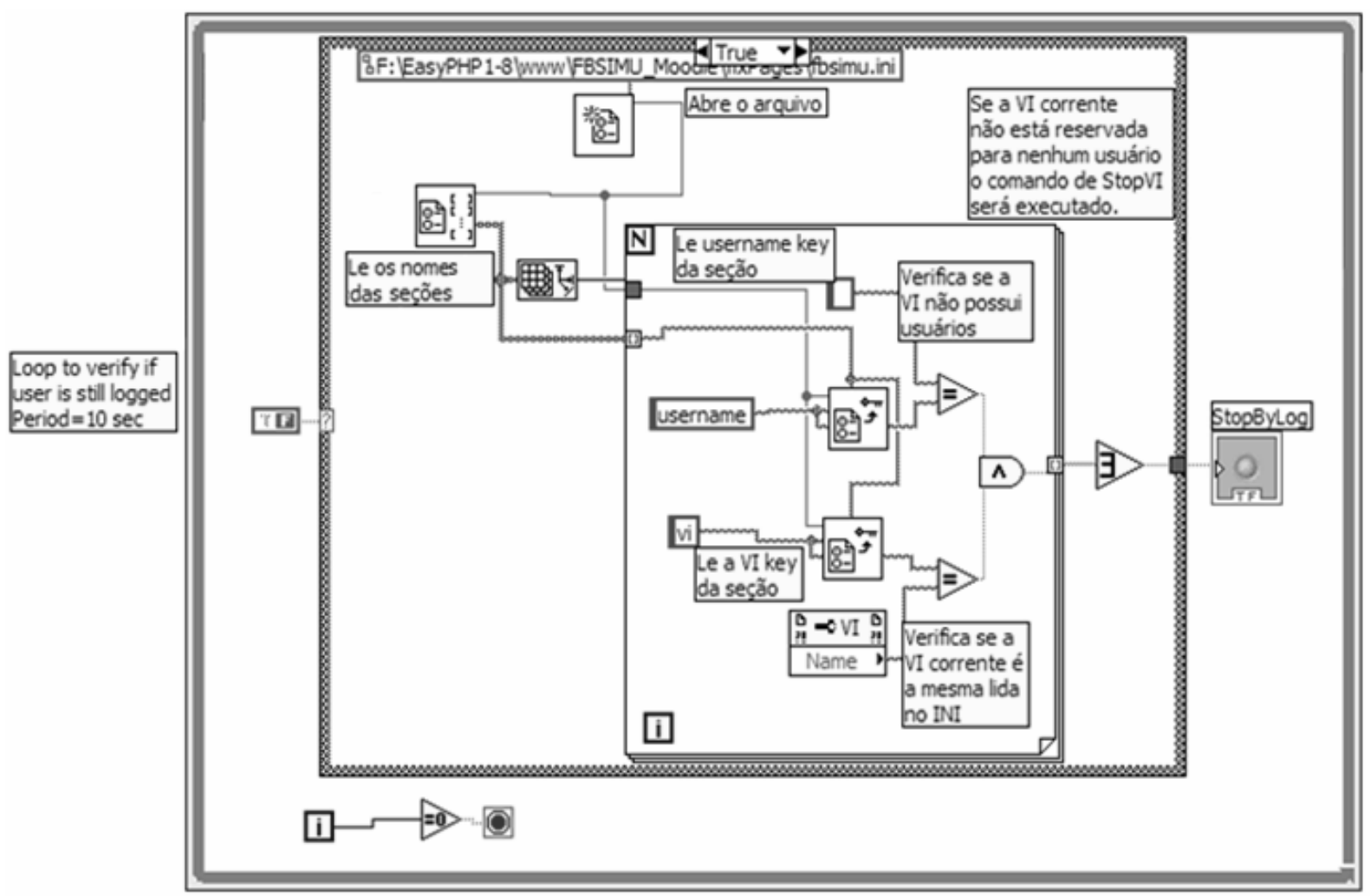

Figura 16 - Diagrama de blocos do LabView para controle de uso do FBSIMU

Através do diagrama, nota-se que o algoritmo irá verificar qual é o usuário corrente da instância em questão e se este valor for uma seqüência de caracteres vazia, o comando de parada (stop) será disparado para tal VI. Nota-se também que o algoritmo é executado de tempos em tempos (período de 10s).

\subsection{Controle para tempo ocioso de uma VI do FBSIMU}

Considerando o fato de que um usuário poderá acessar uma dada instância do FBSIMU, colocá-la em modo "Run" e simplesmente não utilizá-la, foi criado o processo descrito neste item. A figura 17 mostra o código na linguagem $G$ (linguagem de programação gráfica fornecida pelo LabView) criado para este fim. Este código possui um temporizador que é reiniciado sempre que o mouse é movido pelo usuário. Se este temporizador não for reiniciado por um determinado período de tempo (dez minutos é o tempo padrão), a instância em questão será reiniciada e liberada para acesso de outro usuário. 


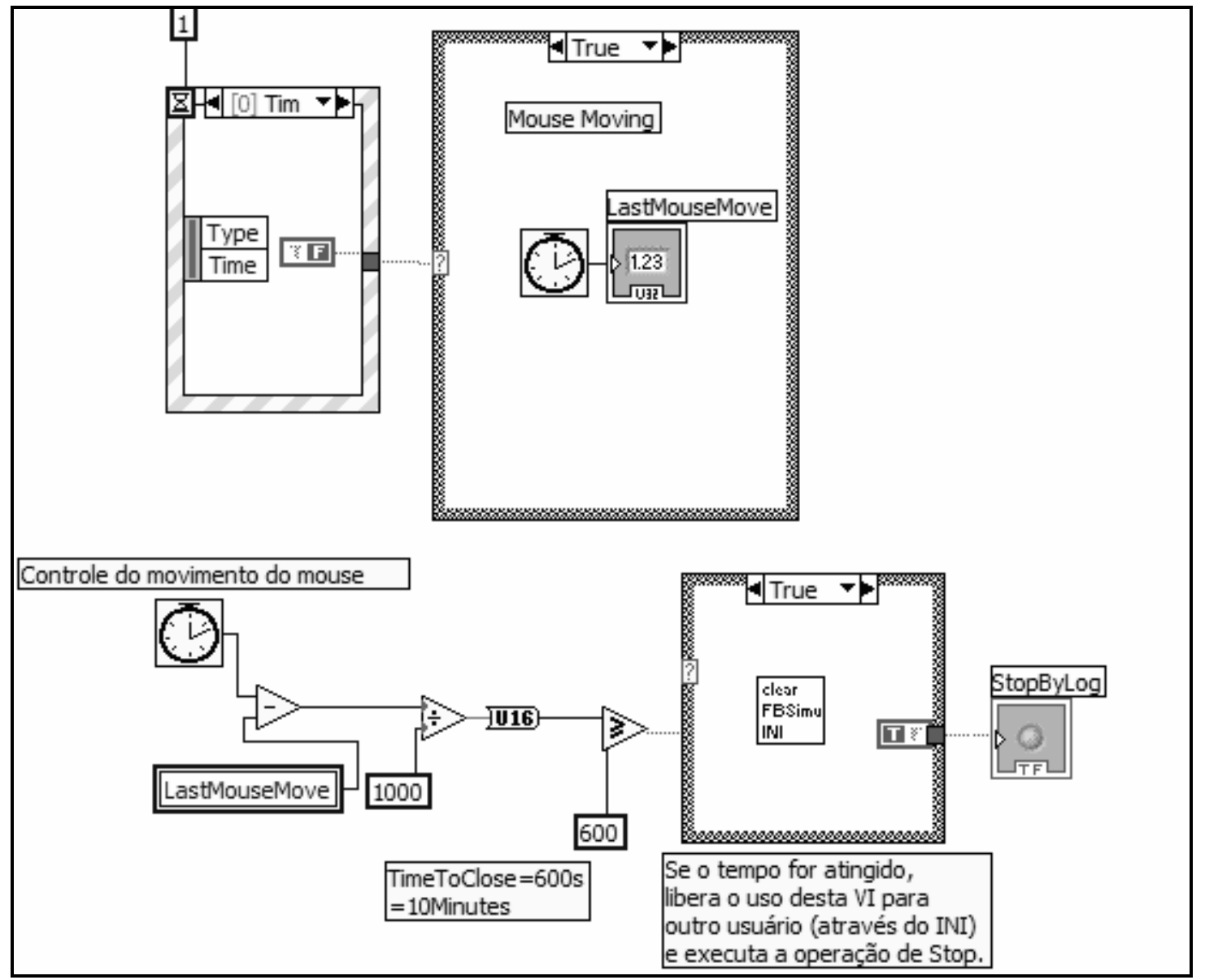

Figura 17 - Diagrama de blocos do LabView para controle de tempo ocioso do FBSIMU

\subsubsection{Ferramenta de configuração do servidor}

A configuração da máquina servidora não é simples. Considerando que vários cenários (a mudança do endereço IP desta máquina ou mesmo uma nova instalação em uma máquina diferente, entre outros) podem exigir a modificação dos parâmetros deste servidor, foi desenvolvido o FBSIMU Manager. Outra função é a criação das instâncias das VIs do FBSIMU. Além disso, este software executa o processo que verifica o tempo máximo permitido para o uso do FBSIMU. Esta ferramenta possui várias abas (tabs) onde cada uma é responsável por uma tarefa diferente.

A primeira aba (figura 18), denominada $W e b$, é responsável pela configuração dos arquivos de configuração do Apache e do Moodle. Estas informações ficam no arquivo 
httpd.conf do diretório de instalação do Apache, e no arquivo config.php do diretório de instalação do Moodle. Além disso, através desta interface, o usuário modifica o banco de dados do Moodle onde informações de páginas do sistema que dependem do endereço de IP da máquina servidora são armazenadas. Por fim, é feita a modificação dos arquivos $P H P$ criados especificamente para este trabalho. Tais arquivos ficam no diretório fixPages que está localizado no diretório de instalação do Moodle. A figura 18 mostra detalhes da interface gráfica desta aba.

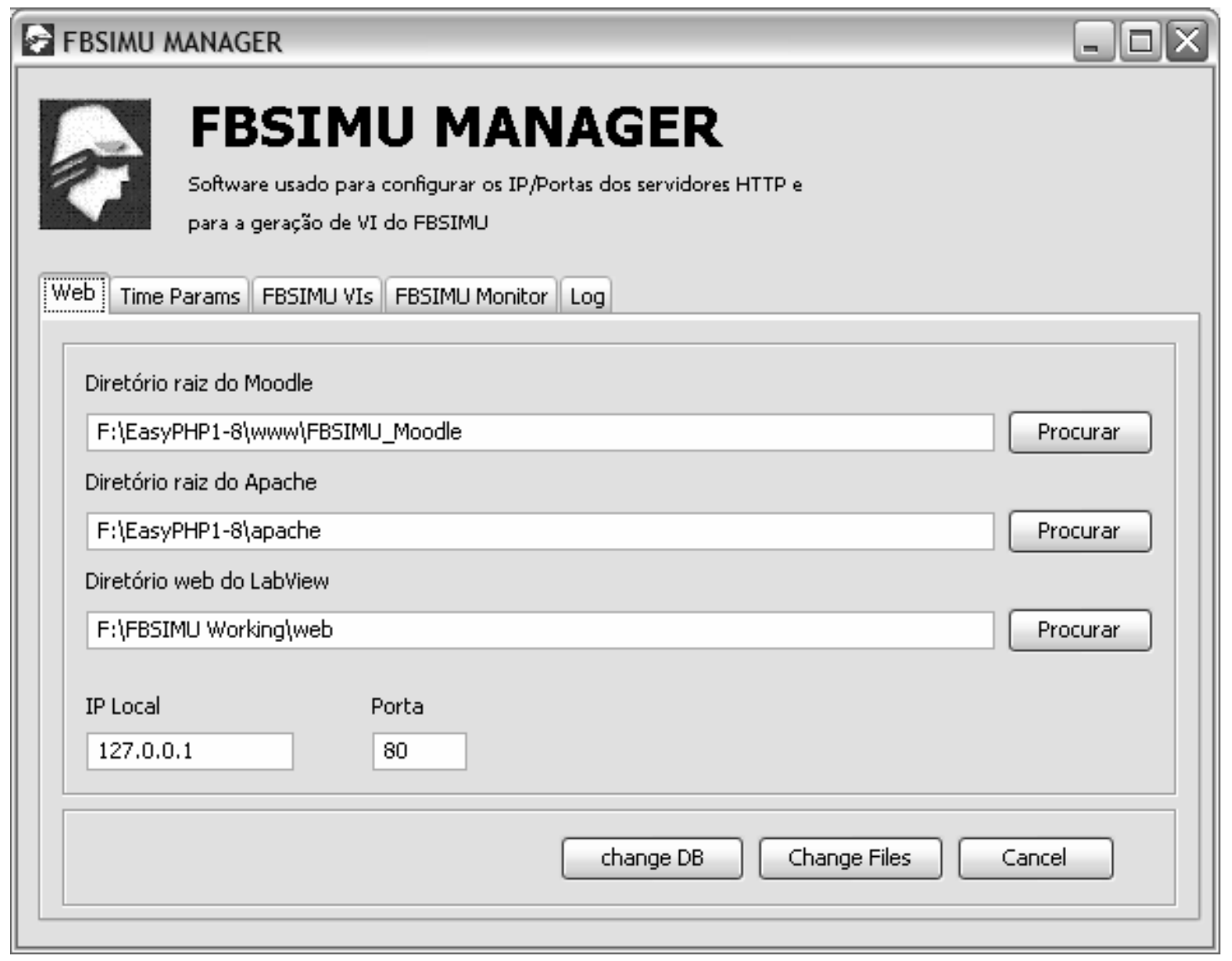

Figura 18 - Aba (tab) de configuração relacionadas a IP do Moodle e Apache

É importante lembrar-se que o IP e a porta configurados nesta aba são relacionados apenas ao servidor Apache. Para configurar o servidor Web do LabView, o usuário deverá seguir as instruções descritas no APÊNDICE A. 
Além dessa preocupação com a configuração destes IPs, é possível configurar-se os tempos relacionados ao não uso de uma determinada $V I$, e o tempo em que o arquivo fbsimu.ini deve ser analisado a fim de encontrar registros de usuários que fizeram log-out do sistema. A figura 19 mostra a interface gráfica usada para a configuração desses tempos.

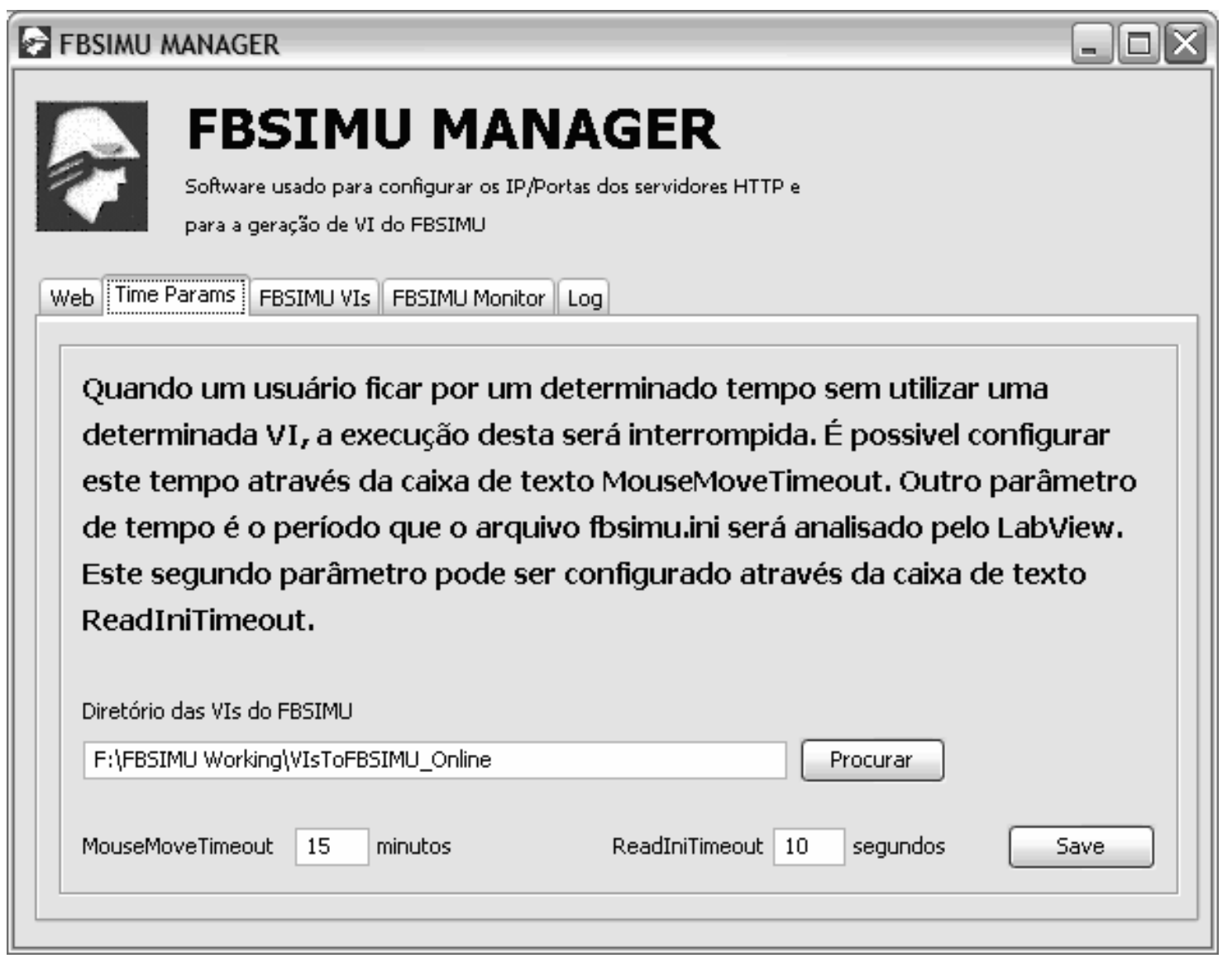

Figura 19 - Aba (tab) de configuração relacionada aos tempos usados no sistema

Uma outra necessidade está em configurar o número de VIs do FBSIMU que deverão ser abertas e disponibilizadas para acesso remoto. Sem uma ferramenta de configuração, o administrador deveria criar todos os arquivos de VIs e executá-los de forma a deixá-los disponíveis. Além disso, o arquivo fbsimu.ini deveria ser editado manualmente para criar uma nova entrada para cada nova $V I$. 
Como exemplo, pode-se usar um servidor onde oito VIs do FBSIMU seriam disponibilizadas. Neste caso, o administrador precisaria criar cópias dos arquivos fonte do FBSIMU para cada uma das oito instancias renomeá-los da seguinte forma: vil.vi, vi2.vi, vi3.vi, ..., vi8.vi. No arquivo fbsimu.ini, oito novas entradas do modelo da figura 15 (página 70) deveriam ser criadas. Para a configuração e criação dessas VIs de forma automática, uma outra aba denominada FBSIMU VIs foi criada na ferramenta. A figura 20 mostra a interface gráfica desta aba.

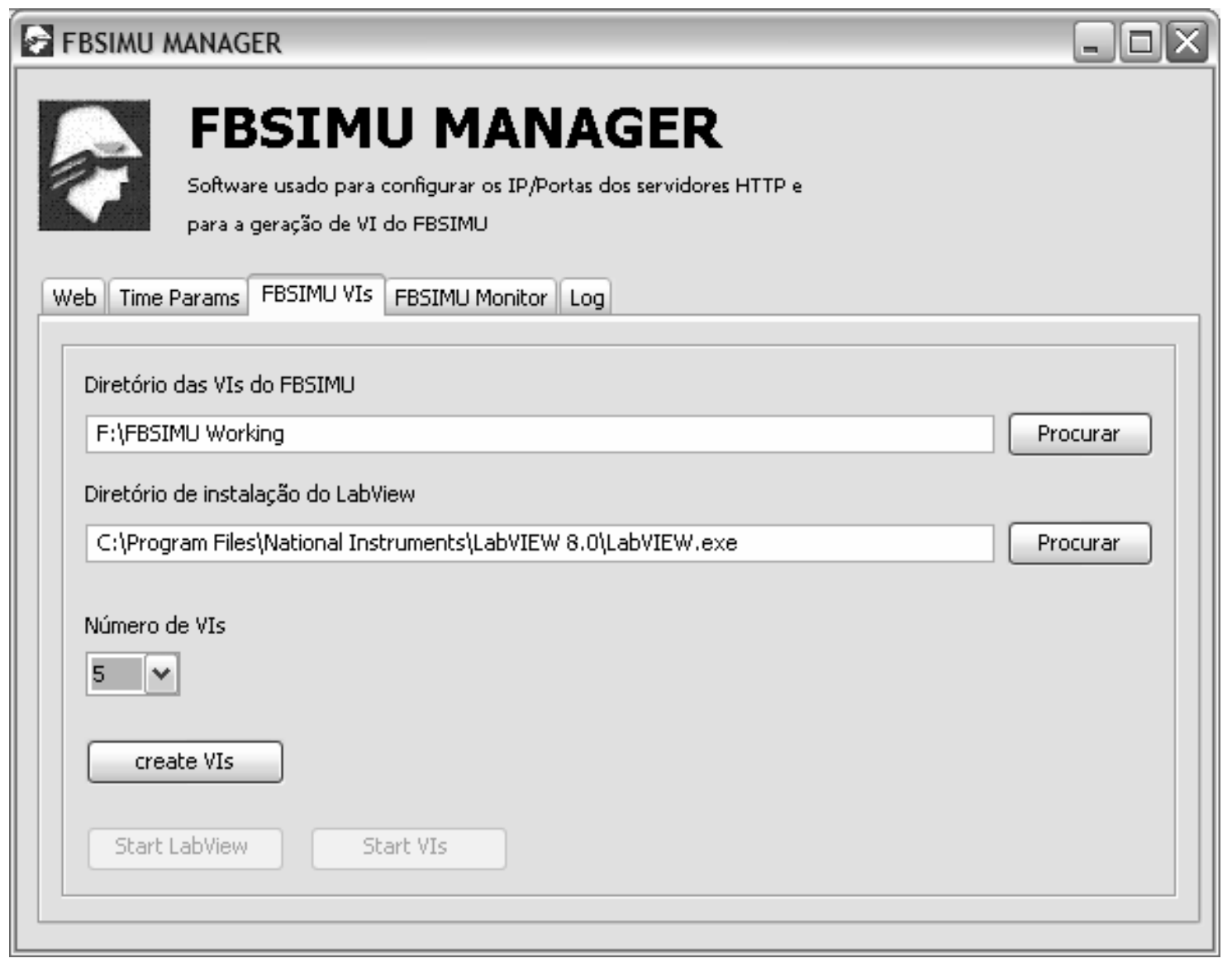

Figura 20 - Aba (tab) para criação das VIs do FBSIMU

A terceira função do FBSIMU Manager está relacionada ao processo que, de tempos em tempos, analisa a base de dados do Moodle e verifica se o tempo máximo de uso de uma VI foi atingido. A aba responsável por isso foi denominada FBSIMU Monitor e está ilustrada na figura 21. 


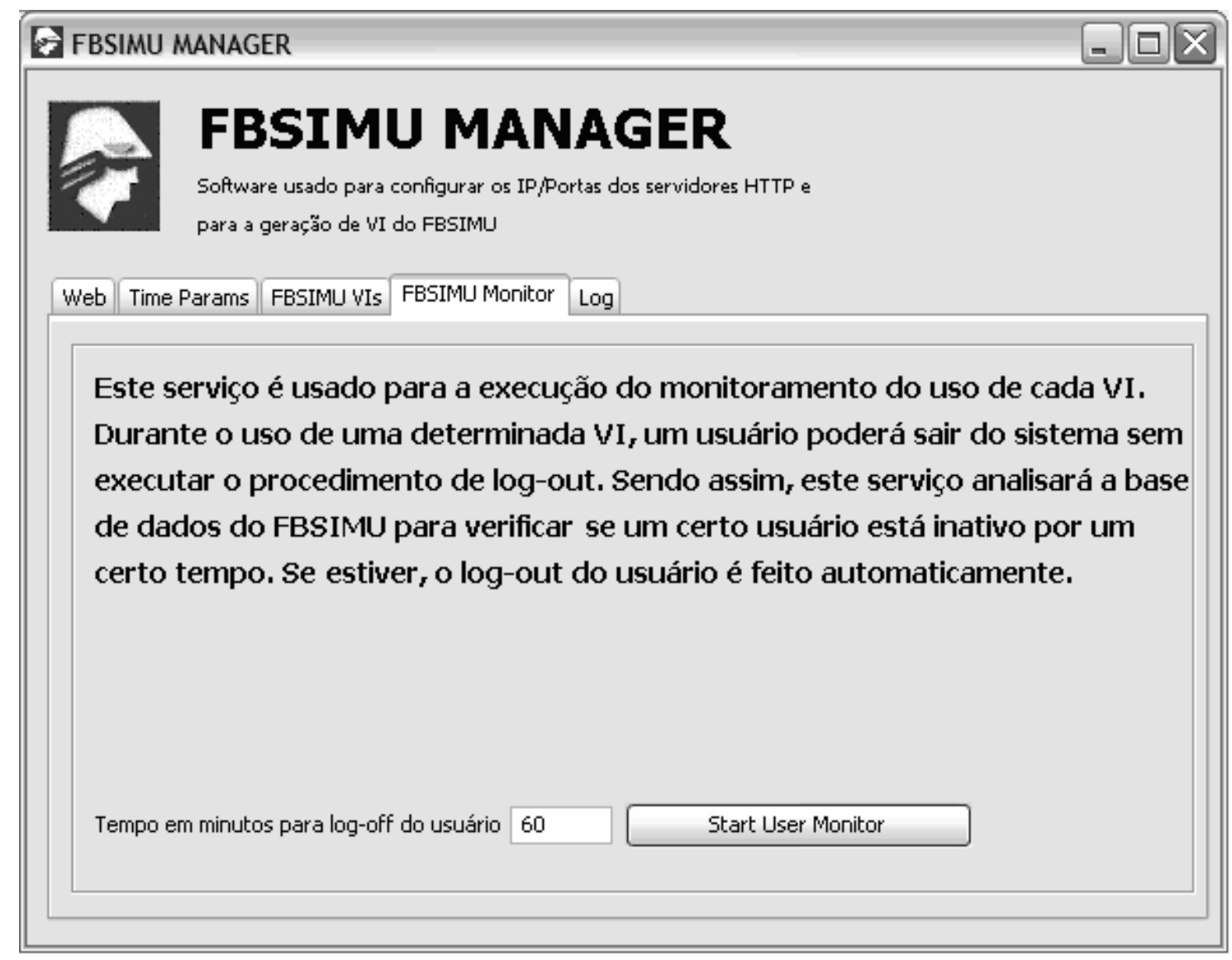

Figura 21 - Aba (tab) FBSIMU Monitor

Por fim, tem-se a última aba que fornece um registro de execução do software que fornece informações sobre o funcionamento de cada operação feita pela ferramenta. A figura 22 mostra a interface gráfica desta aba. 


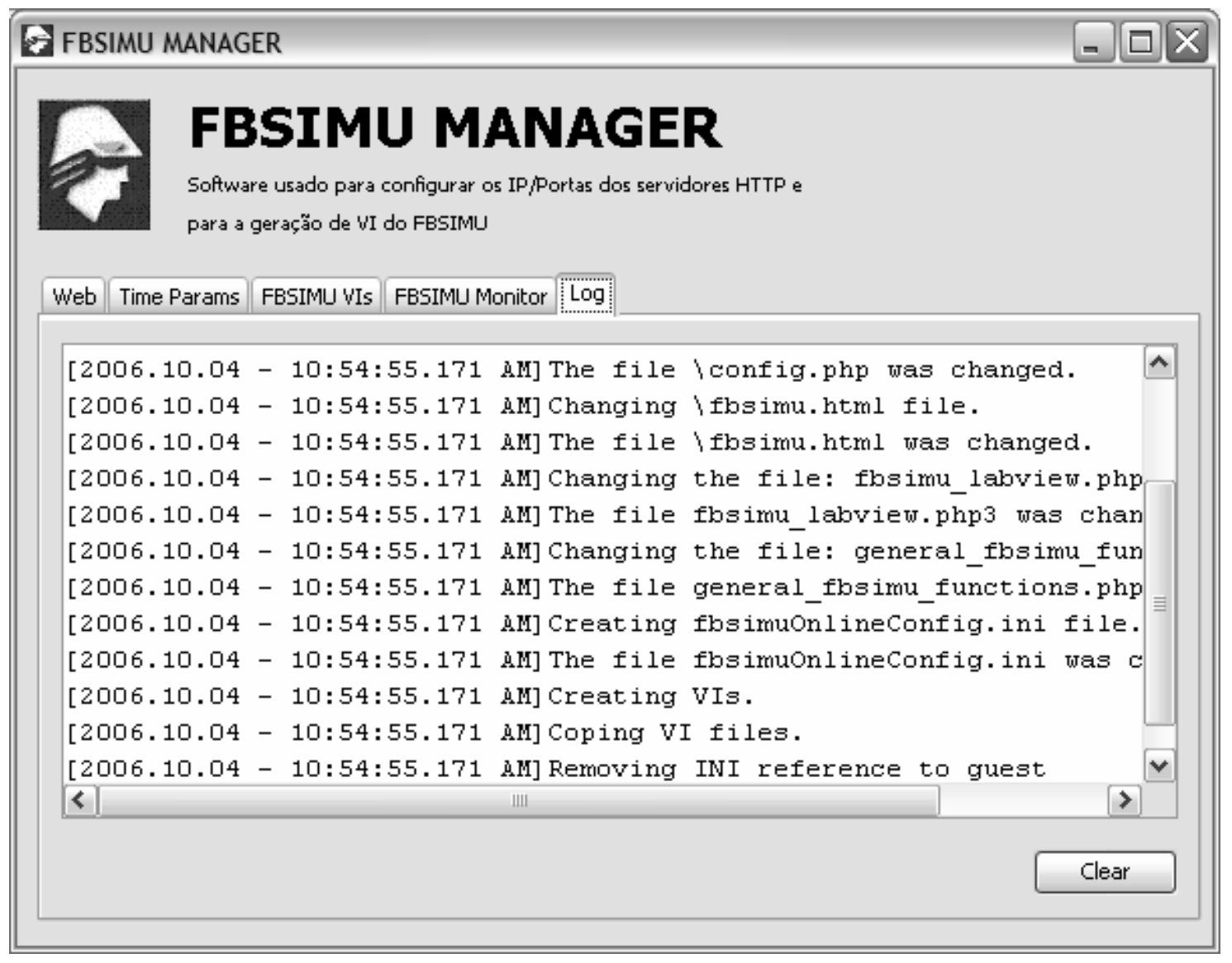

Figura 22 - Aba (tab) de registro de informações de execução do FBSIMU Manager

O FBSIMU Manager foi desenvolvido em Java e tem por objetivo ajustar todos os parâmetros necessários para o funcionamento do sistema.

O item 3.3.2.1 mostra o detalhes do código criado na implementação desta ferramenta.

\subsubsection{Código do FBSIMU Manager}

Neste item, uma breve descrição do modelo do software que foi utilizado para desenvolver o FBSIMU Manager é feita. O aplicativo foi desenvolvido utilizando-se a linguagem Java com o paradigma de programação orientado a objetos. A figura 23 mostra o diagrama de classes detalhando os métodos e a relação de uso de cada uma das classes envolvidas. 


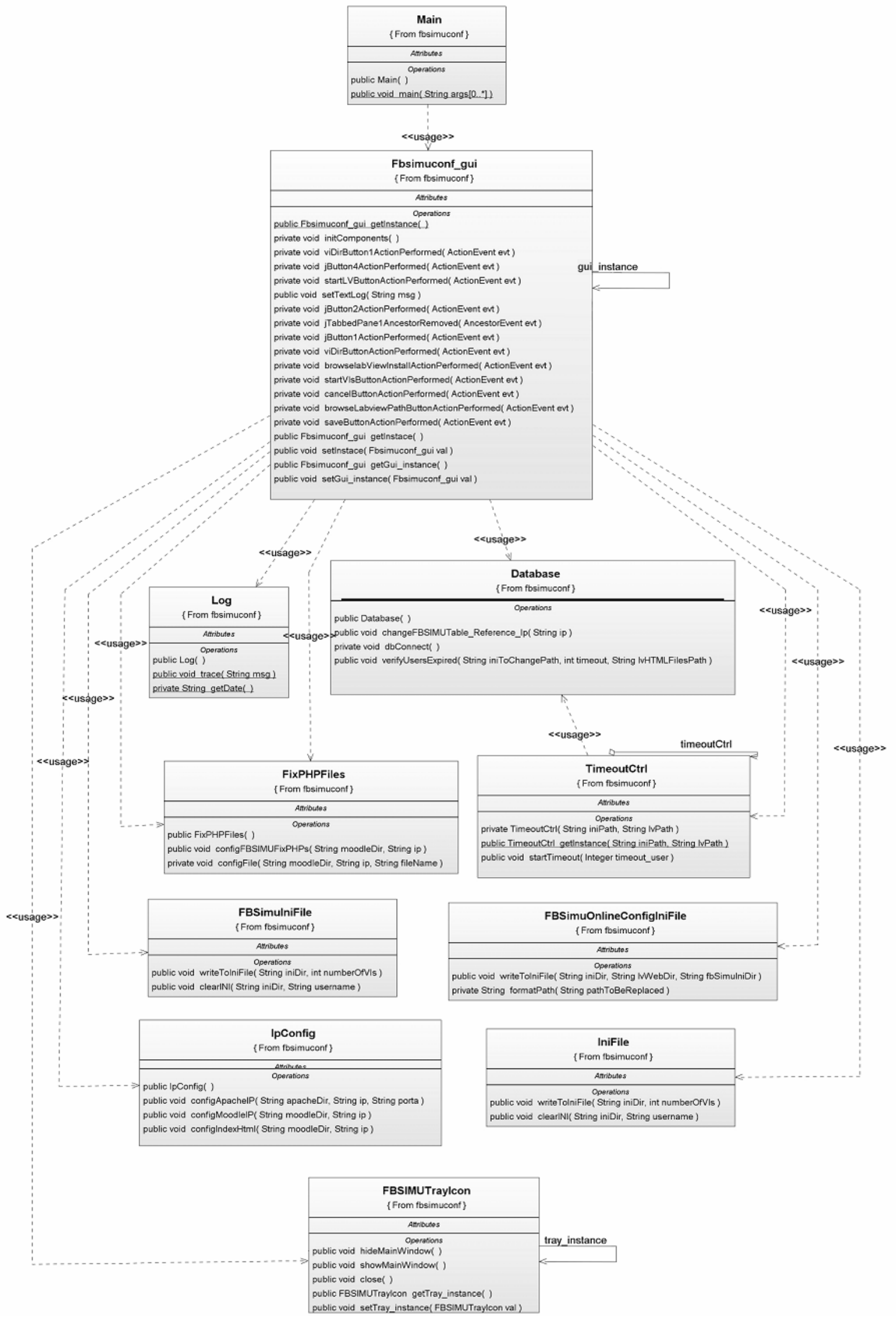

Figura 23 - Diagrama de Classes do FBSIMU Manager 
Seguindo o diagrama de classes, tem-se a tabela 4 que detalha a função de cada classe.

Tabela 4 - Descrição das classes do FBSIMU Manager

\begin{tabular}{|c|c|}
\hline \multicolumn{2}{|c|}{ Classes do FBSIMU Manager } \\
\hline Nome da Classe & Descrição \\
\hline Main & $\begin{array}{l}\text { A classe Main é a classe chamada quando a aplicação é } \\
\text { iniciada. Nesta classe, uma instância da classe } \\
\text { Fbsimuconf_gui será criada. }\end{array}$ \\
\hline Fbsimuconf_gui & $\begin{array}{l}\text { Esta classe é a interface gráfica do software. É a partir desta } \\
\text { classe que os eventos de modificar as configurações do } \\
\text { sistema e de criação de } V I \text {, entre outros, serão disparados. }\end{array}$ \\
\hline FBSimuOnlineConfigIniFile & $\begin{array}{l}\text { Esta classe é responsável por criar o arquivo de configuração } \\
\text { onde informações de tempo e de diretórios são armazenadas. }\end{array}$ \\
\hline FBSimuIniFile & $\begin{array}{l}\text { Esta classe é responsável pela criação do arquivo de } \\
\text { configuração (fbsimu.ini) que será responsável por armazenar } \\
\text { as informações de usuários que estão utilizando as VIs. Na } \\
\text { criação deste arquivo, todas as VIs são inicializadas sem } \\
\text { relação com nenhum usuário. O conteúdo do arquivo de } \\
\text { configuração dependerá do número de VIs que o usuário } \\
\text { selecionar através da interface gráfica. }\end{array}$ \\
\hline $\log$ & $\begin{array}{l}\text { Esta classe é responsável por controlar o log deste software. } \\
\text { É através de métodos contidos nesta classe que informações } \\
\text { sobre as operações que estão sendo feitas são mostradas na } \\
\text { aba de logs. }\end{array}$ \\
\hline FixPHPFiles & $\begin{array}{l}\text { Esta classe é responsável por modificar informações de IPs e } \\
\text { diretórios nos arquivos } P H P \text { criados para o funcionamento } \\
\text { deste sistema (general_fbsimu_functions.php e } \\
\text { fbsimu_labview.php3). }\end{array}$ \\
\hline
\end{tabular}




\begin{tabular}{|c|c|}
\hline Nome da Classe & Descrição \\
\hline LabViewManager & $\begin{array}{l}\text { Esta classe é responsável pela criação dos arquivos a serem } \\
\text { usados pelo LabView. Nesta classe existem métodos } \\
\text { responsáveis pela criação dos arquivos de VI e métodos para } \\
\text { a inicialização destas VIs na máquina servidora. Além disso, } \\
\text { possui métodos para apagar os arquivos } H T M L \text { criados para o } \\
\text { acesso ao FBSIMU por um determinado usuário. }\end{array}$ \\
\hline TimeoutCtrl & $\begin{array}{l}\text { Esta classe é responsável pelo controle do tempo máximo de } \\
\text { uso do sistema. Ela será executada a cada minuto para } \\
\text { verificar se algum usuário atingiu este tempo. Esta } \\
\text { verificação é feita com auxílio do método verifyUsersExpired } \\
\text { pertencente a classe Database. }\end{array}$ \\
\hline FBSIMUTrayIcon & $\begin{array}{l}\text { Esta classe é responsável por controlar o ícone deste software } \\
\text { na barra de tarefas (ícone que aparece ao lado do relógio do } \\
\text { Windows). }\end{array}$ \\
\hline Database & $\begin{array}{l}\text { Esta classe é responsável por modificar o banco de dados do } \\
\text { Moodle onde os endereços das páginas criadas por ele estão } \\
\text { armazenados. Por exemplo, para acessar a lista de arquivos } \\
\text { de log, foi criada uma página e o endereço desta página é do } \\
\text { tipo http://ipDoServidor/userName/logs/. Quando o IP do } \\
\text { servidor é modificado, este endereço também deve ser } \\
\text { modificado. Além disso, esta classe verifica se o tempo } \\
\text { máximo de permanência no sistema foi alcançado. }\end{array}$ \\
\hline IpConfig & $\begin{array}{l}\text { Esta classe será responsável por modificar os arquivos de } \\
\text { configuração do Apache e do Moodle. O primeiro método } \\
\text { modificará o arquivo httpd.conf que é responsável por } \\
\text { armazenar as informações do IP e da Porta do Apache. O } \\
\text { segundo método modificará o arquivo config.php, } \\
\text { responsável pelo endereço de acesso para o Moodle. Além } \\
\text { disso, a classe modifica o arquivo HTML responsável pelo } \\
\text { acesso principal do sistema (fbsimu.html) }\end{array}$ \\
\hline
\end{tabular}




\subsubsection{Gerenciamento dos arquivos do usuário}

O uso do FBSIMU remotamente gera como saída arquivos de $\log$ e, além disso, um usuário poderá salvar arquivos com informações sobre as configurações de blocos geradas em tal ferramenta.

Com o objetivo de fornecer ao usuário uma maneira de acessar e gerenciar estes arquivos, foi implementado um gerenciador de arquivos utilizando a linguagem PHP. Além disso, usando a linguagem $G$ do LabView, foi criada uma operação para o usuário escolher e carregar um arquivo de configuração em uma determinada instância do FBSIMU de forma que cada usuário manipule apenas os arquivos salvos em seu respectivo diretório.

\subsubsection{Gerenciador de arquivos desenvolvido em $\mathbf{P H P}$}

O código $P H P$ utilizado para a implementação desse gerenciador, usa os termos de licença GNU/LGPL. Tal código foi adaptado para o modo de funcionamento específico do FBSIMU. Maiores detalhes das modificações feitas no código encontram-se no APÊNDICE C.

Com as modificações implementadas, este código irá fornecer uma lista com todos os arquivos de log e de configuração de blocos pertencentes a um dado usuário. Além disso, este usuário poderá apagar e fazer download desses arquivos.

As figuras 24 e 25 mostram exemplos das páginas de gerenciamento de logs e de arquivos de configuração, respectivamente. 


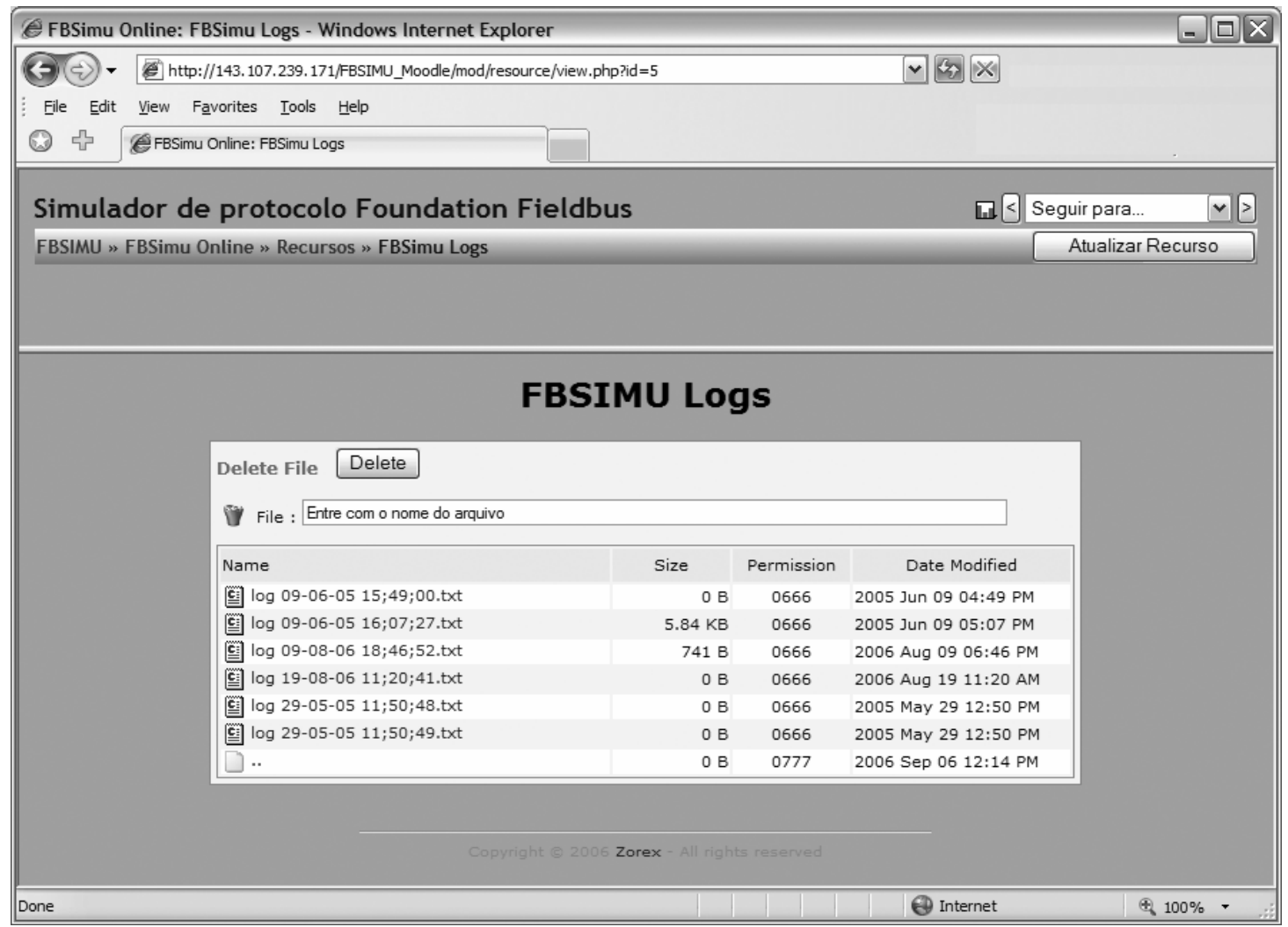

Figura 24 - Gerenciador de $\log s$ de usuários do FBSIMU

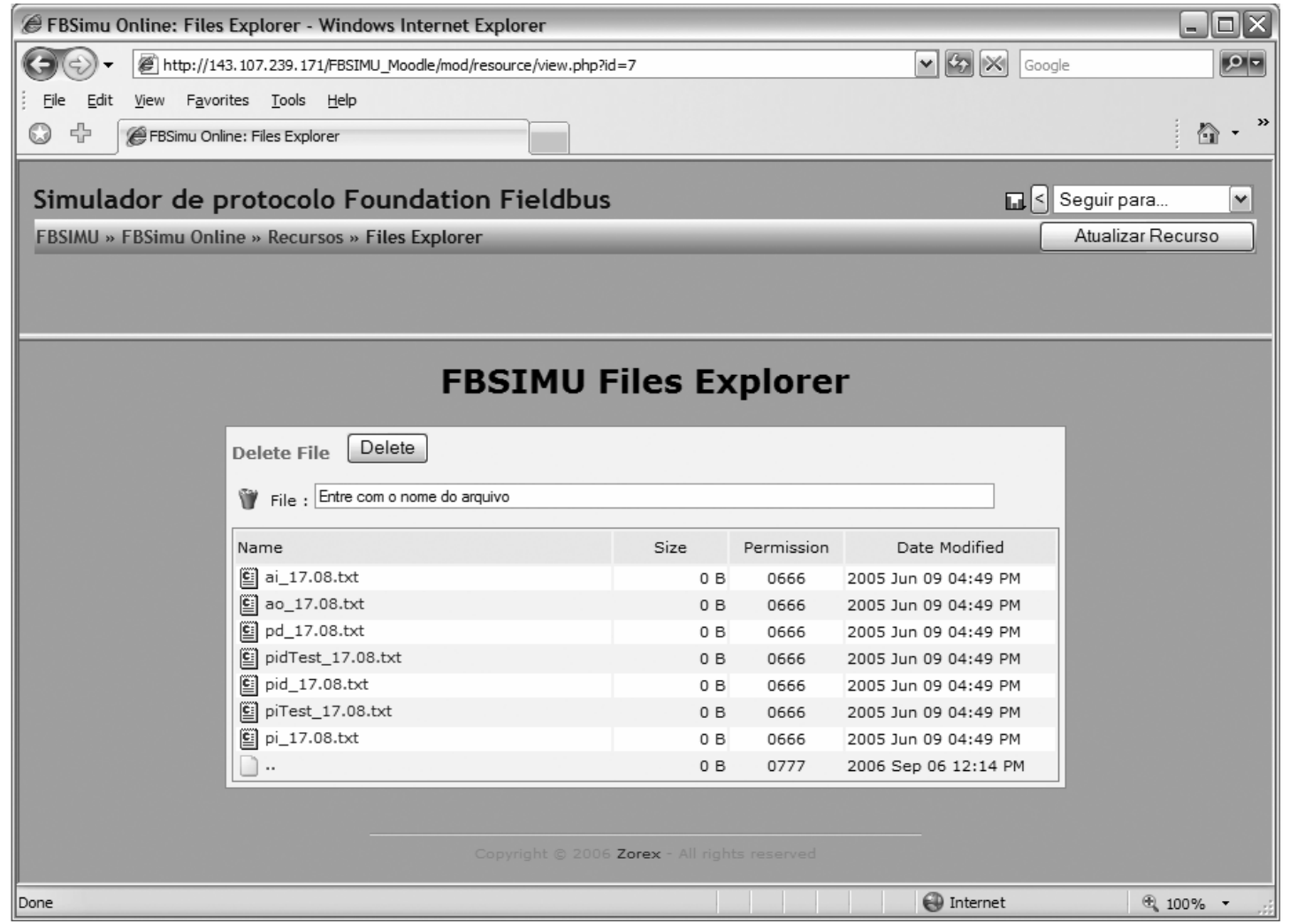

Figura 25 - Gerenciador de arquivos de blocos dos usuários do FBSIMU 


\subsubsection{Lista dos arquivos de configuração de blocos (FBSIMU)}

Originalmente, o FBSIMU fornecia uma opção para o usuário salvar uma configuração de um bloco e, em um outro momento, carregar estas informações e reutilizá-las.

Considerando-se que neste trabalho a ferramenta deverá trabalhar de forma remota, o modelo feito para salvar e posteriormente abrir estes arquivos foi modificado. Assim, a opção de escolher um diretório para salvar um arquivo não deverá mais existir. Tal arquivo será salvo sempre em um mesmo diretório (relacionado ao usuário que está operando) e para abri-lo novamente, uma lista com os arquivos salvos neste mesmo diretório será mostrada sem permitir a navegação por diretórios diferentes. A figura 26 mostra a parte gráfica da $V I$ onde o usuário poderá escolher o arquivo a ser carregado. 


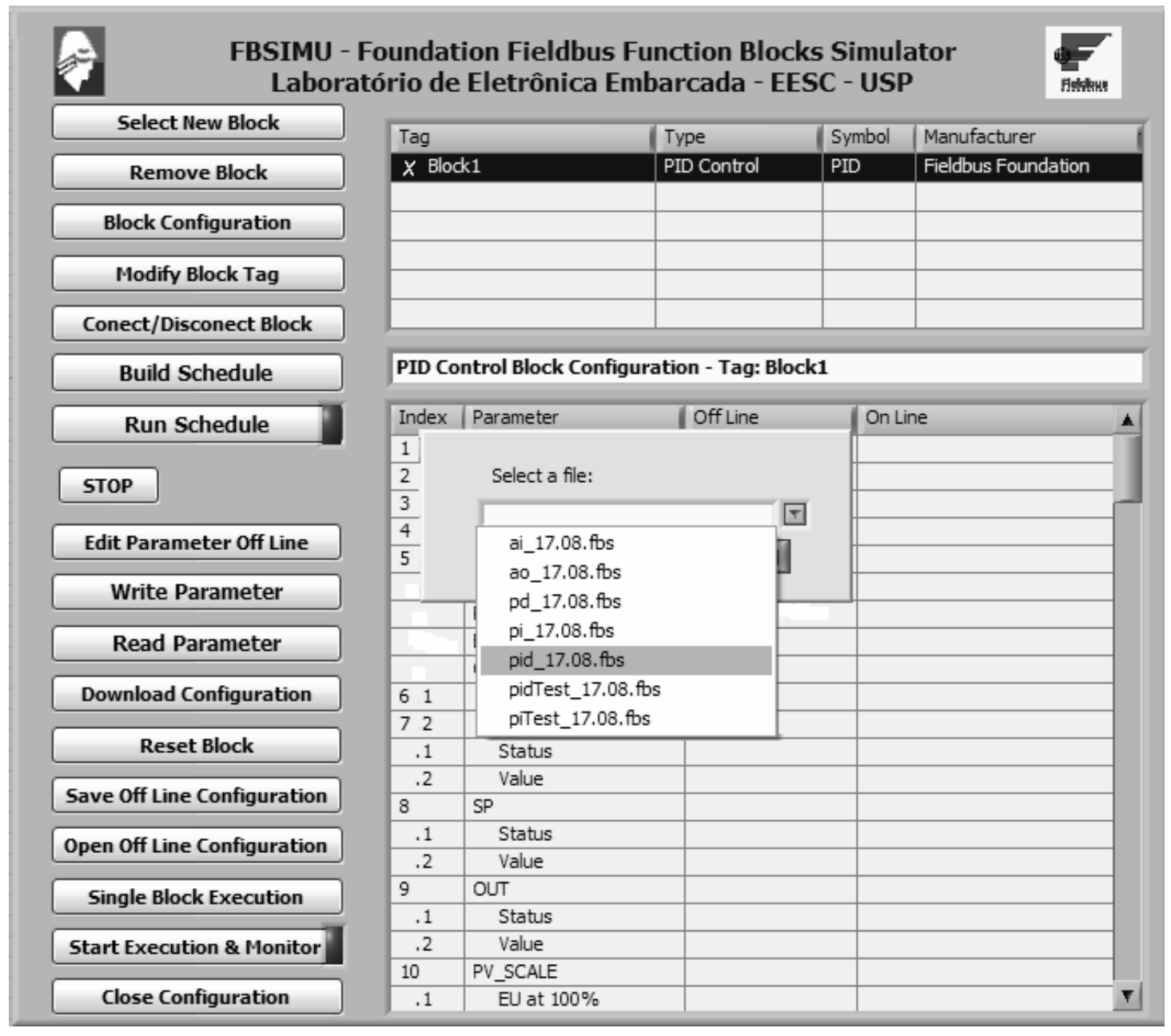

Figura 26 - VI onde o usuário carrega o arquivo com a configuração

No próximo capítulo, uma análise dos resultados relacionados ao uso do sistema descrito nessa dissertação é feita de maneira a validar o uso do acesso remoto ao FBSIMU. 


\section{Resultados}

A análise dos resultados deste sistema poderia ser feita com o objetivo de avaliar a efetividade do uso de um laboratório remoto para o ensino, ou alternativamente, ser focada em testes realizados a fim de validar esta ferramenta.

Considerando-se que o uso da metodologia de ensino a distância está bastante difundido e a sua efetividade já foi provada por vários autores citados neste trabalho (por exemplo, IRVINE et al., 1999; MORCOS et al., 2001; DEMING, 2001), os resultados deste trabalho serão adquiridos a partir de testes relacionados ao controle do acesso remoto às VIs do FBSIMU. Além destes testes pontuais, um teste piloto utilizando uma planta simulada foi realizado a fim de analisar o comportamento do sistema.

\subsection{Teste do controle de acesso}

Neste item, são descritos os resultados dos testes realizados para a validação do controle de usuário. Como explicado no capítulo anterior, este controle é dividido e está distribuído entre três softwares (FBSIMU Manager, LabView e código PHP do FBSIMU).

\subsubsection{Teste do controle realizado no FBSIMU Manager}

Este primeiro controle está relacionado ao tempo máximo que uma sessão pode ficar aberta. A forma de funcionamento deste controle foi explicada no item 3.3.2 na página 76. Para realizar este teste, foram utilizados dois computadores clientes no qual 
cada um acessou uma instância de FBSIMU diferente. O sistema foi utilizado durante 45 minutos por ambos os usuários. No momento em que o tempo de uso máximo foi atingido, o FBSIMU Manager modificou o arquivo fbsimu.ini e apagou os arquivos HTML usados para acesso ao FBSIMU. Logo em seguida, a ação de "Stop" aconteceu nas VIs que estavam sendo usadas.

\subsubsection{Teste do controle realizado na $V I$ do FBSIMU}

Para realizar o teste referente aos controles realizados pela VI do FBSIMU, dois cenários foram criados: cenário para o teste do controle do tempo máximo que uma VI pode ficar sem ser usada, detalhado no item 4.1.2.1, e o cenário para o teste do controle de tempo relacionado à liberação de uso de uma VI, detalhado no item 4.1.2.2.

\subsubsection{Teste do controle por tempo sem uso da $V I$}

Para este teste, usaram-se duas máquinas no qual cada uma acessou uma VI do FBSIMU diferente. Em uma das máquinas, o usuário ficou executando um experimento de forma a não deixar a $V I$ ociosa. Na outra, o usuário não executou nenhuma operação de forma a deixar a respectiva VI parada. Após dez minutos sem uso, o algoritmo de liberação (algoritmo detalhado no item 3.3.1.1.2.2 na página 75) foi executado. Como resultado, o arquivo fbsimu.ini foi modificado a fim de liberar o acesso a esta VI e, em seguida, a ação de "Stop" foi executada. A outra VI, onde o usuário estava executando suas tarefas, continuou funcionando normalmente.

\subsubsection{Teste do controle relacionado à liberação da $V I$}

Para executar este teste, um usuário acessou o sistema, executou o acesso ao FBSIMU e iniciou um experimento. Com a VI em modo "Run", este usuário foi até a janela principal do sistema (navegador Web) e executou a operação de log-out. Neste 
momento, o controle implementado na VI que estava sendo executada (algoritmo detalhado no item 3.3.1.1.2.1 na página 74) verificou que o usuário que estava usando tal VI saiu do sistema (fbsimu.ini indica isso) e a operação de "Stop" foi realizada.

\subsubsection{Teste do controle realizado em $P H P$}

Este controle está relacionado à operação de log-out do sistema. Sendo assim, este teste é o mais simples de todos. Usaram-se três máquinas e, a partir de cada uma, usuários diferentes acessaram o sistema. Para cada usuário, três acessos ao FBSIMU foram feitos sem que a operação de log-out fosse executada. Por fim, o log-out foi realizado e o arquivo fbsimu.ini foi modificado para liberar um futuro acesso à VI utilizada. Além disso, os arquivos $H T M L$ de acesso ao FBSIMU foram apagados (algoritmo detalhado no item 3.3.1.1.1 na página 71).

\subsection{Teste Piloto}

Este item descreve o teste piloto realizado a fim de validar esta ferramenta. $\mathrm{O}$ resultado esperado com a realização deste teste é verificar quais recursos não foram previstos para o funcionamento ideal do sistema, quais problemas poderiam surgir com sua utilização e, por fim, validar o modelo criado para permitir o acesso remoto ao FBSIMU por mais de um aluno de forma paralela, sem que um aluno interferisse no trabalho de outro.

\subsubsection{Plano de teste executado}

Para a realização de tal teste, um planejamento foi feito a fim de montar um cenário de teste mais próximo do uso real do portal. 
A idéia foi configurar o sistema com cinco instâncias de VIs do FBSIMU para proporcionar o uso remoto simultâneo da ferramenta por cinco diferentes usuários.

Estes usuários fizeram o procedimento de acesso desde o início. Assim, cada usuário enviou um e-mail ao professor ou administrador pedindo o cadastramento no sistema. Com as cinco contas criadas, um e-mail de confirmação foi enviado para estes mesmos usuários. A próxima etapa foi o acesso de cada um destes usuários ao portal e, em seguida, o acesso à ferramenta FBSIMU. Nesta ferramenta, cada usuário realizou um experimento. As etapas deste experimento foram:

- Criação de um bloco PID

- Criação de um bloco AI

- Criação de um bloco AO

- Parametrização de todos os blocos

- Habilitação dos $\log s$

- Conexão desses blocos

- Configuração do schedule da estratégia

- Link da estratégia montada com a planta simulada

- Execução do sistema criado

A planta utilizada é uma simulação implementada usando a linguagem $G$ nativa do LabView. A figura 27 mostra a interface gráfica da VI que possui a implementação da planta. Esta interface possui um gráfico que ilustra o comportamento da saída da planta. Além disso, através dessa interface, o usuário pode modificar os parâmetros relacionados ao modelo da planta, e dessa maneira, diferentes modelos de plantas podem ser utilizados. 


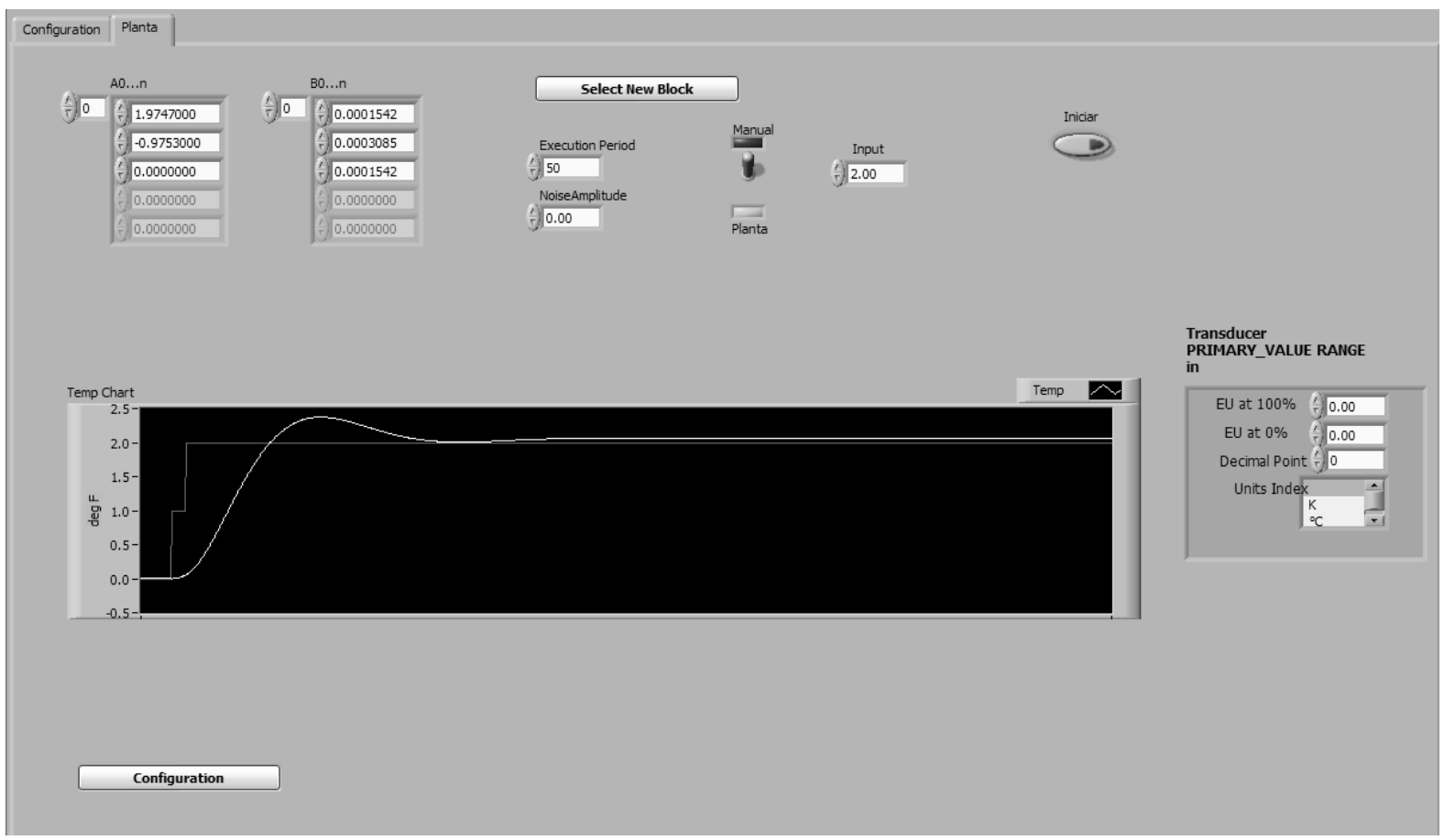

Figura 27 - Interface gráfica da VI da planta utilizada para a execução das simulações

A função transferência da planta representa um forno elétrico e foi obtida a partir de um algoritmo de identificação de sistemas. A descrição deste algoritmo foi apresentada em CUNHA (2004). O resultado desta identificação é a representação do sistema dinâmico na forma da equação diferença no modelo ARX (Modelo linear, auto-regressivo e com entrada externa) apresentada na equação 1:

$$
\begin{aligned}
& \mathrm{y}(\mathrm{k})=1,9747 \mathrm{y}(\mathrm{k}-1)-0,9753 \mathrm{y}(\mathrm{k}-2)+ \\
& 1,542 \mathrm{E}-3 \mathrm{u}(\mathrm{k}-1)+3,085 \mathrm{E}-3 \mathrm{u}(\mathrm{k}-2)+1,542 \mathrm{E}-3 \mathrm{u}(\mathrm{k}-3)
\end{aligned}
$$

Assim, com a planta simulada disponível para uso, o aluno poderá criar uma estratégia de controle e realizar os testes. Na análise dos resultados deste trabalho, um bloco AI (Analog Input) é criado para receber o valor de saída (sensor da planta) e passá-lo para um bloco PID (Proportional/Integral/Derivative), que executa o algoritmo de controle. O PID repassa este valor para o bloco AO (Analog Output), que 
informa para a planta a ação a ser tomada. A figura 28 mostra o modelo usado para o teste.

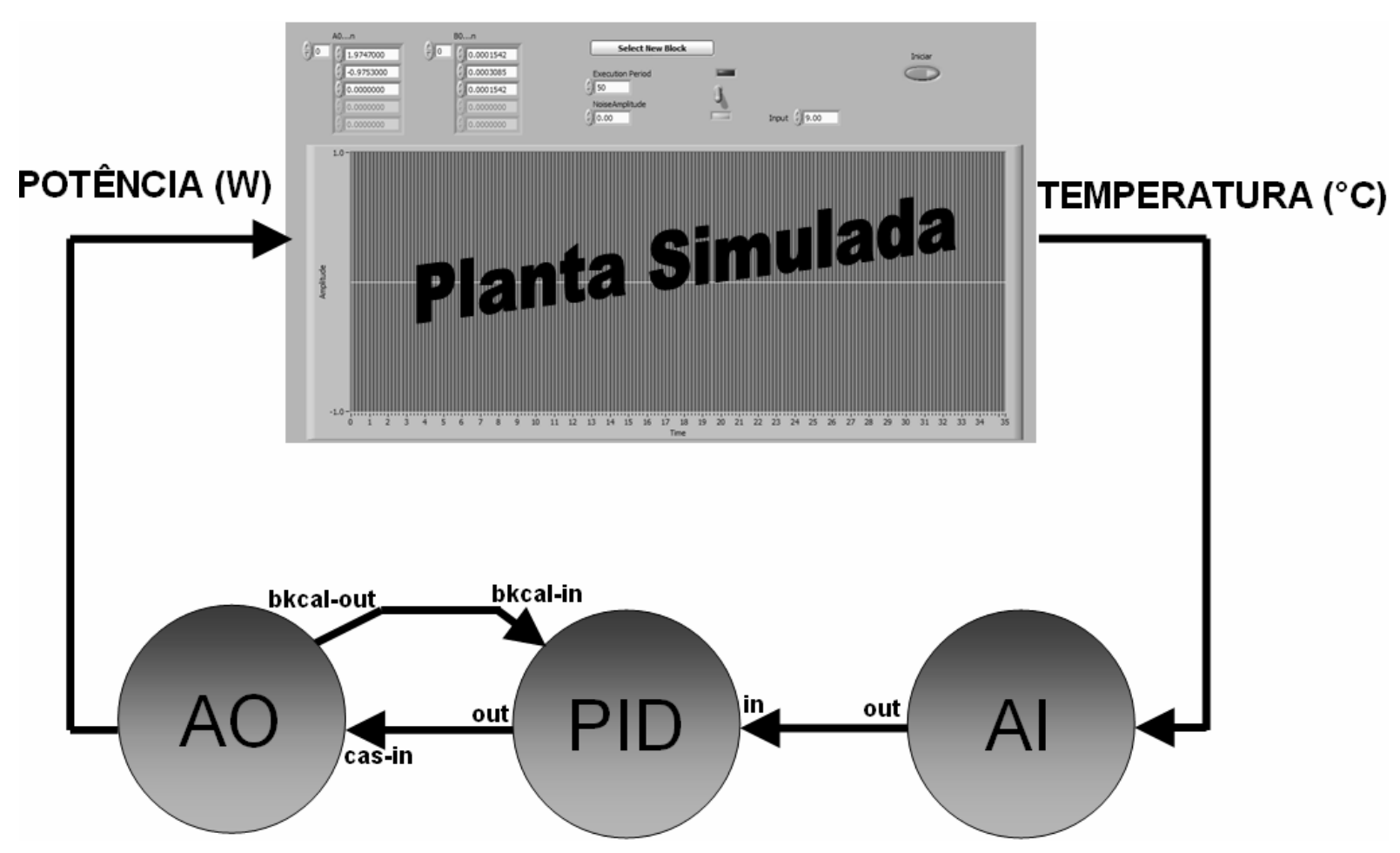

Figura 28 - Planta simulada usada para a execução do teste piloto

Ao fim de tal experimento, o usuário salvou cada uma das configurações dos blocos criados. Com os dados armazenados e o experimento realizado, o usuário fechou o painel remoto do FBSIMU e executou o log-out do sistema.

Para garantir que suas configurações foram armazenadas corretamente, este mesmo usuário acessou novamente o sistema e, em seguida, analisou o conteúdo dos links "FBSIMU Files" e "FBSIMU Logs". A página da internet apresentada mostrou todos os arquivos criados e permitiu que o usuário apagasse ou fizesse o download de cada arquivo.

Por fim, um novo acesso remoto à ferramenta FBSIMU foi feito. Neste novo acesso, o usuário carregou os arquivos salvos no último acesso e modificou outras 
informações. Concluindo o teste, no lugar de sair do sistema efetuando um log-out, o usuário saiu fechando o navegador Web.

\subsubsection{Resultados do Teste}

A parte inicial de cadastramento dos usuários foi feita e nenhum problema foi encontrado. Tal cadastro é oferecido pelo Moodle e já foi testado por milhões de usuários desse sistema, e, por isso, não é necessário preocupar-se em cadastrar um número maior de alunos (MOODLE, 2006).

Feito isso, os alunos acessaram o sistema e iniciaram o acesso ao FBSIMU. Neste momento, o sistema apresentou uma demora para retornar uma resposta. Isto foi causado pela instalação do LabView Runtime Engine. Se a máquina cliente não possui tal software instalado, a mesma executará o download automaticamente, e como o arquivo é grande (aproximadamente 87MB), o procedimento é demorado. Apesar de este problema ter acontecido, o download e instalação do LabView Runtime Engine poderiam ter sido feitos antes de se iniciar qualquer operação. Feita a instalação, o usuário passa a ter o acesso sem este problema. Quando o acesso é feito, observa-se na máquina servidora que o arquivo fbsimu.ini, responsável por armazenar informações sobre a relação de qual usuário está acessando uma determinada VI, foi alterado e que cada VI foi designada para um usuário diferente. A figura 29 mostra o arquivo no momento em que todos os usuários estavam acessando o FBSIMU remotamente. Além da modificação do fbsimu.ini, foram gerados todos os arquivos HTML necessários para permitir o acesso aos painéis remotos do FBSIMU e cada arquivo foi criado no respectivo diretório do usuário que fez o acesso. 


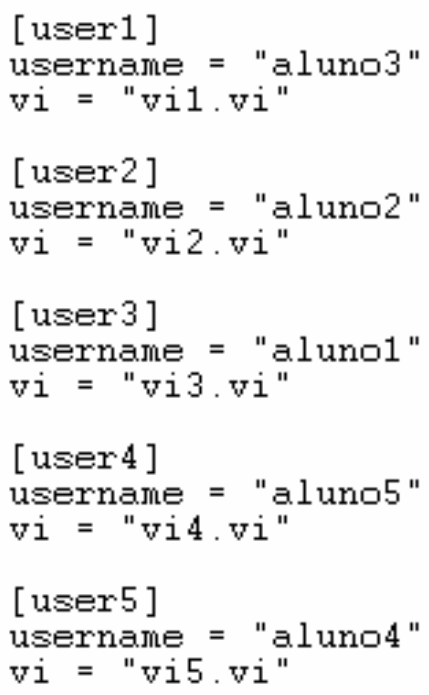

Figura 29 - Arquivo fbsimu.ini com todas as VIs reservadas

O LabView oferece uma ferramenta que mostra todas as VIs que estão sendo acessadas remotamente em um determinado momento. Além disso, esta ferramenta mostra a relação de qual máquina está acessando uma determinada VI. A figura 30 mostra esta ferramenta no momento em que os cinco estudantes acessaram as VIS disponibilizadas no servidor. 


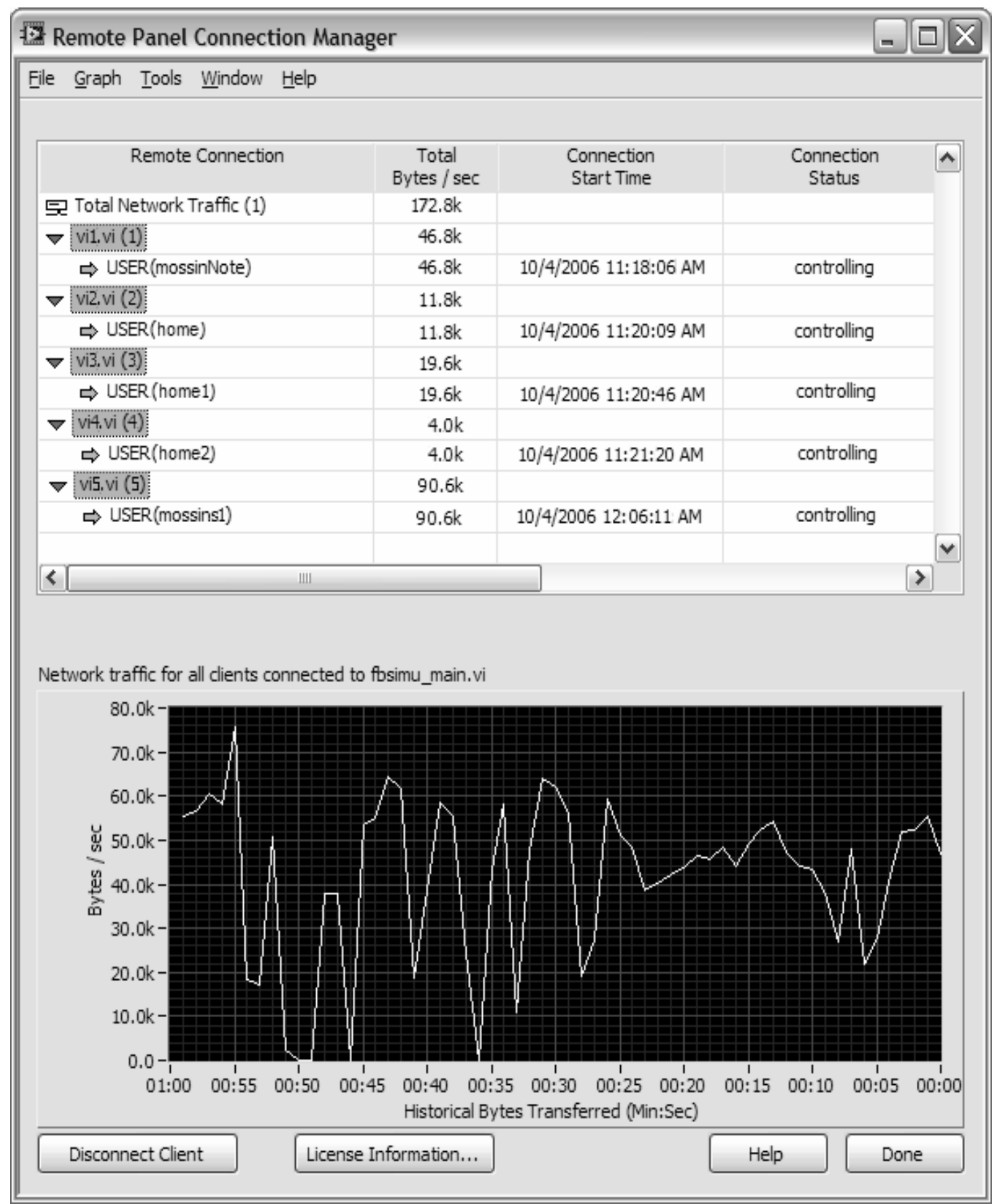

Figura 30 - Gráfico do LabView com status dos acessos de cinco máquinas remotas

A partir daí, cada usuário iniciou o experimento proposto. Em todos os experimentos, as operações foram realizadas sem um comprometimento considerável da resposta do sistema. É válido salientar que quanto mais VIs liberadas para acesso remoto e quanto maior o número de acessos a estas VIs, maior o comprometimento da 
performance do sistema, afinal, todos os comandos são executados apenas pelo processador da máquina servidora.

Considerando-se que foco da análise deste sistema não é a performance, um teste detalhado sobre esta questão não foi executado. O motivo foi que, dependendo da necessidade de mais instâncias, um servidor mais potente pode ser utilizado, e, por isso, a necessidade de um teste detalhado foi considerada inexistente. Apesar disso, um teste simples com 15 instâncias foi executado. Neste teste, todas as instâncias foram colocadas no modo "Run" do LabView porém nenhuma operação foi executada. Utilizando-se o gerenciador de tarefas do sistema operacional Windows (Task Manager), notou-se que o processo LabView utilizou aproximadamente $80 \%$ da capacidade da CPU do servidor e cerca de 200MB de memória. Além disso, cada instância ocupou um espaço de 50MB em disco. Para este teste, as configurações principais do computador usado como servidor foram: processador Pentium 4 com frequiência de 3,33GHz, $1 \mathrm{~GB}$ de memória e disco rígido de 100GB.

Realizado o experimento, o próximo teste está relacionado ao salvamento das informações. Para cada usuário criado no sistema, um diretório é criado. Assim, os logs e os arquivos salvos no experimento devem ser armazenados nesses diretórios de forma transparente ao usuário. No teste piloto, este procedimento foi realizado de forma correta. Cada arquivo de $\log$ ou de configuração foi salvo no diretório do respectivo usuário que criou estes arquivos.

Para concluir a primeira etapa do teste piloto, todos os usuários executaram o log-out do sistema. No servidor, os comandos $P H P$ relativos a ação em questão foram executados corretamente e todos os arquivos HTML de acesso ao FBSIMU e as relações criadas no arquivo fbsimu.ini foram apagados. A figura 31 mostra o conteúdo do arquivo fbsimu.ini após tal operação. 


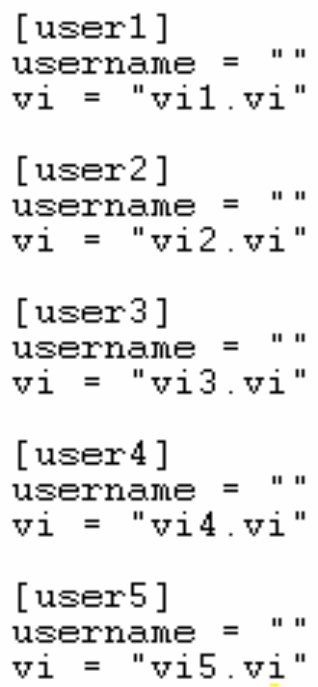

Figura 31 - Arquivo fbsimu.ini com todas as VIs liberadas

Sendo assim, todas as VIs estão livres para acesso novamente. A próxima etapa do teste está relacionada ao gerenciamento dos arquivos de $\log$ e de configuração relativos a cada usuário. Assim, cada usuário acessou os sites responsáveis por este gerenciamento e apagou alguns arquivos de $\log$ e de configuração. Além disso, estes usuários fizeram download de alguns destes arquivos. Como esperado, as modificações foram efetuadas no diretório correto (diretório respectivo ao usuário corrente).

Feitos todos os procedimentos descritos até agora, os usuários acessaram novamente a ferramenta FBSIMU de forma remota e carregaram as configurações salvas na primeira fase. Em todas as máquinas, estas informações foram carregadas corretamente e cada usuário executou novos procedimentos a partir das informações salvas na primeira etapa do teste.

O último teste refere-se ao tratamento dado pelo sistema quando um usuário sai do mesmo sem executar a operação de log-out (simplesmente fecha o navegador Web). Se o usuário em questão sair dessa maneira, o código $P H P$ relativo ao 
destravamento das VIs não será executado e, conseqüentemente, estas VIs ficariam travadas por um tempo indeterminado. É neste momento que aparece a utilidade principal da verificação relacionada ao tempo ocioso de uma dada VI (10 minutos). Passado este tempo, o código criado nas VIs do FBSIMU foi executado e o arquivo fbsimu.ini foi modificado a fim de liberar o acesso a tal VI.

Para finalizar, uma das VIs foi "abandonada" por um dos usuários, sem ser executada (VI em modo "Stop" e o algoritmo de liberação por tempo ocioso não é executado). Neste caso, o serviço implementado em Java para cuidar deste tipo de situação foi executado e liberou o acesso a esta VI 60 minutos após o último acesso do usuário em questão.

\subsubsection{Conclusão do Teste}

O teste funcionou para todos os casos de uso previstos de forma satisfatória. Entretanto, se o usuário usar o sistema corretamente (executando o log-out no momento de saída), o funcionamento do mesmo será mais efetivo. Caso o usuário saia do sistema de forma incorreta, as VIs poderão ficar bloqueadas desnecessariamente por um período que pode chegar a até 45 minutos (tempo máximo de uso de uma $V I$ - este tempo é configurável).

Outro ponto importante a ser discutido está relacionado à performance do sistema. Notou-se que com 15 instâncias abertas em modo "Run", o processamento do computador atingiu $80 \%$ de sua capacidade. Esta degradação da performance está relacionada à maneira com que o FBSIMU foi implementado e, assim sendo, algoritmos de otimização precisarão ser implementados a fim de atender um número maior de acessos paralelos. 
Por fim, com o uso da planta simulada, foi possível ver a variação do valor de entrada e de saída da planta utilizada, e com isso, notou-se que os blocos PID, AI e AO funcionaram de maneira adequada para controlar o sistema, dando uma visão exata da variação das variáveis da planta. 



\section{Conclusões}

Desde o início da criação dos protocolos fieldbus, existe um grande interesse em pesquisas sobre os diferentes aspectos e funcionalidades da tecnologia. Várias ferramentas didáticas de simulação foram criadas com o objetivo de facilitar estas pesquisas, como, por exemplo, o acesso a instrumentos reais para a realização de experimentos. Além do custo menor em relação ao uso desses instrumentos, uma vantagem das ferramentas de simulação é permitir que o aluno faça qualquer tipo de experimento sem restrições de segurança. Já no uso de instrumentos reais, tem-se a desvantagem de limitar o estudante a executar poucos tipos de experimentos para preservar sua segurança pessoal, a segurança dos dispositivos e até mesmo do laboratório. Apesar disso, o contato direto com dispositivos reais proporciona ao estudante uma experiência mais realista com equipamentos industriais. Entretanto, se o simulador for realista o suficiente, essa vantagem desaparece.

Com o grande crescimento da internet, acessos remotos poderiam ser disponibilizados oferecendo uma flexibilidade ainda maior aos usuários das ferramentas de simulação e até mesmo de sistemas com instrumentos reais.

Considerando-se o escopo da implementação do acesso remoto do FBSIMU, foi comprovado que é possível implementar um acesso via internet de maneira eficiente utilizando sistemas CMS (Moodle), voltados a oferecer uma estrutura padronizada para a construção de portais Web para ensino a distância. Usando o Moodle, ficou evidente a facilidade obtida na manutenção e adição de novas funcionalidades ou mesmo novos cursos ao sistema. 
Através dos testes executados, foi comprovado que o funcionamento remoto de ferramentas desenvolvidas através da linguagem $G$ do software LabView é possível, lembrando que ajustes (descritos no capítulo 3, página 49) precisaram ser feitos para garantir o funcionamento correto da mesma.

Deve-se lembrar que apesar das facilidades apresentadas por este tipo de ferramenta, o modelo usado neste trabalho gerou dificuldades devido à necessidade do uso de dois servidores Web (Apache para o Moodle e o servidor Web do LabView para a ferramenta FBSIMU). A dificuldade apareceu por causa da necessidade de validação de usuários (senha, permissão de acesso, etc.) integrada entre os dois servidores. Se uma nova ferramenta for adicionada e o servidor Web para acessá-la for o mesmo servidor usado pelo Moodle (Apache), estas dificuldades desaparecem, pois a validação é feita automaticamente pela estrutura já fornecida por este CMS.

Por fim, notou-se que o uso da metodologia de ensino a distância está bastante difundido e a sua efetividade já foi comprovada por autores como IRVINE et al. (1999), MORCOS et al. (2001) e DEMING (2001). Levando-se em conta este legado do ensino a distância (CMS, efetividade comprovada, etc.), a obtenção de resultados de sistemas deste modelo pode ser focada totalmente no funcionamento correto da ferramenta através da execução de testes.

\subsection{Trabalhos Futuros}

Como foi destacado neste trabalho, uma grande preocupação com a capacidade de extensão do portal FBSIMU On-line existiu em todos os momentos da implementação. Esta preocupação existiu porque um dos objetivos deste trabalho é disponibilizar, futuramente, o acesso remoto não apenas para o FBSIMU, mas também para outras ferramentas ou outros 
cursos no qual o aluno, após registrar-se no sistema, terá acesso a um acervo sempre crescente de materiais voltados para a área de automação.

Em trabalhos futuros, várias outras características, como a integração de novas plantas simuladas, provas on-line, novos simuladores de outros protocolos fieldbus, aulas remotas, etc, poderão ser acopladas a este portal fazendo com o que o acesso remoto ao FBSIMU se transforme apenas em uma das partes de um sistema on-line completo para a área de automação.

Além disso, a ferramenta FBSIMU propriamente dita tem um grande potencial para crescimento. Atualmente, esta ferramenta oferece apenas simulações relacionadas ao funcionamento dos blocos FOUNDATION Fieldbus. O crescimento desta ferramenta pode ir desde a criação de simulações de devices e de configuradores até a criação de simulações para outros protocolos fieldbus. Outro ponto importante a ser destacado para o melhoramento do FBSIMU é a implementação de algoritmos otimizados com o objetivo de melhorar a performance da ferramenta e permitir que mais instâncias sejam abertas e executadas de maneira paralela em uma única máquina.

Com o objetivo de evitar problemas de concorrência relacionados ao arquivo fbsimu.ini (detalhado no item 3.3.1, página 68), uma adaptação deste arquivo para um banco de dados faz parte de planos futuros sobre este sistema.

Por fim, outra possibilidade é a criação de acessos remotos a plantas reais também através deste portal. Neste caso, a restrição de segurança necessária limitaria a execução de alguns testes aos alunos possibilitando, entretanto, uma idéia mais real do funcionamento dos protocolos fieldbus. 



\section{Referências Bibliográficas}

ABED (2006). Associação Brasileira de Educação a Distância. Disponível em: <http://www2.abed.org.br/noticia.asp?Noticia_ID=93>. Acesso em: 15 ago. 2006.

ADKINS, S.S. (2005). Wake-up call: open source LMS. In: LEARNING Circuits Glossary. (2006). Compiled by Kaplan-Leiserson E. E-Learning Glossary. Disponível em: <www.learningcircuits.org/glossary.html>. Acesso em: 11 ago. 2006.

AKTAN, B. et al. (1996). Distance learning applied to control engineering laboratories. IEEE Transactions on Education, New York, v.39, n.3, p.320-326, Aug.

APACHE HTTP SERVER PROJECT (2006). About. Disponível em: $<$ http://httpd.apache.org/ABOUT_APACHE.html>. Acesso em: 14 fev. 2006.

APKARIAN, J.; DAWES, A. (2000). Interactive control education with virtual presence on the web. In: AMERICAN CONTROL CONFERENCE, 2000, Chicago. Proceedings... Chicago: AACC. v.6, p.3985-3990.

AVILAR (2006). Avilar e-Learning. Disponível em: $<$ http://www.avilar.com/services/quickstart.htm>. Acesso em: 15 fev. 2006.

BERGE, J. (2002). Fieldbus for process control: engineering, operation, and maintenance. Research Triangle Park: ISA Books.

BING, D.; KECK-VOON, L.; HABIB MIR, M.H. (2004). Developing and implementing online laboratory for control engineering education. In: INTERNATIONAL CONFERENCE ON CONTROL, AUTOMATION, ROBOTICS \& VISION, 5., 2004, Kunming, China.

Proceeding... Kunming.

BLACKBOARD (2006). Blackboard academic suite. Disponível em: $<$ http://www.blackboard.com/us/>. Acesso em: 15 fev. 2006.

BRANDÃO, D. (2005). Ferramenta de simulação para projeto, avaliação e ensino de redes fieldbus. Tese (Doutorado). Escola de Engenharia de São Carlos, USP.

BUHLER, D. et al. (2000). The virtual automation lab-web based teaching of automation engineering concepts. In: IEEE INTERNATIONAL CONFERENCE AND WORKSHOP 
ON THE ENGINEERING OF COMPUTER BASED SYSTEMS, 7., 2000, Edinburgh, Scotland. Proceedings... New York: IEEE. p.156-164.

BUTLER, M.; BLASHKI, K. (2003). Creating new distance learning environments from contemporary technologies. In: INTERNATIONAL CONFERENCE ON INFORMATION TECHNOLOGY: research and education, 2003, New Jersey. Proceedings... New York: IEEE. p.635-639.

CARSWELL, L. (1998). The 'Virtual University': toward an internet paradigm?. ACM SIGCSE BULLETIN, New York, v.30, n.3, p.46-50.

CASINI, M.; PRATTICHIZZO, D.; VICINO, A. (2003). E-learning by remote laboratories: a new tool for control education. In: IFAC SYMPOSIUM ON ADVANCES IN CONTROL EDUCATION, 6., 2003, Oulu. Proceedings... Finland. University of Oulu. p.95-1000.

CASTRO, M. et al. (2001). Multimedia design and development for distance teaching of electronics Frontiers. In: ANNUAL FRONTIERS IN EDUCATION CONFERENCE, 31., 2001, Reno. Proceedings... New York: IEEE. v.2, p.F3F-13-18.

(2001). Examples of distance learning projects in the european community. IEEE

Transactions on Education, New York, v.434, n.4, p.406-411, Nov.

CHAN C. C., KWAN R. E CHAN S. F. J. (2002). Learning Control Systems on the Web. International Conference on Computers in Education (ICCE'02) pp.894-895

CISAER (2006). Courses on the internet: survey, analysis, evaluation, recommendation. Disponível em: <http://home.nettskolen.nki.no/\%7Emorten/cisaer/>. Acesso em: 11 ago. 2006.

COHEN, M.S.; ELLIS T.J. (2001). Teaching technology in an online, distance education environment. In: ANNUAL FRONTIERS IN EDUCATION CONFERENCE, 31., 2001, Reno. Proceedings... New York: IEEE. T1F-1-T1F-6.

COPINGA, G.J.C. et al. (2001). A web-based study support environment for systems and control courses. In: AMERICAN CONTROL CONFERENCE, 2001, Arlington.

Proceedings... Arlington“IEEE. v.2, p.1155-1160.

COSTAS, R. (2006). Já vale a pena fazer pós a distância. Veja, São Paulo, ano 39, n.1943, p.94-95, fev. 
CUNHA, M. J. (2004) Desenvolvimento e implementação de uma ferramenta computacional aplicada no processo de identificação de sistemas em ambientes Fieldbus Foundation. 81p. Dissertação (Mestrado) . Escola de Engenharia de São Carlos, Universidade de São Paulo, São Carlos. 2004.

DALL’OGLIO, P. (2004). PHP-GTK: criando aplicações gráficas com PHP. São Paulo: Novatec.

DANIELS, M., DAVIES, G., GAL-EZER, J., PETRE, M., \& TEAGUE, J. (1997). Teaching Computing at a Distance. Presentation at the IEEE Frontiers in Education 1997 Conference: Teaching and Learning in an Era of Change, Pittsburgh.

DEMING, L.H. (2001). The rhetoric of distance learning. In: IEEE INTERNATIONAL PROFESSIONAL COMMUNICATION CONFERENCE, 2001, Santa Fe, NM.

Proceedings... New York: IEEE. p.305-311.

EASYPHP (2006). Apache I MySQL I PHP I PhpAdmin. Disponível em: <http://www.easyphp.org/>. Acesso em: 14 fev. 2006.

EBERHARDT, R. (1998). An interactive multimedia distance learning system using distributed-object computing technology. In: IEEE GLOBAL TELECOMMUNICATIONS CONFERENCE, 1998, Sydney. The Bridge to Global Integration. New York: IEEE. v.3, p.1568-1573.

EDUTOOLS (2006). EduTools Homepage. Disponível em: < http://www.edutools.com>. Acesso em: 26 Jun. 2006.

EXEL, M. et al. (2000). Simulation workshop and remote laboratory: two web-based training approaches for control. In: AMERICAN CONTROL CONFERENCE, 2000, Chicago.

Proceedings... Chicago: AACC. v.5, p.3468-3472.

FIELDBUS CENTER (2006). Foundation fieldbus. Disponível em:

$<$ http://www.knowthebus.org/fieldbus/foundation.asp>. Acesso em: 14 fev. 2006.

FIELDBUS FOUNDATION (1999a). FF-800-1.4: foundation specification system architecture. Austin. (1999b). FF-890-1.3: foundation specification function block application process, part 1. Austin. 
FIELDBUS FOUNDATION ONLINE (2006). Disponível em:

$<$ http://www.fieldbus.org/About/>. Acesso em: 21 jun. 2006.

FREE SOFTWARE FOUNDATION (2006). Disponível em: < https://www.fsf.org/>. Acesso em: 21 jun. 2006.

GAL-EZER, J. et al. (1997). Teaching computing at a distance. In: ASEE/IEEE FRONTIERS IN EDUCATION CONFERENCE, 1997, Pittsburgh. Proceedings... New York: IEEE. Session F4D, panel.

HALL, B. (2001). Getting Up to Speed on Learning Management Systems. Sunnyvale: Brandon Hall.

HECH, B.S.; POINDEXTER, S.E.; GARCIA, R.C. (2000). Integrating the web into traditional teaching methods. In: AMERICAN CONTROL CONFERENCE, 2000, Chicago. Proceedings... Chicago: AACC. v.5, p.3444-3448.

HPAC ENGINEERING (2006). Networked controls fundamentals. Disponível em: <http://www.hpac.com/microsites/networkedcontrols/newmanf_0105.htm>. Acesso em: 14 fev. 2006.

IBM LOTUS LEARNING (2006). IBM lotus learning management system. Disponível em: <http://www.ibm.com/developerworks/lotus/products/elearning/>. Acesso em: 15 fev. 2006.

ILLYEFALVI-VITEZ, Z. et al. (2005). Analysis of distance learning courses offered by the EuroTraining course directory. In: ELECTRONIC COMPONENTS AND TECHNOLOGY CONFERENCE, 55. 2005, Lake Buena Vista, USA. Proceedings... New York: IEEE. v.2, p.1909-1915.

IMBRIE, P.K.; RAGHAVAN, S. (2005). Work in progress - a remote e-laboratory for student investigation, manipulation and learning. In: ASEE/IEEE FRONTIERS IN EDUCATION CONFERENCE, 35., 2005, Indianapolis. Proceedings... New York: IEEE. p.TR2C-7-T2C-8.

INTERNATIONAL ORGANIZATION FOR STANDARDIZATION. (1994). ISO/IEC 7498-1: Information technology - open systems interconnection - basic reference model: the basic model. Suiça. CD-ROM. 
INTRALEARN (2006). Intralearn suite of e-learning applications. Disponível em: $<$ http://www.intralearn.com/default.asp>. Acesso em: 15 fev. 2006.

IRVINE, S.E.; HEIN, T.L.; LAUGHLIN, D. (1999). Different degrees of distance: the impact of the technology-based instructional environment on student learning. In: ASEE/IEEE FRONTIERS IN EDUCATION CONFERENCE, 29., 1999, San Juan. Proceedings... New York: IEEE. p.13c-7-13c-12.

JONES, D. (1996). Computing by distance education: problems and solutions. In: ANNUAL JOINT CONFERENCE INTEGRATING TECHNOLOGY INTO COMPUTER SCIENCE EDUCATION, 1996, Barcelona. Proceedings... New York: ACM. p.139-146.

KEEGAN, D.; SEWART, D.; HOLMBERG, B. (1988). On defining distance education. Distance Education, Toowoomba, v.1, n.2, p.13-36.

KO, C.C. et al. (2001). Development of a web-based laboratory for control experiments on a coupled tank apparatus. IEEE Transactions on Education, New York, v.44, n.1, p.76-86, Feb.

KOVACIC, B.; SKOCIR, Z. (2003). Development of distance learning system based on dialogue. In: ISA/IEEE REGION 8 - EUROCON 2003: computer as a tool, 2003, Ljubljama. Proceedings... New York: IEEE. v.1, p.224-228.

LAWHEAD, P.B. et al. (1997). The web and distance learning: what is appropriate and what is not. In: ANNUAL JOINT CONFERENCE INTEGRATING TECHNOLOGY INTO COMPUTER SCIENCE EDUCATION, 1997, Uppsda. Proceedings... New York: ACM. p.27-37. Supplement.

LEARNING Circuits Glossary. (2006). Compiled by Kaplan-Leiserson E. E-Learning Glossary. Disponível em: <www.learningcircuits.org/glossary.html>. Acesso em: 11 ago. 2006.

LIOU S., SOELAEMAN H. E LEUNG P. (1999). Distance Learning Power Engineering Laboratory. Submitted to IEEE Computer Applications in Power.

MAIA, C. (2002). Universia Brasil - ferramentas aliadas. Disponível em: $<$ http://www.universia.com.br/materia/materia.jsp?materia=970>. Acesso em: 15 jun. 2006. 
MOODLE (2006). A Free, Open Source Cource Management System for Online

Learning. Disponível em: <http://www.moodle.org/>. Acesso em: 15 ago. 2006.

MORCOS, M.M.; SOLDAN, D.L. (2001). Supporting distance engineering education is greatly needed. In: LARGE ENGINEERING SYSTEMS CONFERENCE ON POWER ENGINEERING, 2001, Halifax. Proceedings... New York: IEEE. p.69-72.

MYSQL AB (2006). The world's most popular open source database. Disponível em: $<$ http://www.mysql.com/>. Acesso em: 15 ago. 2006.

NETCRAFT (2006). Web Server Survey. Disponível em: < http://news.netcraft.com/>. Acesso em: 15 ago. 2006.

NG, S.C. et al. (1999). Learn@ Net: an integrated multimedia system for distance learning. In: INTERNATIONAL CONFERENCE ON COMPUTATIONAL INTELLIGENCE AND MULTIMEDIA APPLICATIONS, 3., 1999, New York. Proceedings... New York: IEEE. p.479-483.

OPEN TEXT CORPORATION (2006). FirstClass division. Disponível em: $<$ http://www.centrinity.com/>. Acesso em: 22 fev. 2006.

PAHWA, A. et al. (2005). Distance learning for power professionals: virtual classrooms allow students flexibility in location and time. IEEE Power and Energy Magazine, New York, v.3, n.1, p.53-58, Jan./Feb.

PASCHOAL JÚNIOR, F. Desenvolvimento de um weblab para experimentos remotos em fotônica integrado a um ambiente virtual de ensino-aprendizagem. 2006. Dissertação (Mestrado em Engenharia Elétrica) - Universidade Presbiteriana Mackenzie.

PAULSEN, M.F. (2003). Online education and learning management systems-global elearning in a scandinavian perspective. Disponível em:

<http://www.studymentor.com/studymentor/>. Acesso em: 10 set. 2006.

PHP GROUP (2006). Disponível em: < http://www.php.net//>. Acesso em: 14 fev. 2006.

PINOTTI JÚNIOR, M.; BRANDÃO, D. (2001). Projecting and integrating fieldbus foundation function blocks. In: ISA/IEEE CONFERENCE SENSOR FOR INDUSTRY, 2001, Rosemont. Proceedings... New York: IEEE. CD-ROM. 
POINDEXTER, S.E; HECK, B.S. (1999). Using the web in your courses: what can you do? What should you do?. IEEE Control System Magazine, New York, v.19, n.1, p.83-92, Feb.

QINGCANG,Y.U.; CHEN, B.; CHENG, H.H. (2004). Web based control system design and analysis. IEEE Control Systems Magazine, New York, v.24, n.3, p.45-57, June.

SÁNCHEZ, J. et al. (2002). Virtual control lab using Java and Matlab: a qualitative approach. IEEE Control Systems Magazine, New York, v.22, n.2, p.8-20, Apr.

SCHMID, C.; ALI, A. (2000). A web-based system for control engineering education. In: AMERICAN CONTROL CONFERENCE, 2000, Chicago. Proceedings... Chicago: AACC. p.3463-3990.

SELLAMI, H.M. (2005). Some difficulties in distance learning in developing countries. In: INTERNATIONAL CONFERENCE ON ADVANCED LEARNING TECHNOLOGIES, 6 , 2006, Kerkrade. Proceedings... New York: IEEE. p.133-135.

SHIH, T.K.; LIN, N.H.; CHANG, H.P. (2003). An intelligent e-learning system with authoring and assessment mechanism. In: INTERNATIONAL CONFERENCE ON ADVANCED INFORMATION NETWORKING AND APPLICATIONS, 17., 2003, Xi'an, China. Proceedings... New York: IEEE. p.782-787.

SIDDIQUI, K.J.; ZUBAIRI, J.A. (2000). Distance learning using web-based multimedia environment. In: ACADEMIA/ INDUSTRY WORKING CONFERENCE ON RESEARCH CHALlENGES, 2000, Buffalo. Proceedings... New Yor: IEEE. p.325-330.

SITE GROUND (2006). Drupal tutorial. Disponível em: <http://www.siteground.com/tutorials/drupal-tutorial/>. Acesso em: 14 fev. 2006.

SPANIAS, A. et al. (2000). Development and evaluation of a web-based signal and speech processing laboratory for distance learning. In: IEEE INTERNATIONAL ON ACOUSTICS, SPEECH, AND SIGNAL, 2000, Istanbul. Proceedings... New York: IEEE. v.6, p.35343537.

TAYLOR, K.D.; HONCHELL, J.W.; DEWITT, W.E. (1996). Distance learning in courses with a laboratory. In: ANNUAL CONFERENCE OF FRONTIERS IN EDUCATION, 26., 1996, Salt Lake City. Proceedings... New York: IEEE. v.1, p.44-46.

TELEDUC (2006). Ambiente de ensino a distância. Disponível em: $<$ http://hera.nied.unicamp.br/teleduc/>. Acesso em: 14 fev. 2006. 
THOMESSE, J.P. (2005). Fieldbus technology in industrial automation. Proceedings of IEEE, New York, v.93, n.6, p.1073-1101, June.

TIPSUWAN, Y. E CHOW, M. (2003). Control methodologies in networked controle systems. Control Engineering Practice, pp.1099-1111.

TOOLBOOK BY SUMTOTAL (2006). The leading authoring for developing efficient elearnig. Disponível em: <http://www.toolbook.com/>. Acesso em: 14 fev. 2006.

TSANG, H.W.; HUNG, L.M.; NG, S.C. (1999). A multimedia distance learning system on the internet. In: IEEE INTERNATIONAL CONFERENCE ON SYSTEMS, MAN, AND CYBERNETICS, 1999, Tokyo. Proceedings... New York: IEEE. v.2, p.243-246.

UNIVERSIDADE DE SÃO PAULO. Centro de Computação Eletrônica (2006). Serviços: apoio ao ensino. Disponível em:

$<$ http:www.usp.br/cce/serviços/ensino.php?source=213\&PHPSESSID=3cdcfca72352b3188ac faec135cd0120>. Acesso em: 30 fev. 2006.

VIEDMA, G.; DANCY, I.; LUNDBERG, K. (2005). A web-based linear-systems iLab. In: AMERICAN CONTROL CONFERENCE, 2005, Natal. Proceedings... Portland: [S.1.].

WEBCT (2006). WebCT e-Learning system. Disponível em:

$<$ http://www.webct.com/entrypage>. Acesso em: 15 fev. 2006.

ZHANG, Y. (1999). Web database step-by-step guide. Disponível em: $<$ http://www.mmg.tu-sofia.bg/ebooks/PHP-ASP-webatabaseguide.pdf\#search=\%22Web\%20database\%20step-by-step\%20guide\%22>. Acesso em: 14 set. 2006.

ZEILMANN, R.P. et al. (2003). Web-based control experiments on a FOUNDATION Fieldbus pilot plant. In: IFAC INTERNATIONAL CONFERENCE ON FIELDBUS AND THEIR APPLICATIONS, 5., 2003, Aveiro. Proceedings... Oxford: Elsevier. p.323-328. 
Anexo A

ANEXO A - Descrição detalhada do FBSIMU 
Antes de entrar em detalhes de como o FBSIMU foi desenvolvido e quais as bibliotecas de trabalho o mesmo possui, uma breve descrição relacionada ao funcionamento dos blocos do FOUNDATION fieldbus é feita.

As informações deste anexo foram retiradas de BRANDÃO (2005).

\section{Bloco Funcional}

A norma do protocolo FOUNDATION fieldbus descreve conjuntos de blocos funcionais padrão básicos, avançados, de múltiplo I/O e um bloco funcional flexível. (Tais conjuntos são listados no quadro a seguir, bem como os parâmetros universais utilizados nos blocos funcionais e uma classificação de blocos funcionais segundo o tipo de função que executam). Tal descrição é apresentada na norma de modo a permitir a extensão de definições na medida em que novos requisitos se façam necessários com o avanço da tecnologia de instrumentação e de controle de processos.

\begin{tabular}{llll}
\hline \multicolumn{1}{c}{ Blocos Funcionais Básicos } & \multicolumn{1}{c}{$\begin{array}{c}\text { Blocos Funcionais } \\
\text { Avançados }\end{array}$} & $\begin{array}{c}\text { Blocos Funcionais de } \\
\text { Múltiplo I/O }\end{array}$ & $\begin{array}{c}\text { Bloco Funcional } \\
\text { Flexível }\end{array}$ \\
\hline AI - Entrada analógica & DC - Controle de & MDI - Entradas digitais & FFB - Bloco \\
dispositivo & múltiplas & Funcional Flexível \\
DI - Entrada discreta & OS - Divisor de saída & mDO - Saídas digitas & \\
AO - Saída analógicas & SC - Caracterizador de & MAI - Entradas & \\
& sinais & analógicas múltiplas & \\
DO - Saída discreta & LL - Lead lag & MAO - Saídas & \\
& analógicas múltiplas & \\
ML - Carregador manual & DT - Deadtime & & \\
BG - Bias / Ganho & IT - Integrador & & \\
& (Totalizador) & & \\
CS - Seletor de controle & SPG - Gerador de rampa & & \\
& de referência & & \\
PD - Controlador proporcional & ISEL - Seletor de entradas & & \\
derivativo & & & \\
PID - Controlador proporcional & AR - Aritmético & & \\
\hline
\end{tabular}


integral derivativo

RA - Controle de relação

TMR - Timer

AALM - Alarme

analógico

Conjuntos de blocos funcionais normalizados

Conforme citado anteriormente, o bloco funcional ou function block (FB) é uma função de automação básica realizada por uma aplicação, projetado de modo a torná-lo independente do meio físico e da estrutura da rede. Os blocos funcionais processam parâmetros de entrada em função da sua configuração e assim geram saídas que serão utilizadas por outros blocos. A norma os classifica em:

- Blocos de Entrada: acessam medidas físicas através da comunicação com blocos transdutores de entrada por meio de canais. Estas medidas são então convertidas, linearizadas e disponibilizadas para outros blocos funcionais através dos parâmetros de saída;

- Blocos de Saída: acionam blocos transdutores de saída pelos canais a partir de um valor recebido pelos links com outros blocos nos seus parâmetros de entrada;

- Blocos de controle: realizam cálculos com parâmetros de blocos de entrada e enviam parâmetros para outros blocos de controle ou para blocos de saída;

- Blocos de Cálculo: realizam cálculos matemáticos sobre parâmetros de entrada, gerando parâmetros de saída.

O modelo representado na figura a seguir é definido por norma para representar um bloco funcional. 


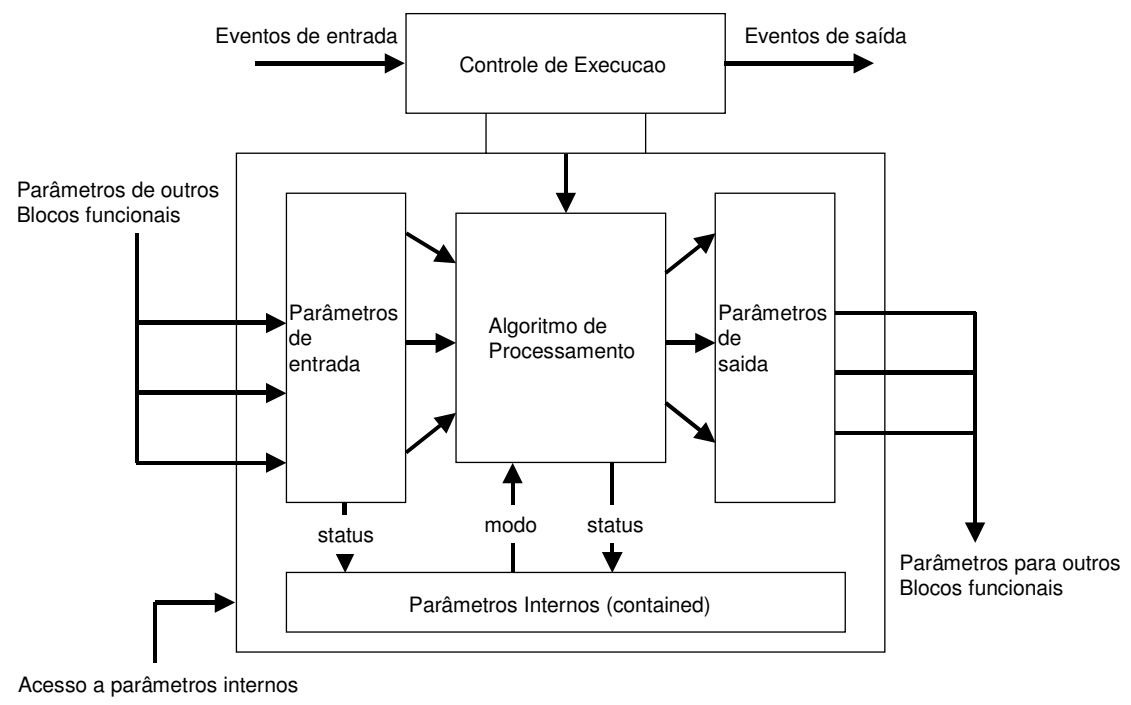

Representação da atividade de blocos funcionais Fonte: Norma Fieldbus Foundation

Com referência na figura, os valores dos parâmetros de entrada são coletados de outros blocos funcionais e retidos pelo bloco em questão assim que sua execução é iniciada. Este processo garante que os parâmetros de entrada tenham coerência temporal e que não sejam alterados durante a execução do bloco funcional por fontes externas. Caso novos parâmetros de entrada sejam recebidos após este momento inicial, eles não serão utilizados durante a execução em processo no bloco.

No momento em que os parâmetros de entrada são retidos, a execução do bloco funcional tem início. O algoritmo do bloco operando então sobre os parâmetros de entrada produz parâmetros de saída. A execução do algoritmo é controlada por uma série de parâmetros "contained", ou internos, os quais não podem ser transmitidos entre blocos funcionais como parâmetros de entrada e de saída, mas podem ser acessados e modificados remotamente. Alguns eventos externos, da mesma forma, podem afetar a execução do algoritmo.

Após o término da execução do algoritmo, os dados internos do bloco são salvos para serem utilizados na próxima execução, e os parâmetros de saída são disponibilizados para outros blocos funcionais. 
Além dos parâmetros que podem ser acessados pela rede, existem variáveis internas que não podem ser acessadas por nenhuma estrutura ou função externa, como o algoritmo interno do bloco funcional, sendo suas especificações definidas pelo próprio fabricante, já que não existe orientação a este respeito na norma.

Em cada uma de suas instâncias, um bloco funcional é identificado por seu tipo e por um nível de revisão, ou versão. Com estas especificações é possível identificar seu conjunto de parâmetros e as características de execução de seu algoritmo.

A execução de um bloco funcional se dá em resposta a um evento, o qual pode ter diversas naturezas:

- Escalonado: no qual a taxa de execução do bloco funcional é definida segundo uma tabela de agendamento. (O instante em que cada bloco funcional tem sua execução iniciada é definido nesta tabela);

- Término da execução de outro bloco: quando o início da execução de um bloco funcional pode estar atrelado ao término da execução de outro bloco funcional pertencente ao mesmo dispositivo;

- Específico do fabricante.

A interoperação de blocos funcionais se dá pelo estabelecimento de uma ligação lógica entre um parâmetro de saída de um bloco e um parâmetro de entrada de outro bloco. Tal ligação pode ser estabelecida local, entre blocos de um mesmo dispositivo, ou remotamente, entre blocos de dispositivos distintos.

A capacidade de interconexão entre blocos aliada a um plano temporal de seqüência de execução de cada bloco em seu respectivo dispositivo permite a configuração de malhas de controle distribuídas em tempo real nos dispositivos sincronizados de uma rede fieldbus, como representa a figura a seguir. 


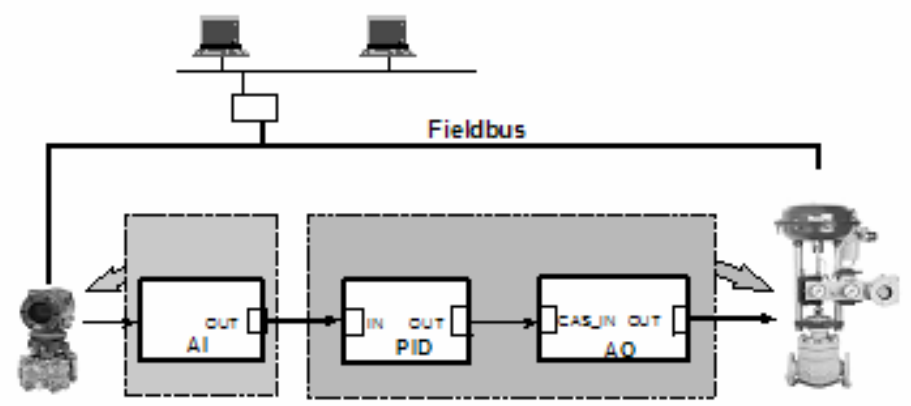

Malha de controle distribuída

Quando todos os blocos funcionais de uma malha de controle são executados e são efetuadas todas as interconexões estabelecidas entre eles, a malha de controle é completamente executada.

\section{Parâmetros de configuração}

Cada parâmetro, variável ou variáveis que controla(m) e regula(m) a operação de um bloco funcional, é caracterizado por:

- Nome ou mnemônico;

- Tipo de dado: a norma Fieldbus Foundation especifica um conjunto de tipos padrão de dados indexados para parâmetros de blocos funcionais. Cada parâmetro pode ser do tipo variável simples ou do tipo estrutura de dado, nos casos em que reúne duas ou mais variáveis simples. O quadro a seguir lista os tipos de dados da norma:

\begin{tabular}{lll}
\hline Índice & Tipo & Nome \\
\hline 1 & Variável simples & Booleano \\
2 & Variável simples & Inteiro (8) \\
3 & Variável simples & Inteiro (16) \\
4 & Variável simples & Inteiro (32) \\
5 & Variável simples & Unsigned (8) \\
6 & Variável simples & Unsigned (16) \\
7 & Variável simples & Unsigned (32) \\
8 & Variável simples & Ponto flutuante \\
9 & Variável simples & String visível \\
10 & Variável simples & String de octetos \\
11 & Variável simples & Data \\
\hline
\end{tabular}




\begin{tabular}{|c|c|c|}
\hline 12 & Variável simples & Horário do dia \\
\hline 13 & Variável simples & Diferença de horário \\
\hline 14 & Variável simples & String de bits \\
\hline 21 & Variável simples & Valor de tempo \\
\hline 64 & Estrutura & Bloco \\
\hline 65 & Estrutura & Valor \& Status - Ponto flutuante \\
\hline 66 & Estrutura & Valor \& Status - Discreto \\
\hline 67 & Estrutura & Valor \& Status - String de bits \\
\hline 68 & Estrutura & Escala \\
\hline 69 & Estrutura & Modo \\
\hline 70 & Estrutura & Permissão de Acesso \\
\hline 71 & Estrutura & Alarme - Ponto Flutuante \\
\hline 72 & Estrutura & Alarme - Discreto \\
\hline 73 & Estrutura & Evento - Atualização \\
\hline 74 & Estrutura & Alarme - Sumário \\
\hline 75 & Estrutura & Alerta - Analógico \\
\hline 76 & Estrutura & Alerta - Discreto \\
\hline 77 & Estrutura & Alerta - Atualização \\
\hline 78 & Estrutura & Tendência - Ponto flutuante \\
\hline 79 & Estrutura & Tendência - Discreto \\
\hline 80 & Estrutura & Tendência - String de bits \\
\hline 81 & Estrutura & FB Link \\
\hline 82 & Estrutura & Simulação - Ponto flutuante \\
\hline 83 & Estrutura & Simulação - Discreto \\
\hline 84 & Estrutura & Simulação - String de bits \\
\hline 85 & Estrutura & Teste \\
\hline 86 & Estrutura & Ação - Instanciação e apagamento \\
\hline
\end{tabular}

- Tipo de uso: parâmetros de entrada, de saída ou internos;

- Modo de armazenamento: dinâmico, estático e não-volátil;

Parâmetros dinâmicos são aqueles calculados pelo algoritmo do bloco, logo não precisam ser recuperados após uma falha por queda de energia, por exemplo.

Parâmetros estáticos são os dados configurados que precisam ser salvos em memória não-volátil no caso de uma falha por queda de energia. Normalmente os parâmetros estáticos 
são periodicamente verificados pelo configurador e eventualmente atualizados pelo mesmo. Para auxiliar na tarefa de monitorar os parâmetros estáticos, um parâmetro numérico denominado $S T \_R E V$ (revisão estática) é incrementado e um evento é gerado sempre que um parâmetro estático for modificado.

Os parâmetros não voláteis são aqueles constantemente atualizados e que devem ser salvos em razão do risco de queda de energia do equipamento. Por estes parâmetros apresentarem constantes modificações, não são verificados por configuradores, como no caso dos parâmetros estáticos.

- Tamanho, em bits;

- Faixa válida: conjunto de possíveis valores que o parâmetro pode assumir;

- Valor inicial;

- Direção: no caso de parâmetros de entrada e de saída, a direção indica se o parâmetro é enviado em links no sentido direto ou contrário ao fluxo à malha de controle;

- Unidade, de engenharia;

- Permissão: regras que definem quais dispositivos externos podem modificar cada parâmetro;

- Modo: modos de operação do bloco funcional nos quais o parâmetro pode ser modificado.

Vinculado aos parâmetros de entrada e saída há um byte de status que se encarrega de indicar a qualidade do valor da variável. Este status é composto por três partes: qualidade, sub-status e limite. A informação de qualidade pode ser:

- Good (Cascade) - quando o dado é confiável e pode ser utilizado em malhas de controle do tipo cascata, aquelas na quais o Setpoint é remoto; 
- Good (Non-Cascade) - quando a qualidade do dado é boa, porém o bloco não pode fazer parte de uma estrutura cascata.;

- Uncertain - neste caso, a qualidade do dado é duvidosa, pode ter ocorrido erro na aquisição ou em cálculos;

- Bad - quando o dado não é válido e não deve ser utilizado.

A figura a seguir mostra a composição do byte de status.

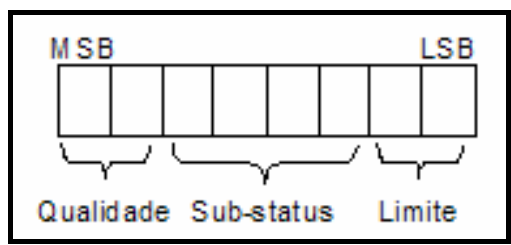

Composição do byte de status

O sub-status é uma informação complementar à da qualidade. É utilizada em alarmes e no início ou finalização de malhas de controle de tipo cascata. O limite informa se o valor é limitado ou não, ou seja, se este foi restringido por extrapolar valores pré-determinados.

A execução do algoritmo do bloco depende de vários fatores, entre eles, de eventos externos e dos valores e status dos parâmetros de entrada e de configuração. Em função destas variáveis, o bloco pode executar seu algoritmo em diferentes modos. Cada modo de execução do bloco impõe características ao algoritmo que influem nas saídas e nos status. A seguir estão descritos os oito modos possíveis de operação dos blocos funcionais:

- Out of Service (OOS): o algoritmo do bloco não é executado;

- Initialization Manual (Iman): o algoritmo não é executado e as saídas do bloco seguem um parâmetro externo vindo do bloco que está ligado em seqüência no fluxo direto;

- Local Override (LO): as saídas do bloco de controle seguem um parâmetro externo.

Este modo é executado em situações de falha; 
- Manual (Man): As saídas do bloco não são calculadas, o operador é quem as configura;

- Automatic (Auto): o algoritmo é executado normalmente e está calculando as saídas;

- Cascade (Cas): o setpoint vem de outro bloco por um link, desta forma o operador não pode atuar diretamente sobre ele;

- Remote Cascade (Rcas): o setpoint vem por um link de outra aplicação de controle remota em um dispositivo de interface;

- Remote-Output (Rout): as saídas do bloco funcional são modificadas por uma outra aplicação de controle remota em um dispositivo de interface.

O parâmetro $M O D E \_B L K$ indica e controla o modo de operação dos blocos funcionais. Este parâmetro é do tipo estrutura, composto por quatro elementos:

- Target: é o modo de operação almejado. Normalmente o target é definido pelo operador;

- Actual: é o modo em que o bloco está sendo executado efetivamente.

- Permitted: são os possíveis modos de operação que o bloco pode apresentar;

- Normal: lista os modos normais de operação do bloco dentre aqueles listados no permitted. Serve para indicar ao operador o momento da seleção do target.

\section{Bloco Transdutor}

Os blocos transdutores são blocos funcionais que ficam entre os blocos de $\mathrm{I} / \mathrm{O}$ e o hardware de I/O. São, portanto, encarregados de transformar sinais físicos em variáveis e vice-versa. Eles isolam os blocos funcionais dos dispositivos e hardware específicos de I/O como sensores, atuadores e chaves de cada dispositivo. Seus algoritmos internos controlam os dispositivos de I/O e apresentam uma interface padronizada para os blocos funcionais, 
realizam também funções como calibração, filtragem de sinais e conversão de dados. Os blocos transdutores seguem definições da norma que os agrupam em "comuns" ou "profiles", embora também possam ser de um tipo particular definido pelo fabricante.

A comunicação entre blocos transdutores e blocos funcionais de entrada ou de saída é realizada através de canais, mapeados em parâmetros CHANNEL, sendo que um bloco transdutor pode ter vários canais. Uma vantagem deste isolamento do bloco funcional em relação ao hardware é a possibilidade da execução inexaurível do bloco transdutor no processamento de um dado de boa qualidade sem o prejuízo de sobrecarregar os blocos funcionais.

Os blocos transdutores são classificados em três tipos:

- Input - os que realizam a interface com sensores;

- Output - os que realizam a interface com atuadores ou dispositivos de saída;

- Display - aqueles que operam dispositivos de interface locais.

Os blocos transdutores não possuem parâmetros de entrada e de saída e sua execução não é comandada por escalonamento, mas definida pelo fabricante.

\section{Bloco de Recurso}

As características de hardware do dispositivo estão descritas nos parâmetros de configuração de um bloco de recurso. Tal qualidade desatrela os blocos funcionais das características de hardware dos dispositivos.

O algoritmo do bloco de recurso é utilizado para monitorar o estado de operação do hardware e indicar possíveis alarmes neste aspecto. 
A execução do bloco de recurso, assim como a do bloco transdutor, não é escalonada, portanto este bloco não possui parâmetros de entrada ou de saída. Tal execução segue regras que são definidas pelo fabricante.

\section{FBSIMU}

Uma rede industrial de instrumentos de campo é composta por diversos elementos, como estações de controle, estações de supervisão, sensores, atuadores e fontes. Tais instrumentos são conectados por um canal de comunicação serial e digital, no qual um protocolo de comunicação específico é utilizado para troca de dados e de variáveis, possibilitando, assim, a comunicação dos dispositivos com o objetivo de realizar uma tarefa de controle e de supervisão de um determinado processo ou equipamento industrial.

Este tipo de sistema de controle pode ser classificado como digital distribuído, pois, além de ser baseado em instrumentos digitais microprocessados, todo o processamento das tarefas é distribuído entre diversos dispositivos ou transmissores dotados de capacidade de processamento digital de dados.

O FBSIMU, Fieldbus Foundation Function Block Simulator, é uma plataforma de desenvolvimento e simulação de redes fieldbus com foco na camada de aplicação de blocos funcionais de estrutura modular e escalonável, composto somente por software. Cada módulo ou unidade de software do FBSIMU simula um elemento ou estrutura de um fieldbus real.

O FBSIMU foi concebido e programado baseando-se nas especificações da Foundation Fieldbus e foi desenvolvido no ambiente LabView através da linguagem de programação gráfica $\mathrm{G}$, nativa deste ambiente.

O quadro da figura 34 relaciona os módulos que constituem a plataforma do FBSIMU desenvolvido: 


\begin{tabular}{ccl}
\hline Módulo & Tipo de Módulo & \multicolumn{1}{c}{ Função } \\
\hline BasicBlock & $\begin{array}{c}\text { Biblioteca de } \\
\text { funções }\end{array}$ & $\begin{array}{l}\text { Biblioteca de funções normalizadas componentes de blocos } \\
\text { funcionais. }\end{array}$ \\
\hline BasicOp & $\begin{array}{c}\text { Biblioteca de } \\
\text { funções }\end{array}$ & $\begin{array}{l}\text { Biblioteca de funções e operações lógicas e matemáticas } \\
\text { utilizadas em algoritmos característicos dos blocos funcionais. }\end{array}$ \\
\hline Plant & Módulo Principal & $\begin{array}{l}\text { Módulo que simula a dinâmica do processo a ser controlado } \\
\text { seja este monovariável ou multivariável. }\end{array}$ \\
\hline ProcessBlock & Módulo Secundário & $\begin{array}{l}\text { Módulo que simula um bloco funcional destinado a ser } \\
\text { operado remotamente }\end{array}$ \\
\hline AnandAloneBlock & Módulo Principal & $\begin{array}{l}\text { Módulo que simula um bloco funcional isoladamente, com } \\
\text { interface de programação e de operação. }\end{array}$ \\
\hline FBSIMUConf & Módulo Principal & $\begin{array}{l}\text { Módulo que analisa a comunicação em um barramento de } \\
\text { dados de uma rede fieldbus real }\end{array}$ \\
\hline Módulo Principal & $\begin{array}{l}\text { Módulo de interface de configuração remota } \\
\text { comunicação) para módulos ProcessBlock. }\end{array}$ \\
\hline
\end{tabular}

Módulos do software FBSIMU

Os módulos listados são classificados como principais, secundários ou como biblioteca de funções.

Cada módulo classificado como principal, embora possa ser operado independentemente, tem a possibilidade de se comunicar com outros módulos. Os módulos ProcessBlock são classificados como secundários por operarem como sub-programas de módulos principais, não podendo ser operados independentemente.

As bibliotecas de funções do FBSIMU são conjuntos de rotinas de funções correlatas freqüentemente utilizadas na construção de módulos principais e secundários. As funções das bibliotecas foram especialmente desenvolvidas para a construção do simulador e simulam as tarefas típicas de uma rede de campo Foundation Fieldbus.

A seguir, a descrição de cada módulo que compõe a plataforma.

\section{Biblioteca BasicOp}

BasicOp (operações básicas) foi elaborada como uma biblioteca de funções elementares de processamento e tratamento de dados utilizados em tarefas de malhas de controle, blocos funcionais ou monitoramento de parâmetros típicas de um sistema Foundation Fieldbus. 
Cada função da biblioteca constitui um VI (Virtual Instrument), arquivo de programa na linguagem $\mathrm{G}$ do LabView, com variáveis de entrada e de saída que podem ser incluídas em qualquer módulo da plataforma FBSIMU na forma de uma Sub-VI, ou seja, um subprograma, ou uma função.

O quadro da figura a seguir lista as funções que compõem a biblioteca BasicOp:

\begin{tabular}{ll}
\hline & Funções \\
\hline ArrayOp & GrantDeny \\
BitStringByteToEnum & InStatus \\
BitStringByteToListbox & LaunchDSServer \\
BlockExecMonit & ListboxToBitstringByte \\
BlockMonitOtherStatic & OutStatus \\
BlockViewDesc & ReadLog \\
CascadeInit & SelectFrom2DTable \\
ConfigDataForConf & SelectFrom2DTablePopup \\
EditBooleanPopup & SelectFromEnumPopup \\
EditFloatPopup & SelectFromTableFBlockPopup \\
EditIntegerPopup & SelectFromTablePopup \\
EditLinkReleaseTimePopup & SelectLinkPopup \\
EditMacrocyclePopup & ShutdownDSServer \\
EditReleaseTimePopoup & StatusPropagation \\
EditScheduleTablePopup & StRev\&UpEvtActionNumber \\
EditStringPopup & StRev\&UpEvtActionString \\
EditTagPopup & ViewElementBuildDecimal \\
EditUnsignedPopup & ViewElementBuildEnum \\
Enumandler & ViewElementBuildFractional \\
EnumToBitstringByte & ViewElementBuildString \\
\hline & \\
\hline
\end{tabular}

Funções da biblioteca BasicOp

\section{Biblioteca BasicBlock}

Esta biblioteca contém funções que constituem os elementos de processamento dos blocos funcionais, segundo a representação esquemática da norma Fieldbus 
Foundation. São funções de nível de programação mais alto em relação às funções BasicOp, e deste modo, utilizam estas últimas nos seus algoritmos.

A norma Fieldbus Foundation representa os algoritmos internos dos blocos funcionais com uma estrutura modular, conforme representado na figura a seguir.

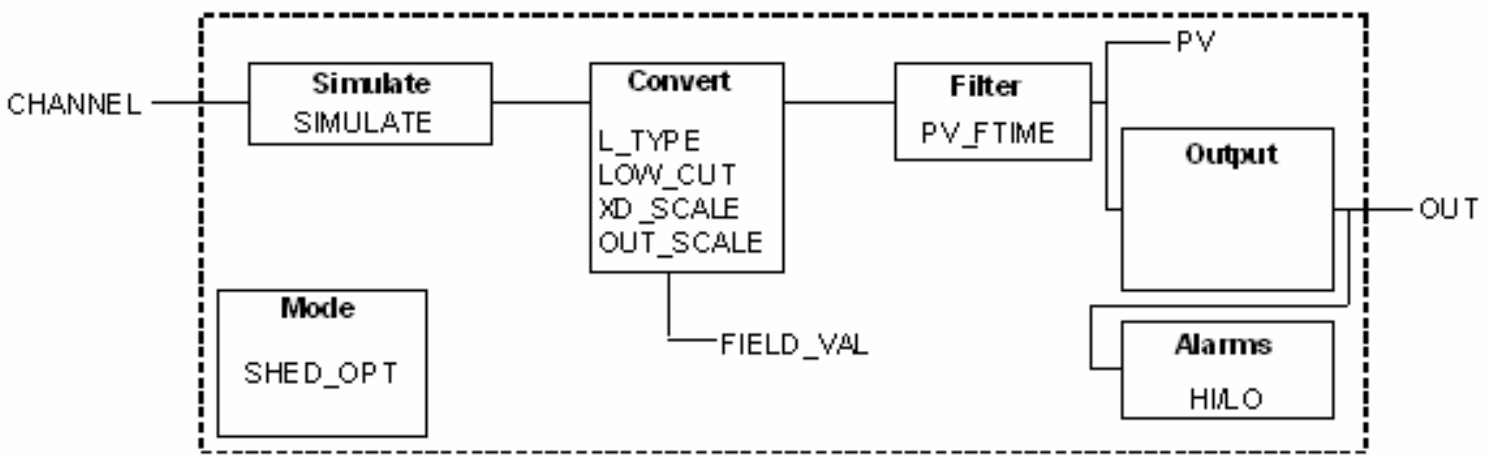

Representação esquemática do bloco funcional AI - Analog Input

Fonte: Norma Fieldbus Foundation

Nesta representação, as funções da biblioteca BasicBlock correspondem aos elementos de processamento encapsulados (indicados na norma por um nome, por exemplo, Simulate, Convert, Filter, Output, Alarms e Mode). Tais elementos possuem entradas, saídas e parâmetros de configuração envolvidos no processamento (por exemplo, SIMULATE, L_TYPE e SHED_OPT).

As funções da biblioteca BasicBlock são destinadas ao uso em blocos funcionais, e, devido à padronização de tais funções pela norma, podem ser reutilizadas em mais de um bloco funcional pelo fato de alguns desses blocos funcionais compartilharem as mesmas funções e processamentos padronizados. Um exemplo deste compartilhamento é a função de alarme: todos os blocos funcionais que utilizam alarme têm esta função padronizada (em parâmetros e processamento) e, deste modo, a função Alarme da biblioteca BasicBlock serve a todos estes blocos funcionais. 
As funções da BasicBlock, tal como as funções da biblioteca BasicOp, são encapsuladas em VIs com entradas e saídas e utilizadas como sub-Vis, ou sub-rotinas, de outros módulos do FBSIMU.

A especificação da Fieldbus Foundation em relação aos blocos funcionais padrão do tipo básico descreve um total de dezenove elementos no nível da biblioteca BasicBlock, listados no quadro figura a seguir, que compõem os dez blocos padrão básicos.

\begin{tabular}{lc}
\hline & Elementos \\
\hline Simulate & Selection \\
Convert & Back Calc \\
Filter & Bypass \\
Output & Control \\
Alarm & Feed Forward \\
Mode & Status \\
Optional Invert & Ratio \\
Output Track & Calc PV \\
Setpoint & Fail Safe \\
Bias \& Gain & \\
\hline
\end{tabular}

Elementos de processamento utilizados nos blocos funcionais padrão básicos

\section{Módulo AnalyseFFData}

O módulo AnalyseFFData do FBSIMU tem a função de analisar a comunicação em um barramento de dados de uma rede fieldbus real e, a partir de procedimentos matemáticos e estatísticos, encontrar valores para algumas variáveis e parâmetros da camada de enlace que regulam o processo de comunicação em tal barramento de dados.

A comunicação serial no barramento fieldbus é captada por meio de um dispositivo eletrônico conversor de sinais (modem). Este dispositivo converte em tempo real os bytes lidos no barramento, codificados segundo a norma Foundation Fieldbus H1 para sinais seriais 
no padrão RS-232 que são lidos pela porta serial de computadores do tipo PC (Personal Computer), conforme o arranjo experimental da figura a seguir.

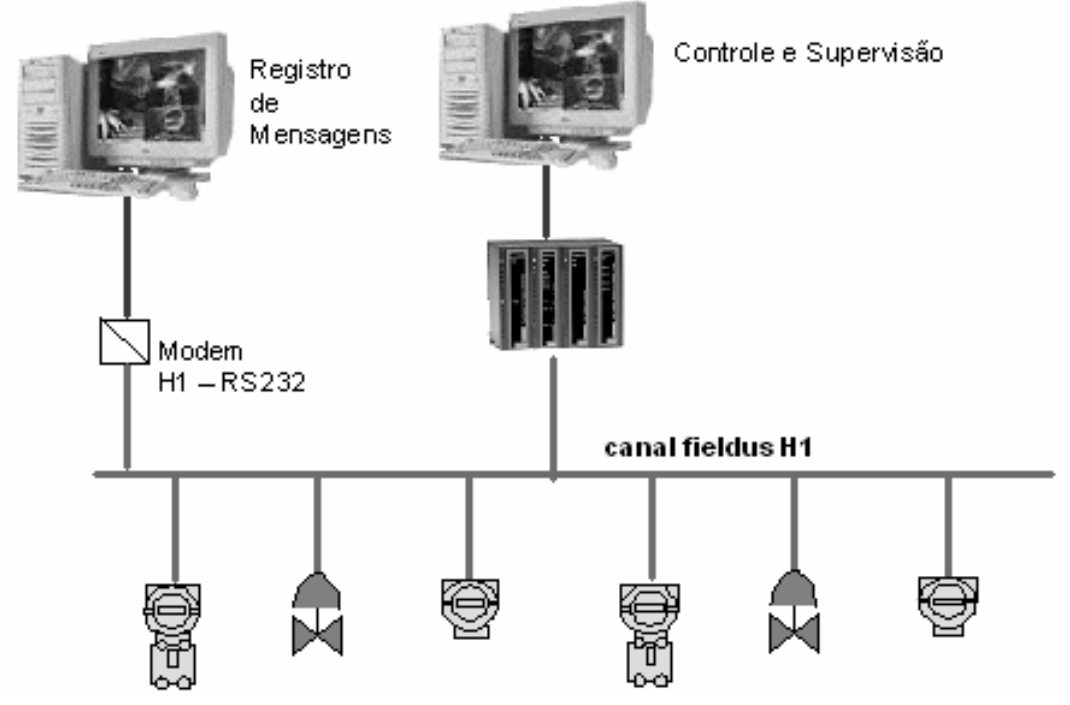

Aquisição serial de mensagens no barramento

\section{Módulo Plant}

O módulo Plant tem a função de simular o comportamento de uma planta ou de um processo dinâmico. É composto por uma equação diferencial no domínio do tempo computada repetitivamente em uma base de tempo conhecida e apropriada. O resultado numérico de tal equação tem um comportamento dinâmico similar ao de variáveis de processo em uma determinada planta. A figura a seguir mostra o modelo deste módulo.

Uma estrutura matemática linear e discreta do tipo ARX (Auto-Regressive with Exogenous Inputs) é utilizada para este propósito, na qual a ordem dinâmica do sistema simulado pode ser selecionada pelo usuário.

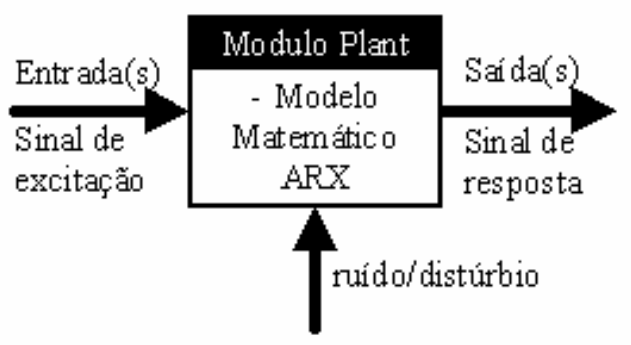

Diagrama de operação do módulo Plant 


\section{Módulos StandAloneFBlocks}

A simulação de blocos funcionais acontece de duas formas distintas: por módulos ProcessFBlocks ou por StandAloneFBlocks. Na segunda, os blocos funcionais são integrados em módulos de operação autônoma e providos de interface com o usuário, de maneira que podem ser utilizados em treinamentos ou como ferramenta didática na qual os usuários operam de modo particular cada bloco.

A concepção e a estrutura dos módulos StandAloneFBlocks baseia-se nos seguintes requisitos de projeto:

- Interface gráfica intuitiva com o usuário;

- Implementação integral da norma referente ao algoritmo e às variáveis de comunicação do bloco funcional;

- Algoritmo de execução baseado em módulos de processamento da biblioteca BasicBlock, conforme proposto na norma;

- Acesso direto aos parâmetros de entrada e de configuração do bloco funcional, via interface com o usuário.

Nestes módulos o algoritmo pode ser executado única ou repetitivamente, com período de execução configurável, enquanto os parâmetros de entrada e de configuração são digitados pelo usuário durante ou entre execuções do bloco funcional.

A interface com o usuário é desenhada de modo a refletir o fluxo da informação no algoritmo de execução, baseada na estrutura modular do último (figura a seguir). 


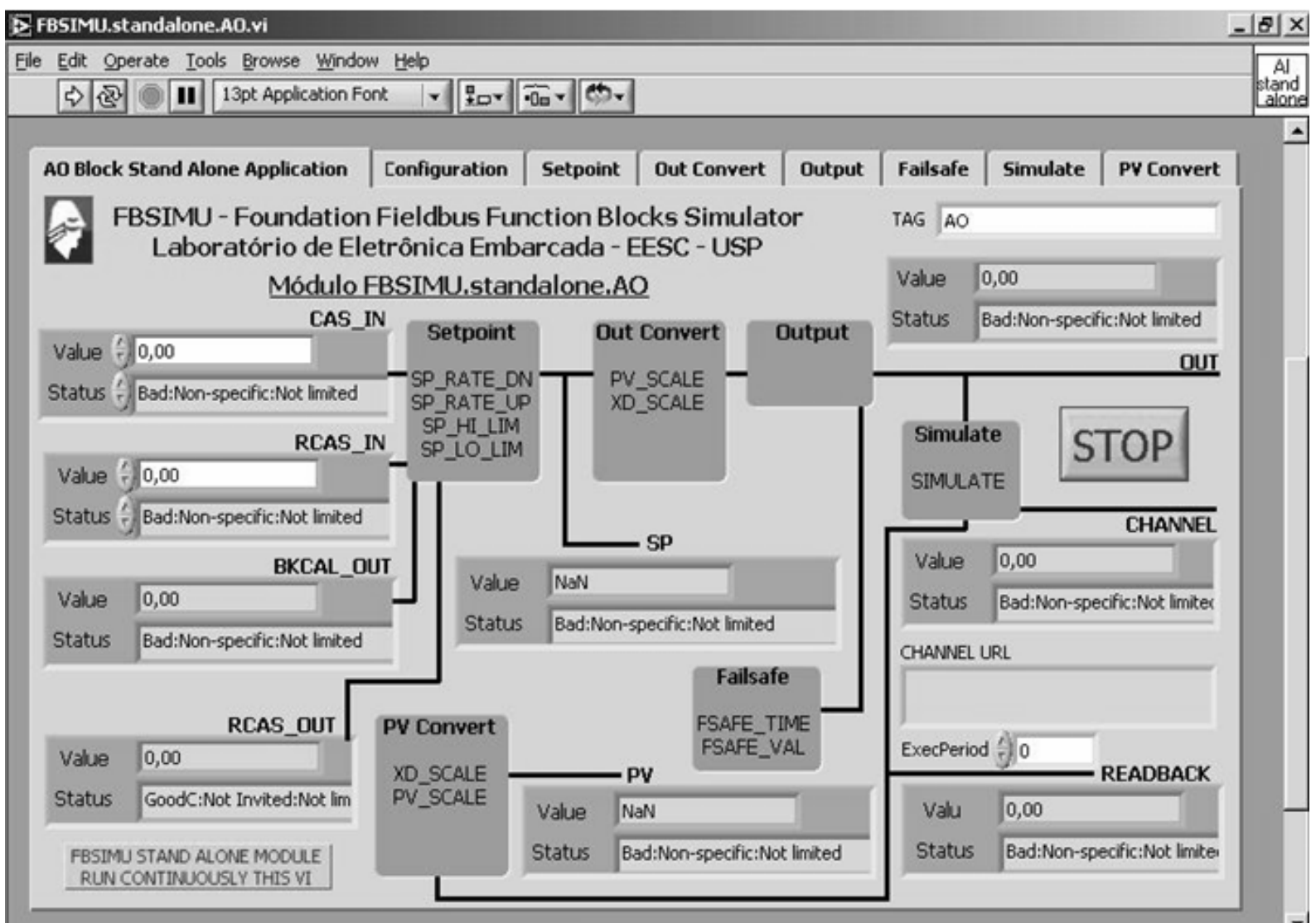

Interface com o usuário do módulo StandAloneFBlocks Analog Output

\section{Módulos ProcessFBlocks}

Com o objetivo de ampliar e complementar o escopo de aplicação da simulação dos módulos StandAloneFBlocks, os módulos ProcessFBlocks foram construídos sobre o mesmo algoritmo dos módulos StandAloneFBlocks, porém apresentam uma estrutura diferente da dos StandAloneFBlocks e se baseia nos seguintes requisitos de operação:

- Acesso remoto (por outros módulos) via serviços (tarefas) normalizados;

- Possibilidade de implementação de links entre distintos módulos ProcessFBlocks;

- Utilização como base para ensaios, testes e estudos de algoritmos de escalonamento e de malhas de controle de blocos funcionais;

- Capacidade de execução em tempo real;

- Ausência de interface com o usuário. 
O algoritmo de processamento interno nas versões ProcessFBlocks é exatamente o mesmo do implementado nas versões StandAloneFBlocks, porém na versão ProcessFBlocks o controle do bloco é realizado remotamente através de quatro serviços disponíveis para sistemas remotos de operação e de configuração. Tais serviços são ativados por comandos remotos que permitem a uma aplicação LabView dinamicamente carregar, executar e editar outras aplicações LabView através de um servidor de arquivos nativo denominado LabView VI Server.

Os seguintes serviços são definidos na versão ProcessFBlocks:

- FB_Init - inicialização default de todas as variáveis e parâmetros do bloco, de acordo com definições da norma (NORMA FOUNDATION FIELDBUS).

- FB_Exec - execução do algoritmo de processamento do bloco. Primeiramente todos os parâmetros são lidos, o algoritmo é executado e então o conjunto de parâmetros é atualizado.

- FB_Read - leitura de uma variável do bloco especificada pelo Index e Subindex ou de uma View. A leitura das Views só é executada para monitoração on-line dos parâmetros (os termos Index, SubIndex e View são definidos por norma).

- FB_Write - escrita em uma variável definida por seu Index e Subindex.

A interface com o usuário dos módulos ProcessFBlock (figura a seguir) possui apenas os parâmetros, ou argumentos, de comando e de resposta necessários para a realização dos serviços descritos. 


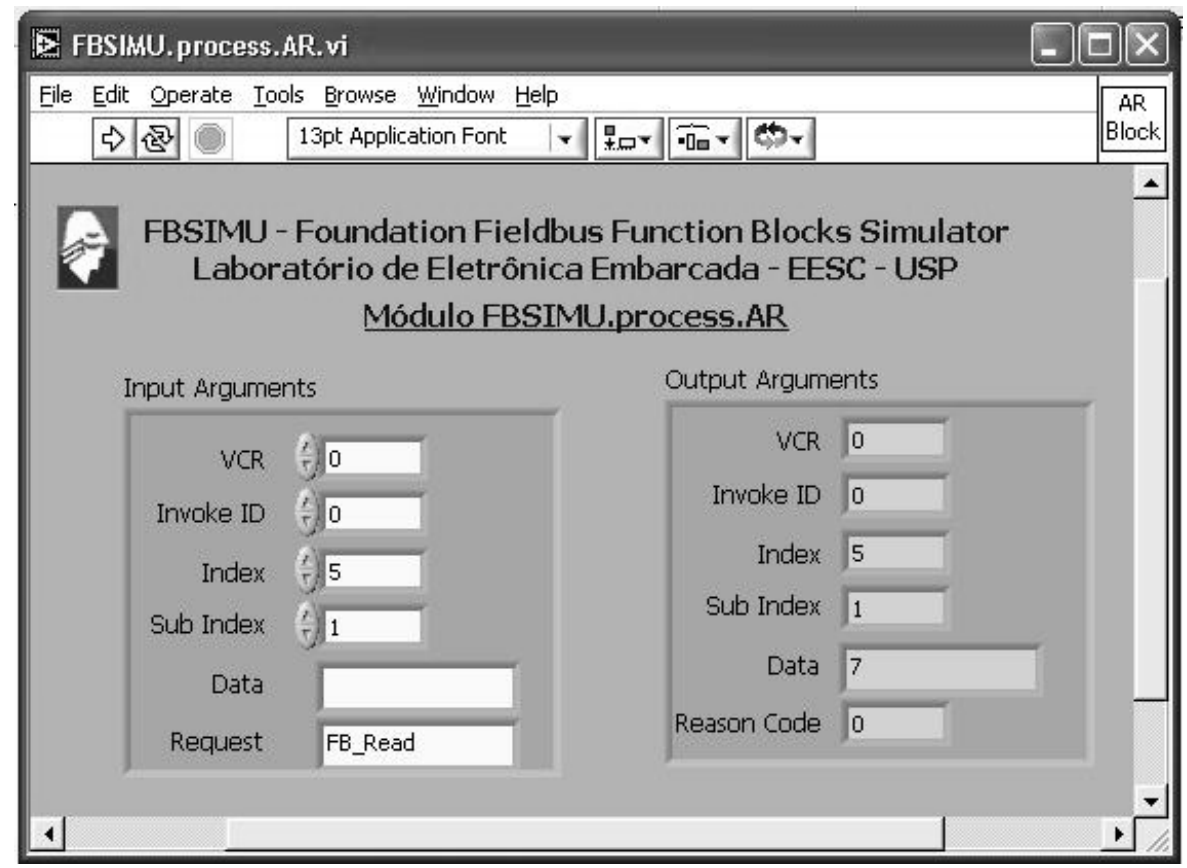

Inteface com o usuário de módulos ProcessFBlock

Cada tipo de bloco funcional (por exemplo, AI, AO, PID) corresponde a um módulo ProcessFBlock. Durante a simulação, entretanto, pode-se criar em um mesmo ambiente de simulação mais de uma instância, ou cópia independente, de cada tipo de bloco. As diferentes instâncias de um mesmo bloco funcional são independentes e cada qual tem sua execução, seus parâmetros e identificação.

\section{Módulo Conf}

Através do módulo configurador Conf é possível operar os módulos ProcessFBlocks. Por meio de uma interface com o usuário, desenhada de modo a permitir a visualização das malhas de controle e de blocos funcionais e seus parâmetros (figura a seguir), é possível instanciar, conectar e apagar remotamente instâncias de módulos ProcessFBlocks através das funções do LabView VI Server. 
Uma vez estabelecida uma conexão entre o módulo Conf e uma instância de um bloco funcional através de um RefNum, a operação desta passa do modo off-line para on-line, e deste modo é possível comandar e monitorar a operação do bloco.

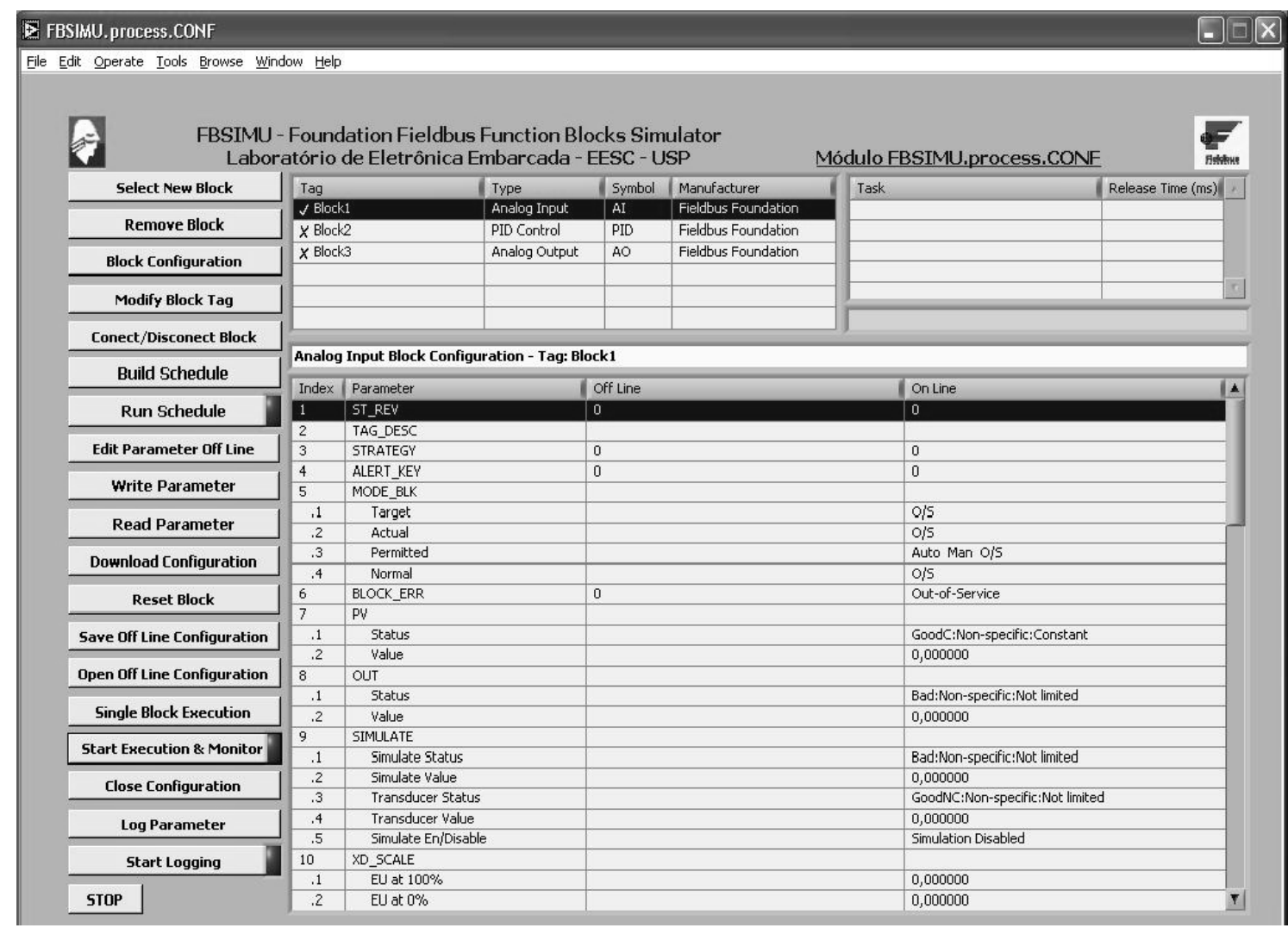

Interface com o usuário do módulo Conf

Para operar os módulos ProcessFBlocks, o módulo Conf possui bases de dados com informações pertinentes aos tipos de dados descritos na norma, ao conjunto de blocos funcionais disponíveis e também pertinentes à configuração e à parametrização de cada bloco funcional.

A operação do módulo Conf se divide em três modos:

- modo off-line: quando todos os comandos são executados sem que o(s) bloco(s) funcionai(s) comandado(s) esteja(m) conectado(s) ao Conf via LabView VI Server,

- modo on-line: nele as operações são executadas e os comandos são transmitidos ao(s) bloco(s) conectado(s) através dos comandos descritos via LabView VI Server, 
- modo malha de controle: com blocos funcionais conectados (on-line), uma malha de controle pode ser configurada e operada em tempo real. Neste modo, além da comunicação entre o Conf e os blocos funcionais, existe também comunicação entre os últimos.

As funções do módulo configurador Conf em modo off-line estão listadas a seguir:

- Selecionar e remover blocos funcionais;

- Abrir ou fechar a janela de visualização dos parâmetros de um bloco, com acesso aos valores off-line e on-line;

- Modificar o tag (ou rótulo) do bloco;

- Editar um parâmetro;

- Salvar o conjunto de parâmetros da configuração off-line de um bloco funcional em arquivo;

- Abrir um arquivo de conjunto de parâmetros da configuração off-line de um bloco funcional.

$\mathrm{Na}$ interface com o usuário do Conf, existe uma lista de blocos funcionais selecionados. Nesta lista, os blocos em modo on-line são diferenciados dos blocos em modo off-line respectivamente pelos símbolos $V$ e $X$, conforme a figura a seguir.

\begin{tabular}{|l|l|l|l|}
\hline Tag & Type & Symbol & Manufacturer \\
\hline$\checkmark$ Block1 & Analog Input & AI & Fieldbus Foundation \\
\hline$X$ Block2 & PID Control & PID & Fieldbus Foundation \\
\hline$\checkmark$ Block3 & Analog Output & AO & Fieldbus Foundation \\
\hline & & & \\
\hline & & & \\
\hline & & & \\
\hline
\end{tabular}

Lista de blocos funcionais ativos no módulo Conf

No modo on-line, as funções disponíveis são:

- Realizar escrita de parâmetro de um bloco; 
- Realizar leitura de parâmetro de um bloco;

- Descarregar uma configuração off-line em um bloco no modo on-line;

- Reinicializar um bloco;

- Executar uma única vez um bloco;

- Executar continuamente um bloco monitorando remotamente seus parâmetros;

- Registrar continuamente em arquivo texto o estado de uma ou mais variáveis do bloco funcional.

A visualização do conjunto completo dos parâmetros on-line de um bloco funcional, bem como uma correspondente configuração off-line para este bloco é realizada em uma lista, conforme a figura a seguir.

\begin{tabular}{|c|c|c|c|c|}
\hline \multicolumn{5}{|c|}{ PID Control Block Configuration - Tag: Block1 } \\
\hline Index & Parameter & Off Line & On Line & a \\
\hline 1 & ST_REV & 0 & 1 & \\
\hline 2 & TAG_DESC & & & \\
\hline 3 & STRATEGY & 0 & 0 & \\
\hline 4 & ALERT_KEY & 0 & 0 & \\
\hline 5 & MOOE_BLK & & & \\
\hline .1 & Target & Auto & Auto & \\
\hline .2 & Actual & & IMan & \\
\hline .3 & Permitted & & ROut RCas Cas Auto Man LO IMan o/S & \\
\hline .4 & Normal & & o/s & \\
\hline 6 & BLOCK_ERR & 0 & & \\
\hline 7 & PV & & & \\
\hline .1 & Status & & Bad:Non-specific:Not limited & \\
\hline .2 & Value & & 0,000000 & \\
\hline 8 & SP & & & \\
\hline .1 & Status & & Bad:Non-specific:Not limited & \\
\hline .2 & Value & & 0,000000 & \\
\hline 9 & OUT & & & \\
\hline .1 & Status & & Bad:Non-specific:Constank & \\
\hline .2 & Value & & 0,000000 & \\
\hline 10 & PV_SCALE & & & \\
\hline .1 & EU at $100 \%$ & & 0,000000 & \\
\hline .2 & EU at $0 \%$ & & 0,000000 & \\
\hline .3 & Units Index & & & \\
\hline .4 & Decimal Point & & 0 & \\
\hline 11 & OUT_SCALE & & & 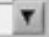 \\
\hline
\end{tabular}

Lista de parâmetros off-line e on-line de blocos funcionais no módulo Conf

A operação de módulo Conf com malhas de controle é realizada através da configuração e execução em tempo real da malha configurada. A configuração de uma malha de controle requer a configuração de um período de macrociclo, e do escalonamento de todos 
os blocos funcionais e das mensagens de transferência de dados periódicos (que enviam os parâmetros de saída de um bloco funcional até o parâmetro de entrada de outro bloco funcional).

Uma vez configurada a malha, esta pode entrar em modo de operação. Neste modo as execuções escalonadas passam a ocorrer nos instantes determinados e, assim, a malha de controle é executada com o período igual ao do macrociclo em uso.

O escalonamento da malha de controle é apresentado em uma lista, conforme a figura a seguir.

\begin{tabular}{|l|l|}
\hline Task & Release Time (ms) \\
\hline Block1 & 0 \\
\hline Block2 & 500 \\
\hline Block3 & 1000 \\
\hline Block1.OUT ->Block2.IN & 100 \\
\hline Block2.OUT -> Block3.CAS_IN & 600 \\
\hline Block3.BKCAL_OUT -> Block2.BKCAL_IN & 1100 \\
\hline Macrocycle Period: 1500 ms & \\
\hline
\end{tabular}

Malha de Controle e seu escalonamento

Quando o escalonamento de malhas é ativado, as execuções de blocos funcionais de modo contínuo (função de monitoramento) são suspensas e o monitoramento dos parâmetros via leitura de views só é realizado caso haja uma janela de tempo adequada entre duas tarefas escalonadas, de modo que o monitoramento não provoque atrasos de escalonamento.

A tabela de escalonamento indicada acima refere-se a uma malha de controle clássica com compensador PID. Uma representação gráfica da malha AI-PID-AO e o escalonamento configurado para tal está na figura a seguir. 

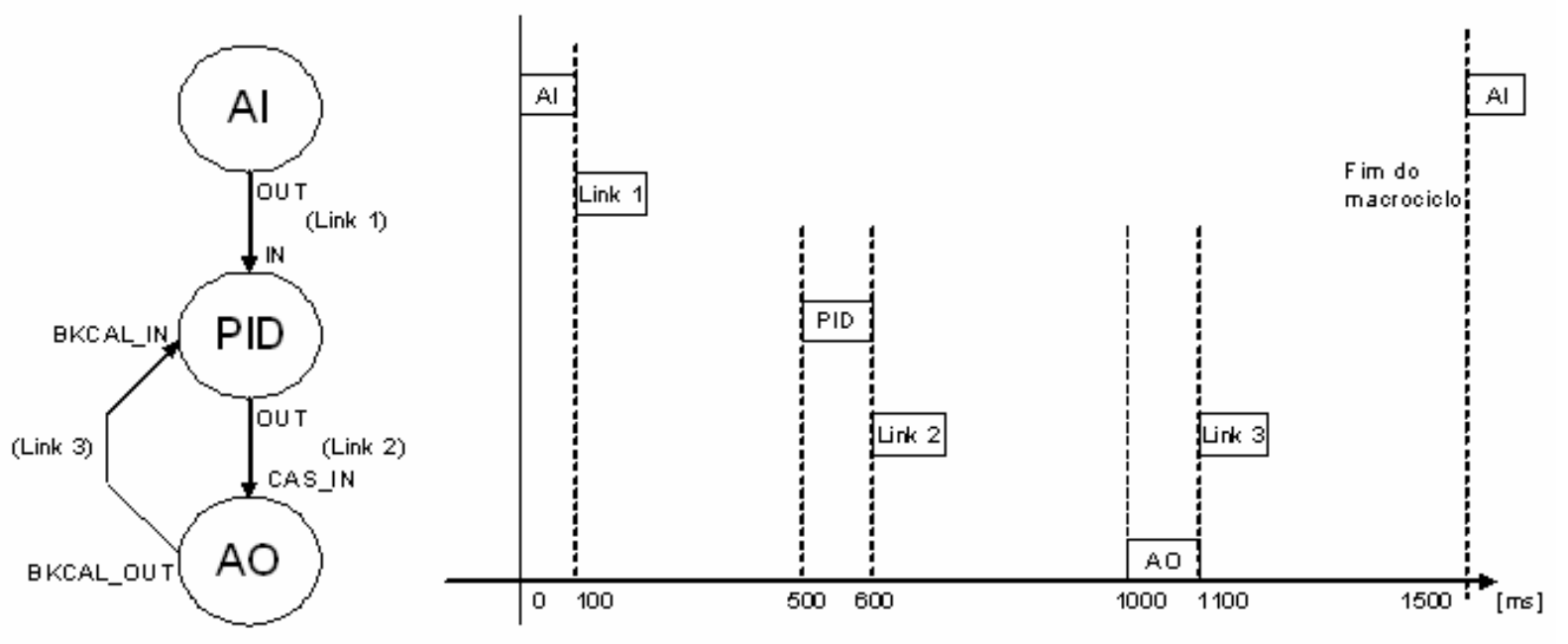

Malha de controle AI-PID-AO e correspondente escalonamento 
Apêndice A

APÊNDICE A - Procedimentos de instalação 
Este apêndice detalha os passos necessários para a instalação e configuração do sistema em uma determinada máquina que funcionará como servidor. Este detalhamento vai desde a instalação de componentes básicos como um servidor HTTP até a instalação e configuração do Moodle e do LabView. Todos estes softwares deverão ser instalados considerando o fato de que a máquina servidora será dedicada ao FBSIMU On-line.

Primeiramente, o EasyPHP e o LabView devem ser instalados na máquina servidora. Feito isso, o Moodle deverá ser instalado e configurado. Neste ponto, a base de dados do Moodle já deverá ter sido criada. Assim, o driver ODBC já pode ser instalado e configurado. Com todos os softwares instalados, os arquivos relacionados ao FBSIMU (as VIs) e os arquivos PHP e HTML criados para uso do Moodle devem ser instalados nos diretórios escolhidos pelos usuários. Por fim, o administrador poderá utilizar a ferramenta de configuração (FBSIMU Manager) para ajustar os parâmetros finais.

\section{Apache, MySQL, PHP (AMP)}

A primeira etapa da instalação deste sistema é instalar os softwares básicos que serão utilizados pelo Moodle. Estes softwares são o Apache, o MySQL e o suporte para PHP. Para a instalação desses softwares, foi utilizado o EasyPHP que é um pacote que contém os três itens comentados acima.

O pacote de instalação do FBSIMU On-line possui o arquivo easyphp1-8_setup.exe que é responsável pela instalação. O processo de instalação é padrão e segue o mesmo modelo de outros softwares convencionais, onde um diretório é selecionado, os termos de licença são apresentados, etc.

Neste caso, as configurações padrão devem ser mantidas, considerando que a máquina que será utilizada, não possuirá outros aplicativos que possam concorrer por recursos. Caso algum conflito ocorra, como por exemplo, alguma porta em uso, o administrador do sistema 
deverá modificar os parâmetros padrão. Este aplicativo também oferece um gerenciador de banco de dados que pode ser acessado através da Web.

A seguir tem-se uma figura com a página HTML inicial de configuração do EasyPHP seguida de outra figura que é a página HTML do sistema de administração de banco de dados.

Na primeira figura é possível visualizar a versão de cada software instalado pelo EasyPHP.

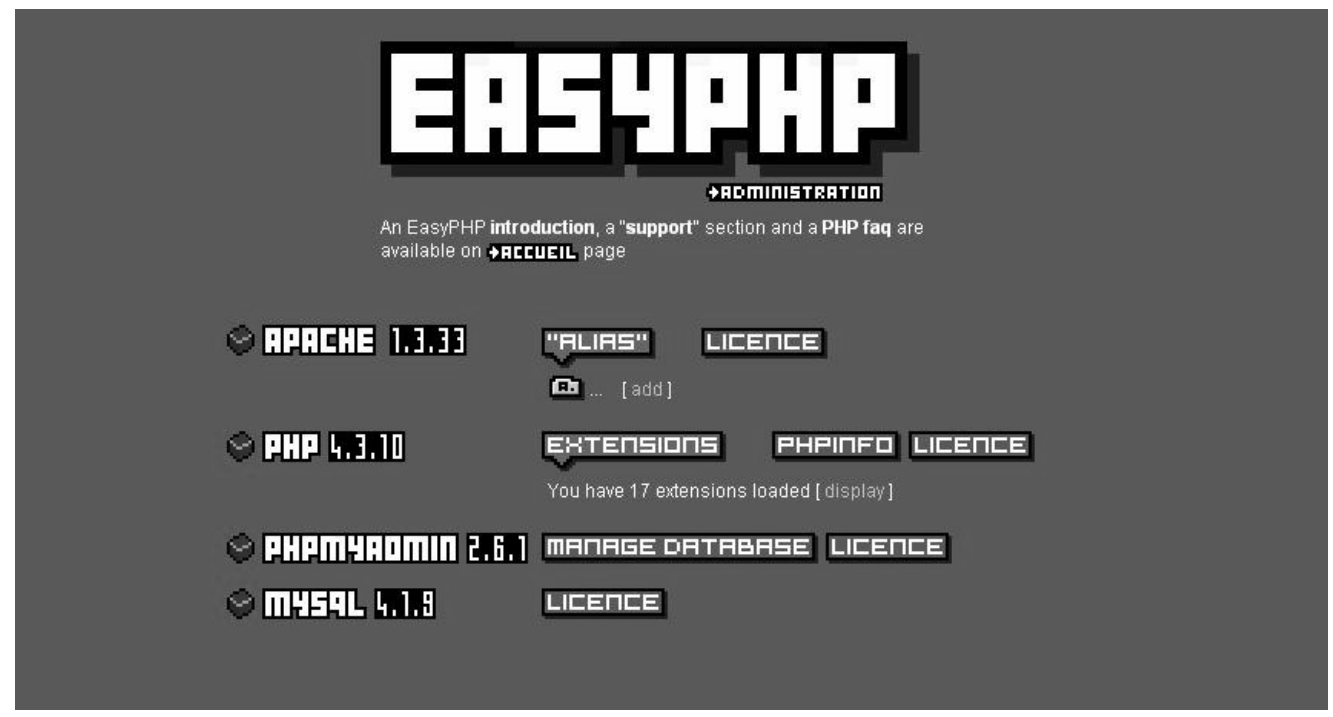

Página inicial do EasyPHP

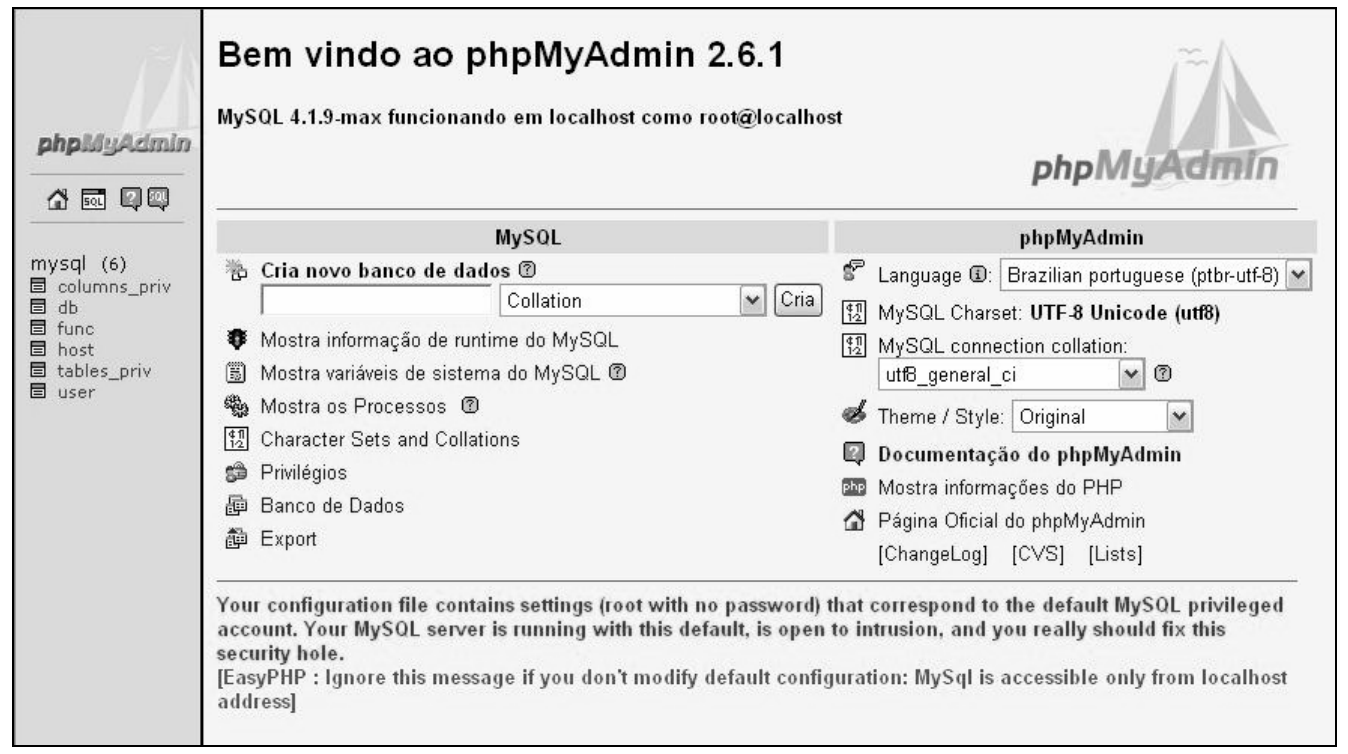

Página HTML para administração de banco de dados 


\section{LabView}

Da mesma forma do EasyPHP, a instalação do LabView também é padrão. A diferença neste caso, está na configuração do LabView em relação ao seu servidor Web. Considerando que um servidor de internet utiliza um IP e uma porta para efetuar seu trabalho, estes devem ser configurados no LabView. Esta ferramenta já possui valores padrão para estes campos, mas devido ao fato de um servidor Apache estar sendo executado na mesma máquina, estes valores deverão ser modificados para evitar um conflito de endereços.

Para realizar esta configuração é necessário ir até a janela do LabView responsável por isso (Tools->Remote Panel Connection Manager). A nova janela também possui um menu "Tools->Options", e, é neste menu que o acesso às configurações é feito.

Com a janela de configuração aberta, o administrador deverá ir até o item "Web Server:Configuration". Neste item, o administrador deverá inserir o diretório raiz correto e modificar o valor do campo "HTTP Port" de 80 para 81. A figura a seguir mostra esta janela de configuração com alguns detalhes. 


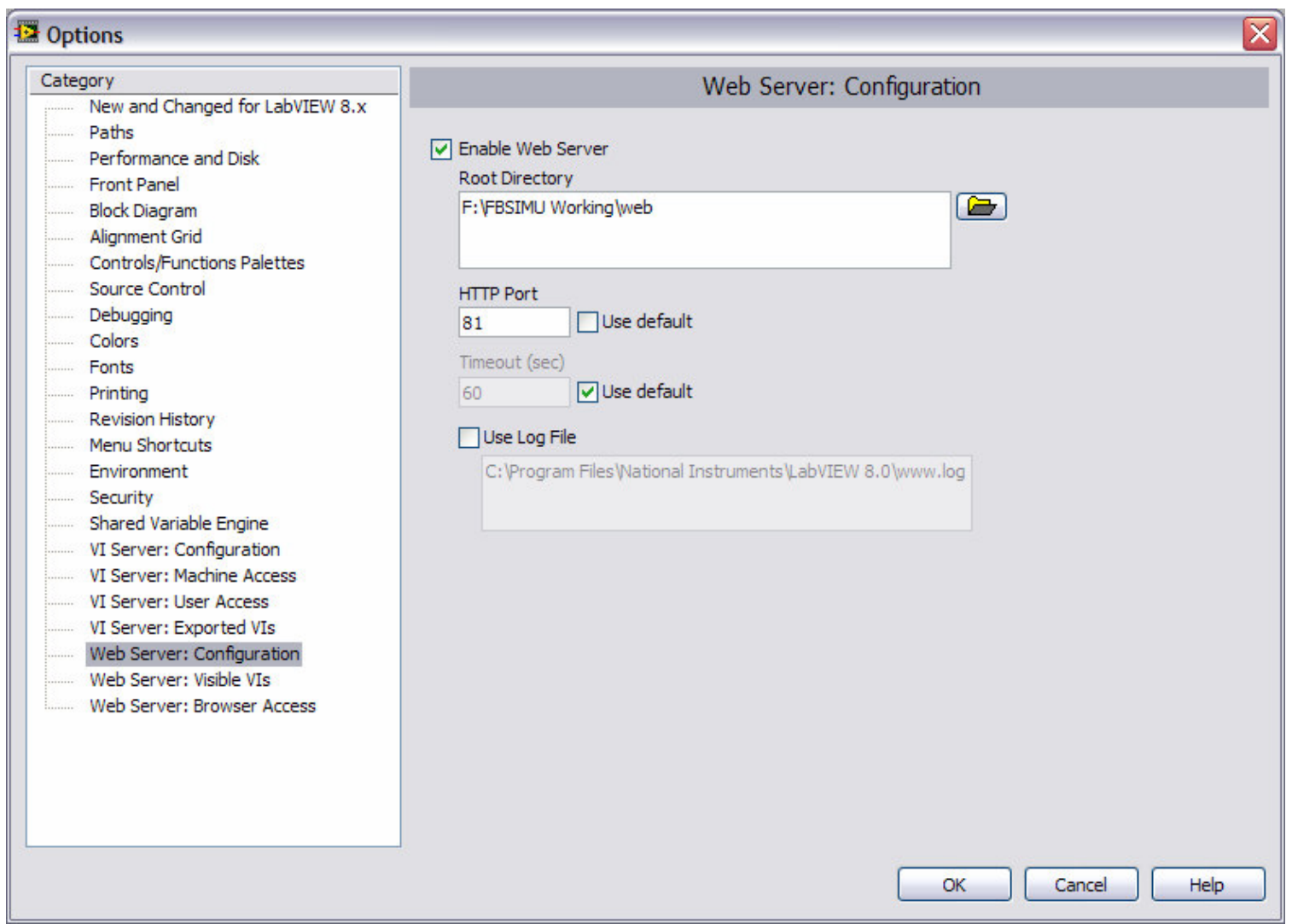

Janela de configuração do servidor Web do LabView

\section{Moodle}

A instalação do Moodle não segue o modelo das outras duas instalações acima. Esta instalação é feita através de páginas HTML/PHP. Para realizar esta instalação, deve-se mover os arquivos extraídos do pacote do Moodle para o diretório onde, através do Apache, foi definido como raiz para os arquivos Web. Considerando que as configurações padrão do EasyPHP foram mantidas, o diretório raiz será o "www" que está localizado no diretório onde o EasyPHP foi instalado.

Feito isso, o administrador do sistema deverá executar o arquivo index.php (http:\127.0.0.1 \moodlelindex.php) para inicializar a instalação e configuração do sistema. A figura a seguir mostra a página HTML que é mostrada no processo de instalação. 


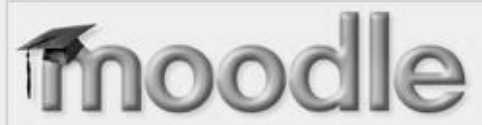

Installation

Choose a language

Language English (en) $v$

Next *

Página inicial da instalação do Moodle

Durante o processo de instalação, parâmetros de configuração são pedidos ao administrador. Primeiramente, o diretório onde o Moodle será configurado deve ser escolhido. Feito isso, a configuração e criação das tabelas do banco de dados são feitos como mostra a figura a seguir.

\section{Thoodle \\ Installation}

Now you need to configure the database where most Moodle data will be stored. This database must already have been created and a username and password created to access it.

Type: mysql or postgres?

Host: eg localhost or db.isp.com

Name: database name, eg moodle

User: your database username

Password: your database password

Tables Prefix: optional prefix to use for all table names

\begin{tabular}{rl|} 
Type & mysql $\checkmark$ \\
Host Server localhost \\
Database moodle \\
User \\
Password \\
Tables prefix \\
mdl_
\end{tabular}

Página onde o banco de dados será configurado. 


\section{Driver ODBC}

O ODBC (Open DataBase Connectivity) é um padrão desenvolvido pelo grupo SQL Access em 1992 com o intuito de permitir o acesso a qualquer base da dados a partir de qualquer software. A idéia foi criar uma camada intermediária chamada de database driver, entre o software que usa o banco de dados e o sistema de gerenciamento de banco de dados.

Considerando que o Moodle utiliza o MySQL para armazenar seus dados e o software configurador (FBSIMU Manager) precisa modificar alguns itens deste banco, um driver ODBC precisa ser instalado.

Assim, o driver MySQL ODBC 3.51 foi escolhido para tal fim. A instalação do driver é padrão em relação aos softwares convencionais do mercado. Feita a instalação, este driver deverá ser configurado. A figura a seguir mostra os valores dos parâmetros que devem ser utilizados.

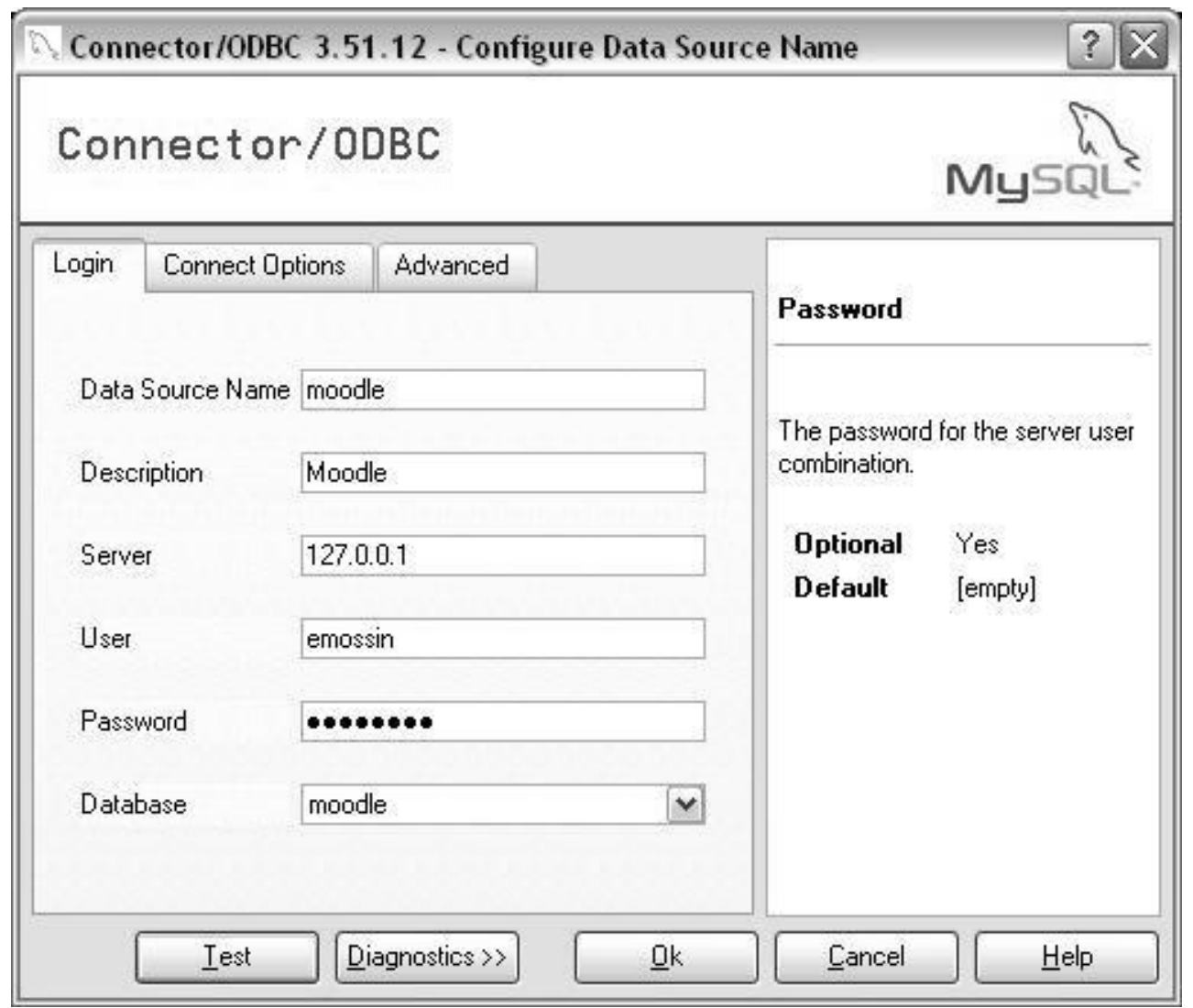

Configuração do driver ODBC 
APÊNDICE B - Ferramentas para criação de cursos a distância. 
Como já dito neste documento, o crescimento do interesse no ensino a distância impulsionou a criação de ferramentas de auxílio para o desenvolvimento desses cursos. Uma lista destas ferramentas (CMSs, LMSs...) é apresentada neste apêndice.

Segundo Adkins (2005), existe um grande crescimento do número de ferramentas LMS no mercado, e boa parte destas ferramentas são as chamadas OS LMS (Open Source Learning Management Systems). Dentre este conjunto de ferramentas de código aberto (as mais interessantes para este trabalho), as que mais se destacam são o Moodle, Ganesha, Claroline, ILIAS, e Sakai. A ferramenta Moodle (escolhida para a implementação deste trabalho) não aparecerá neste apêndice, pois um capítulo dedicado a ela foi escrito.

As informações apresentadas a seguir foram retiradas do site EDUTOOLS (2006) e dos sites dos fabricantes de cada produto (acesso em agosto de 2006).

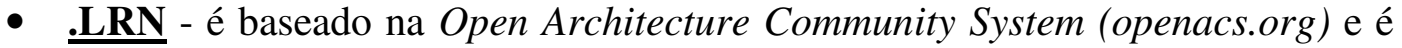
dirigido pelo consórcio .LRN (.LRN Consortium). Como membros deste consórcio incluem-se a Sloan School of Management at MIT e a Heidleberg University. Este produto é livre e distribuído sob os termos de licença GNU GPL. É desenvolvido para trabalhar sobre as plataformas Linux e Unix. Maiores detalhes podem ser encontrados no site http://dotlrn.mit.edu/.

- ATutor - desenvolvido pela Adaptive Technology Resource Centre at the University of Toronto. Este produto é livre, distribuído sob os termos de licença GNU GPL e é disponível para as plataformas Linux, Unix ou Windows. A estação servidora deverá possuir suporte para PHP, Mysql e o servidor Web, poderá ser o Apache ou o Microsoft IIS. Maiores detalhes podem ser encontrado no site http://www.atutor.ca/. 
- Blackboard - companhia fundada em 1997 que desenvolve, entre outros softwares, o Blackboard Academic Suite. Este produto trabalha sobre as plataformas Linux, Unix e Windows. O software usa uma base de dados que poder ser o SQL Server 2000, o Oracle8, o Solaris ou o MySQL. Como servidor Web é possivel utilizar o Apache ou o Microsoft Internet Information Server (IIS). Este software não é livre e está protegido por termos de licença que podem ser encontrados no site do fabricante. Maiores detalhes podem ser encontrados no site http://www.blackboard.com/us/index.aspx.

- CentraOne - é um produto desenvolvido por uma companhia chamada Centra, localizada em Boston. O software armazena seus dados em uma base de dados MySQL ou Oracle. O sistema operacional compatível é o Windows. Este software não é livre e está protegido por termos de licença que podem ser encontrados no site do fabricante. Maiores detalhes podem ser encontrados no site http://www.saba.com/centra-saba/.

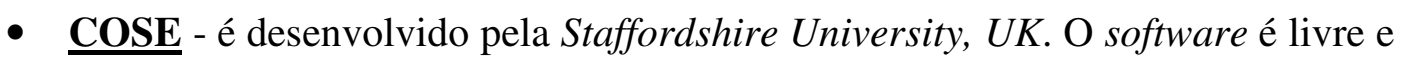
em breve seu código fonte será liberado sob os termos de licença de código livre (Open Source licensing). O servidor Web utilizado pode ser o Apache ou Microsoft Windows Internet Information Server (IIS) 4.0. O COSE utiliza como sistema operacional o Linux, Solaris, Unix ou o Windows. Maiores detalhes podem ser encontrados no site http://www.staffs.ac.uk/COSE/. 
- Educator - é desenvolvido pela Ucompass, que foi originalmente criada em 1995 com o nome Compass Publishing. Inicialmente, produzia guias para orientação de ensino superior. Em 1997 tornou-se uma companhia voltada ao desenvolvimento de produtos para a Web. Em 1998 focou-se apenas em tecnologias voltadas para a educação e desenvolveu o software Educator. Um atributo deste software é que ele suporta acesso a partir de navegadores Web da plataforma Windows CE. O servidor deste produto é compatível com os sistemas operacionais Linux, Unix e MAC OS X. Este software não é livre e está protegido por termos de licença que podem ser encontrados no site do fabricante. Maiores detalhes podem ser encontrados no site http://www.ucompass.com.

- Internet Course Assistant - foi desenvolvido pela Nicenet e é um pouco diferente dos outros cursos. O Nicenet é um portal Web onde um usuário cria um curso e outros usuários utilizam este mesmo curso. A criação é feita no próprio servidor da Nicenet sem a necessidade ou possibilidade de modificações particulares. O software é de uso livre e maiores detalhes podem ser adquiridos no site http://www.nicenet.org/.

- Jones e-education - foi desenvolvido pela empresa Jones Knowledge, Inc. que foi fundada em 1987. Este software requer PHP, MySQL, Java 2SDK, Apache e um Servlet engine como o Tomcat, Jetty ou JRUN. Este software é livre apenas para instituições autorizadas. Maiores detalhes podem ser encontrados em http://www.jonesadvisorygroup.com/. 
- $\quad$ LON-CAPA - foi desenvolvido pelo Laboratory for Instructional Technology in Education at Michigan State University. A origem do software vem da fusão de dois outros projetos. O primeiro é o CAPA (a Computer-Assisted Personalized Approach), que fornecia aos estudantes conjuntos de problemas a serem resolvidos, quizzes e provas. O segundo é o LectureOnline, um projeto para fornecer materiais de um dado curso para a Web. Este produto é livre, distribuído sob os termos de licença GNU GPL e é desenvolvido para trabalhar sobre a plataforma Linux. O acesso aos cursos disponibilizados pelo LONCAPA pode ser feito a partir de navegadores web convencionais, PDAs e navegadores para Windows CE. Maiores detalhes sobre este software podem ser encontrados em http://www.lon-capa.org/.

- The Learning Manager - foi originalmente desenvolvido no Southern Alberta Institute of Technology e mais tarde, foi prolongado para outra companhia chamada The Learning Management Corporation. O sistema é disponível para as plataformas Windows, usa como servidor o Microsoft Internet Information Server (IIS) e armazena seus dados em uma base de dados Microsoft Access. O custo da licença é baseado no número de estudantes de uma dada instituição. Maiores detalhes sobre este software podem ser encontrados em http://thelearningmanager.com/TLM40web/. 
- WebCT - o software foi desenvolvido pelo grupo de Murraw W. Goldberg, da University of British Columbia. Está disponível para as plataformas Linux, UNIX e Windows. Utiliza o Apache como servidor Web e requer Perl para seu funcionamento. A licença é baseada no número de alunos que acessa um dado curso. Maiores detalhes sobre este software podem ser encontrados em http://www.webct.com/.

- ANGEL - o software foi desenvolvido pelo CyberLearning Labs. Está disponível apenas para a plataforma Windows e tem como repositório de dados o Microsoft SQL Server 2000. O custo de sua licença é baseado no número de usuários cadastrados. Maiores detalhes sobre este software podem ser encontrados em http://www.cyberlearninglabs.com/.

- Avilar WebMentor - software desenvolvido pela empresa Avilar® Technologies, Inc. que foi formada em 1997. O sistema é compatível com o sistema operacional Windows. Sua licença não é livre e está o software protegido por termos de licença que podem ser encontrados no site do fabricante. Requer para funcionamento o Netscape Web Server 2.0 ou Microsoft Internet Information Server (IIS) e o Cold Fusion. Como repositório o software usa o MySQL. Maiores detalhes sobre o produto podem ser encontrados em http://home.avilar.com/.

- Bazaar - este sistema é um Open Source que tem como objetivo fornecer um software alternativo para substituir os sistemas proprietários WebCT e Blackboard. Este requer uma base de dados MySQL, um WebServer Apache e 
Perl. O software é disponibilizado para as plataformas Linux, Unix e Windows. Este produto é livre e distribuído sob os termos de licença GNU GPL. Maiores detalhes podem ser encontrados no site http://klaatu.pc.athabascau.ca/.

- Bodington - o software foi desenvolvido por Jon Maber e é usado pela universidade de Leeds. O produto possui seu código aberto e está disponível para as plataformas Linux, Solaris e Windows. Armazena seus dados em um banco de dados MySQL, Oracle ou PostgreSQL. Como servidor Web utiliza o Tomcat ou o iPlanet. Maiores detalhes podem ser encontrados em http://bodington.org.

- $\quad$ BSCW - foi desenvolvido por OrbiTeam Software GmbH que foi fundada em 1998. O sistema é livre para instituições de ensino e está disponível para as plataformas Windows, Solaris, SunOS, Linux, DEC OSF, HP-UX, Irix, BSD/OS e AIX. Usa como servidor Web o Apache ou o Microsoft Internet Information Server (IIS). Como interpretador usa o Python. Maiores detalhes podem ser encontrados em http://bscw.fit.fraunhofer.de/.

- Claroline - desenvolvido pela universidade de Louvain (Université catholique de Louvain) no instituto de Educação e Multimídia (Institut de Pédagogie universitaire et des Multimédias). O software foi disponibilizado como um Open Source em janeiro de 2002. Este produto é livre e distribuído sob os termos de licença GNU GPL. O armazenamento de dados é feito em um banco de dados MySQL e o Apache é usado como servidor Web. Requer suporte para 
a linguagem de script $P H P$. Está disponível para as plataformas Windows $e$ Unix. Maiores detalhes podem ser encontrados em http://www.claroline.net/.

- ClassWeb - o sistema foi desenvolvido por UCLA Social Sciences Computing. Esta instituição usa e desenvolve este software desde 1997. Este produto é um Open Source e é distribuído sob os termos de licença GNU GPL. O armazenamento de dados é feito em um banco de dados $M y S Q L$ e o Apache é usado como servidor Web. Requer suporte para PHP, Perl e CGI. O software é disponível para servidores que usam a plataforma Windows. Maiores detalhes podem ser encontrados em http://classweb.ucla.edu/.

- Colloquia - foi criado pela universidade de Wales, Bangor. O mesmo tem sido usado desde 2000. O software é livre para instituições educacionais sem fins lucrativos. O Colloquia é desenvolvido usando a linguagem Java e maiores detalhes sobre esta plataforma se encontra em http://www.colloquia.net/.

- Desire2Learn - foi desenvolvido pela companhia de mesmo nome do produto que foi fundada em 1999. A licença do software não é livre e possui diferentes formas de cobrança. O software está disponível para servidores Windows. O servidor Web usado é o Microsoft Internet Information Server (IIS). O armazenamento de dados é feito em um banco de dados Microsoft SQL Server. Maiores detalhes sobre este produto podem ser encontrados em http://www.desire2learn.com/. 
- eCollege AUt - desenvolvido pela empresa eCollege que foi fundada em 1996 e previamente nomeada de RealEducation. O software não é de uso livre e está protegido por termos de licença que podem ser encontrados no site do fabricante, entretanto existe uma licença que inclui suporte técnico em seu pacote. O sistema é disponíbilizado para o Windows e usa como base de dados o Microsoft SQL Server. Além disso, requer suporte para a tecnologia ASP. Maiores informações sobre $\mathrm{o}$ produto podem ser encontradas em http://www.ecollege.com.

- Eledge - foi desenvolvido pelo professor Chuck Wight da Universidade de Utah. Esse produto é um Open Source e é distribuído sob os termos de licença GNU GPL. Utiliza como base de dados o $M y S Q L$ e está disponível para a maioria das plataformas UNIX e para outros sistemas que possuem o Java Servlet Engine. Segundo o desenvolvedor do produto, líderes comerciais como o WebCT e Blackboard oferecem uma solução mais madura e de melhor qualidade mas com um preço substancial. Maiores detalhes sobre o Eledge podem ser encontrados em http://eledge.sourceforge.net/.

- FirstClass - o software foi originalmente desenvolvido pela companhia SoftArc em 1990. Em 1999 a companhia MC2 Learning Systems adquiriu a SoftArc e formou-se a Centrinity. O sistema está disponível para Windows, Macintosh OS X, Macintosh OS 9 e Linux. Este software requer alguns termos de licença para usá-lo. Maiores detalhes sobre esta ferramenta podem ser encontrados em http://www.centrinity.com/. 
- $\quad \underline{\text { Fle3 }}$ - o software é desenvolvido pela UIAH Media Lab, University of Art and Design Helsinki em cooperação com Center for Research on Networked Learning and Knowledge Building, Department of Psychology, University of Helsinki. Este produto é um Open Source e é distribuído sob os termos de licença GNU GPL. O software está disponível para a maioria das variações dos sistemas UNIX e para versões do Windows compatíveis com o ZOPE e o Python. Maiores detalhes sobre o produto encontram-se em http://fle3.uiah.fi/.

- ILIAS - foi desenvolvido originalmente como parte de um projeto chamado VIRTUS na Faculty of Economics, Business Administration and Social Sciences at the University of Cologne. O software é livre e distribuído sob os termos de licença GNU GPL. O sistema está disponível para a maioria das distribuições Linux, para o Solaris e para sistemas UNIX. Usa como servidor Web o Apache, armazena seus dados em uma base de dados MySQL e utiliza também a linguagem PHP. Maiores detalhes sobre este produto podem ser encontrados em http://www.ilias.de/ios/index-e.html.

- IntraLearn SME - o software foi desenvolvido pela empresa IntraLearn Software Corporation que foi fundada em 1994. Esta empresa possui uma parceria com a Microsoft (Microsoft Gold Certified Solution Provider Partner). A licença deste produto não é livre e está protegido por termos de licença que podem ser encontrados no site do fabricante. Está disponível para os sistemas Windows e usa como servidor Web o Microsoft Internet Information Server(IIS). A base de dados deste produto é o Microsoft SQL 
Server. O software requer o Macromedia Cold Fusion Professional e o Crystal Reports Developer. Maiores detalhes deste produto podem ser encontrados em http://www.intralearn.com/.

- Janison Toolbox - foi desenvolvido pela companhia Janison Solutions Pty Ltd, situada na Austrália e fundada em 1996. Sua licença não é livre e os valores variam dependendo o local onde a mesma será usada. Possui um valor para institutos educacionais australianos, um valor para instituições educacionais internacionais, um para corporações australianas e um outro valor para corporações internacionais. O sistema é disponível para sistemas operacionais Windows e usa como base de dados o Microsoft Access database com MS Data Engine database ou Microsoft SQL Server. Maiores detalhes sobre este produto podem ser encontrados em http://www.janison.com.au/janison/.

- Jenzabar Internet Campus Solution - sistema foi desenvolvido pela empresa Jenzabar que foi fundada em 1998. A licença do software não é livre e está protegido por termos de licença que podem ser encontrados no site do fabricante. O sistema é disponível para Windows, usa como servidor Web o Microsoft Internet Information Server (IIS) e como base de dados o Microsoft SQL Server 2000. Maiores detalhes sobre o produto encontram-se em http://www.jenzabar.net/. 
- KEWL - o sistema foi desenvolvido pelo professor Derek Keats, da University of Western Cape, África do Sul, sendo que a primeira versão foi desenvolvida por Derek Keats e Martin Cocks. KEWL é uma abreviatura para Knowledge Environment for Web-based Learning. O sistema é livre e possui seu código fonte aberto (Open Source). Está disponível para o sistema operacional Windows, usa como servidor Web o Microsoft Internet Information Server (IIS) e como base de dados o Microsoft SQL Server. Maiores informações sobre o produto podem ser encontradas em http://kewl.uwc.ac.za.

- KnowEdge eLearning Suite - é um Learning Management System desenvolvido pela empresa Inter Netion que tem base em Singapura. Este software é um freeware que está disponível para as plataformas Windows. Usa como base de dados o Microsoft Access ou o Microsoft SQL Server. Como servidor Web, o software usa o Microsoft Internet Information Server. Maiores detalhes sobre este produto podem ser encontrados em http://www.knowedge.net/.

- Learnwise - o sistema foi desenvolvido através de uma parceria entre a empresa Granada Learning e a Universidade de Wolverhampton sob o gerenciamento do professor Steve Molyneux. A licença do sistema não é livre e a taxa da mesma é cobrada com base no número de usuários que usarão o sistema. O software está disponível para o Windows 2000 ou 2003. Requer um servidor Web como o Apache e um Java Servlet Engine como o Tomcat. O armazenamento de dados é feito no banco de dados Microsoft SQL Server ou 
no Oracle. Maiores detalhes deste produto podem ser encontrados em http://www.learnwise.com/.

- Manhattan Virtual Classroom - o sistema foi originalmente desenvolvido em 1997 no Western New England College, por Steven Narmontas. O software é livre e distribuído sob os termos de licença GNU GPL. O servidor Web utilizado é o Apache e o sistema foi escrito inteiramente em linguagem C. O software está disponível para plataformas Linux e Unix. O armazenamento de informações é feito com o uso da base de dados Mysql. Maiores detalhes sobre este produto podem ser encontradas em http://manhattan.sourceforge.net/.

- MimerDesk - este software é desenvolvido pela companhia Ionstream Ltd que tem base em Espoo, na Finlandia. O sistema é livre e distribuído sob os termos de licença GNU GPL. O servidor Web utilizado é o Apache, e a base de informações é armazenada em um banco de dados $M y S Q L$. Além disso, o software requer a linguagem Perl. O sistema está disponível para as plataformas Linux e Unix. Maiores detalhes sobre o produto podem ser encontradas em http://www.mimerdesk.org/.

- Teknical Virtual Campus - o sistema foi desenvolvido pela companhia Teknical Ltd fundada em 1997 e localizada no Reino Unido. O preço da licença para uso do software é baseado no número de usuários registrados no mesmo. O suporte técnico para o sistema é incluso na taxa dessa licença. O software está disponível para as plataformas Windows 2000 ou 2003. Para 
armazenamento de informações, a base de dados Microsoft SQL Server é utilizada. Maiores detalhes sobre o produto podem ser encontrados em http://www.teknical.com/default.htm.

- TeleTop - o software foi desenvolvido pela Universidade de Twente. O mesmo usa como suporte a tecnologia LOTUS/IBM e é disponível para o Windows e para qualquer variação de Linux e Unix que sejam capazes de executar o Lotus Dominio. Para o armazenamento de dados o sistema utiliza o IBM Lotus Dominio server. Maiores detalhes sobre este sistema podem ser encontrados em http://www.teletop.nl/.

- Virtual-U - o sistema foi desenvolvido pela companhia Virtual Learning Environments Inc., fundada em 1996. A licença do sistema é cobrada com relação ao número de servidores a serem instalados. O suporte técnico do sistema também é cobrado através de uma taxa adicional ao valor da licença. $\mathrm{O}$ software requer como servidor Web o Apache e utiliza a linguagem Perl. Está disponível para a maioria das variantes da plataforma UNIX. Maiores detalhes sobre este produto podem ser encontrados em http://www.virtual-u.org/.

- Sakai - O projeto teve origem na Universidade de Michigan e na Universidade Indiana. O projeto Sakai é uma comunidade de desenvolvimento de software com o objetivo de desenvolver um novo CLE (Collaboration and Learning Environment). O projeto teve início em Janeiro de 2004. O software é livre e distribuido sob os termos da Educational Community License Version 1.0. O sistema é desenvolvido utilizando-se a linguagem Java e pode ser executado 
em plataformas Unix, Linux e Windows. Maiores detalhes sobre este produto podem ser encontrados em http://www.sakaiproject.org/

- Unicon Academus - O sistema é desenvolvido pela empresa UNICON. O software está protegido por termos de licença que podem ser encontrados no site do fabricante. O sistema tem suporte para a plataforma Unix e Windows e requer uma Java Servlet Engine como o Tomcat. Como base de dados pode ser usado o Oracle, o PostgreSQL e o Microsoft SQL Server. Maiores detalhes sobre este produto podem ser encontrados em http://www.unicon.net/products_519.html.

- Aulanet - O AulaNet é um software LMS (Learning Management System) que possui uma eficiente plataforma de ensino. A ferramenta foi desenvolvida no Laboratório de Engenharia de Software - LES - do Departamento de Informática da PUC-Rio, em 1997. A EduWeb é distribuidora e representante exclusiva desse software. Sua distribuição é feita gratuitamente pela empresa por meio de download ou por aquisição de $C D$-Rom. Com uma base instalada de mais de 4.100 AulaNet's no Brasil e no exterior, o software já possui versões em inglês e espanhol. Maiores detalhes sobre este produto podem ser encontrados em http://guiaaulanet.eduweb.com.br/.

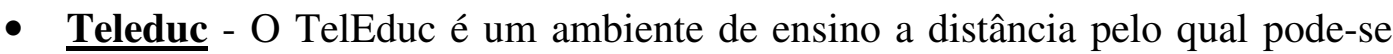
realizar cursos através da Internet. Está sendo desenvolvido pelo Núcleo de Informática Aplicada à Educação (Nied) e pelo Instituto de Computação (IC) 
da Universidade Estadual de Campinas (Unicamp). O TelEduc é um software livre, onde o usuário pode redistribuí-lo e/ou modificá-lo sob os termos de licença GNU GPL. Tem suporte para o sistema operacional Linux, usa como servidor Web o Apache e para o armazenamento de dados utiliza o MySQL. Usa como linguagem de programação o $P H P$ e o $C$ (compilador $g c c$ ). Maiores detalhes sobre este produto podem ser encontrados em http://hera.nied.unicamp.br/teleduc/.

- Ganesha - O produto é desenvolvido por uma empresa francesa chamada Anema Formation. Este sistema é um Open Source e é distribuído sob os termos de licença GNU GPL. O software está disponível para a maioria das variações dos sistemas UNIX, Linux, MAC OS X, e para versões do Windows. É compatível com o servidor Web Apache e IIS e possui como base de dados o MySQL. Como linguagem de programação utiliza o PHP. Maiores detalhes sobre o produto encontra-se em http://savannah.nongnu.org/projects/ganesha/. 
Apêndice C

APÊNDICE C - Open Source modificados. 
Os códigos apresentados a seguir foram utilizados na implementação deste trabalho. Primeiramente, é necessário saber que esses códigos só puderam ser modificados, pois estão sob os termos de licença GPL GNU General Public. Este tipo de licença permite executar o programa de terceiros para qualquer propósito, permite estudar como o programa funciona e adaptá-lo para as suas necessidades, permitem redistribuir cópias e aperfeiçoar o programa liberando os seus aperfeiçoamentos (Free Software Foundation, 2006).

O primeiro código a ser mostrado neste apêndice é o código escrito no arquivo logout.php. A figura a seguir mostra a comparação entre o código original (fornecido no pacote do Moodle) e o código modificado. A única mudança é uma chamada de função e portando uma modificação pontual foi feita.

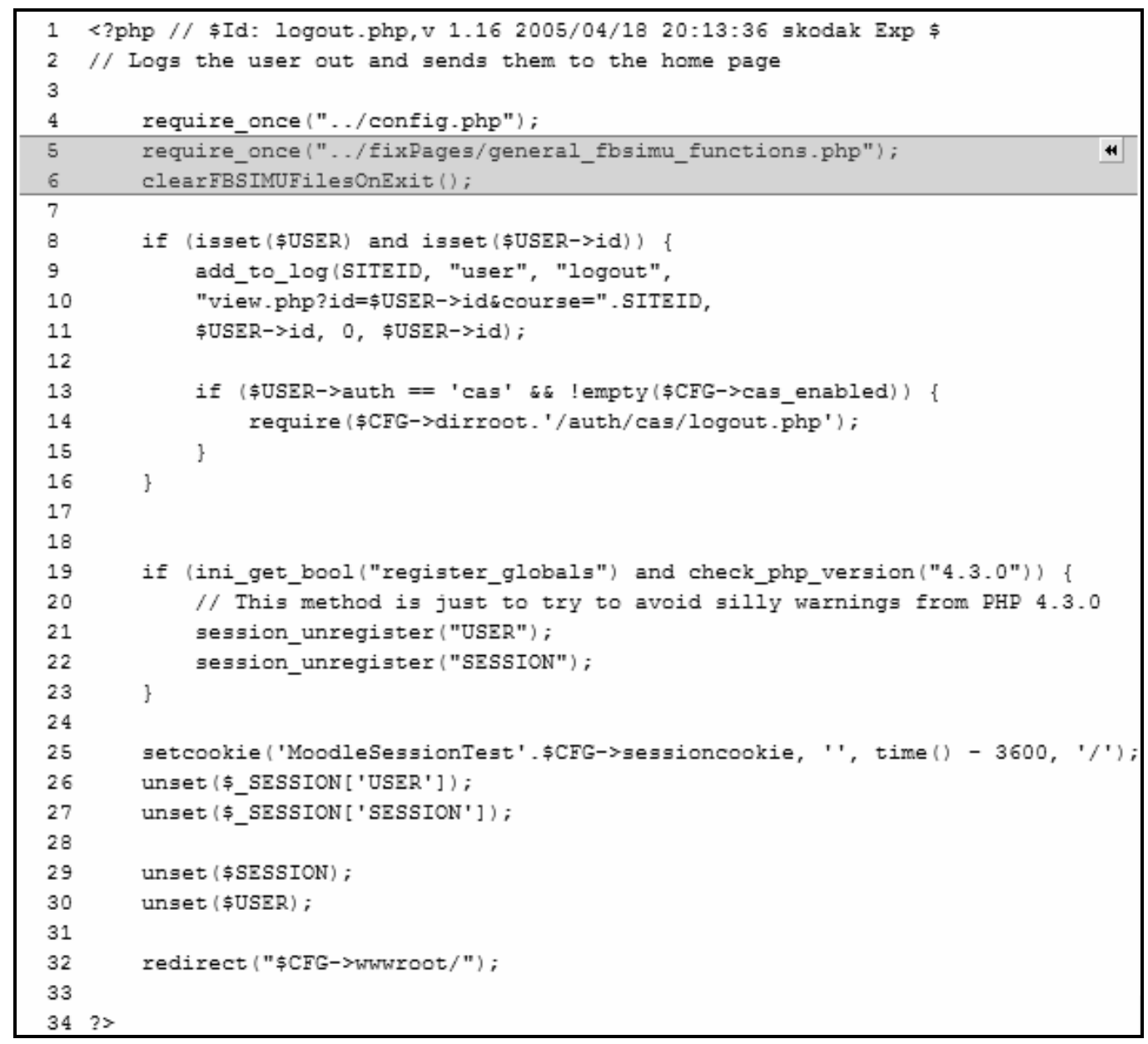

Código do arquivo logout.php 
Outro Open Source usado foi o código responsável por apresentar aos usuários do sistema os arquivos de $\log$ e de configurações salvas. As figuras a seguir mostram uma comparação entre o código original escrito por Law Eng Soon e o código modificado e usado neste sistema. Devido a grande quantidade de código existente neste arquivo, apenas as partes onde as modificações foram feitas são apresentadas.

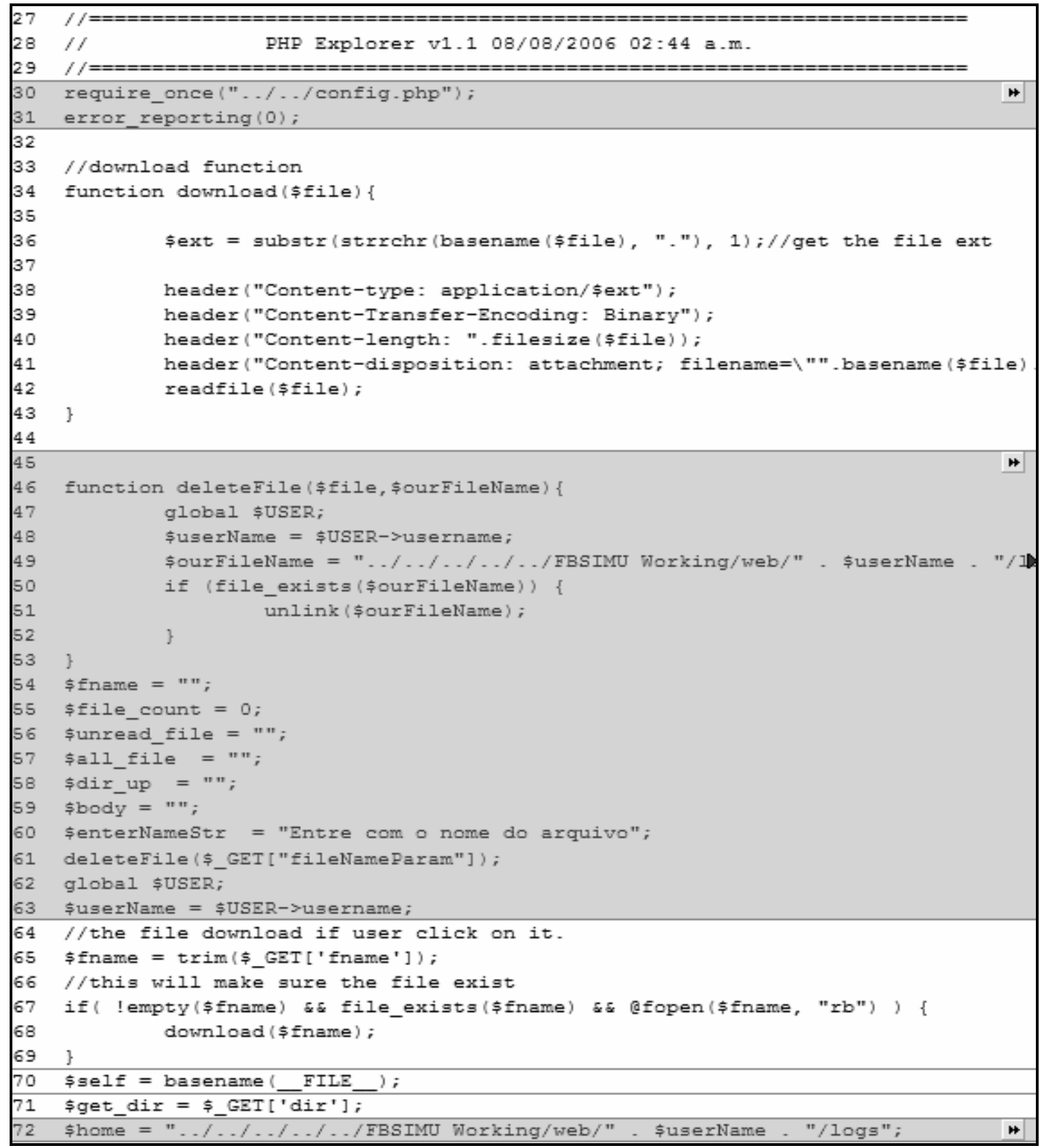

Código do PHP Explorer modificado - linha 27 a 72. 


\begin{tabular}{|c|c|}
\hline 240 & <hodv bacolor $=" \pm$ \\
\hline 241 & <SCRIPT LANGUAGE=" JavaScript"> \\
\hline 242 & function goToURL (fName) \{ \\
\hline 243 & var1 = location.href. substring $(0$, location.href.indexof $("$.php \\
\hline 244 & locationAddr = var1 + "-php3?fileNameParam=" + fName; \\
\hline 245 & window.location = locationAddr; \\
\hline 246 & \\
\hline 247 & $</$ script $>$ \\
\hline 248 & H \\
\hline 249 & $<$ h2 align="center" >FBSIMU Logs $\langle/ \mathrm{h} 2\rangle$ \\
\hline 250 & <table align="center" border="0" style="border:1px solid \#999999; background-c \\
\hline 251 & $\langle$ tr $><t d$ align="left" valign="top"> \\
\hline 252 & <table width=" 600 " border="0" align="center" style="border: $\boldsymbol{\|}$ \\
\hline \multicolumn{2}{|l|}{253} \\
\hline 254 & <font style="color: \#FF0000; font-size: 12px;"><b>Dele te File+mb: \\
\hline 255 & <input type="button" onclick= "goToURL (document.getEl ementByl \\
\hline 256 & <div id="script_box" style="display:none; width:600px;"> \\
\hline 257 & $<\mathrm{br} />$ \\
\hline \multicolumn{2}{|l|}{258} \\
\hline 259 & <form action=" " method="post"> \\
\hline 260 & <textarea name="editor" cols=" 68 " rows=" $20 "$ class="editor" $></ t$ \\
\hline 261 & $<\mathrm{br} /><\mathrm{br} /><$ input type="submit" value="Execute" $/>$ \\
\hline 262 & $</$ forms $>$ \\
\hline 263 & $</$ div $><b r /><b r />$ \\
\hline \multicolumn{2}{|l|}{264} \\
\hline 265 & \&nbsp;<a href="<?php echo \$self. "?dir=" . \$home; ?>"><imcH \\
\hline 266 & title="Go back to \&quot;<?php echo thome; ?>\&quot;" alt=" " />- \\
\hline 267 & <form action="<?php echo \$self; ?>" method="get" > \\
\hline 268 & File : <input type="text" name="dir" value="<?php echo \$ent +1 \\
\hline 269 & $</$ form $>$ \\
\hline 270 & $<\mathrm{br} /><\mathrm{br} />$ \\
\hline
\end{tabular}

Código do PHP Explorer modificado - linha 240 a 270. 